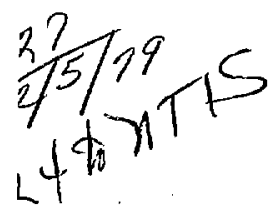

$4 C-78^{\prime}$ MASTER

UCRL-52506

j

\title{
THE EFFECTS OF TORUS WALL \\ FLEXIBILITY ON FORCES IN \\ THE MARK I BOILING WATER \\ REACTOR PRESSURE \\ SUPPRESSION SYSTEM-PART I
}

R. W. Martin

E. W. McCauley

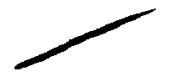

September 1977

June 1978

This work was supported by the U.S. Nuclear Regulatory Commission undrer Interagency Agreement DOE 40-550-75 with the U.S. Department of Energy.

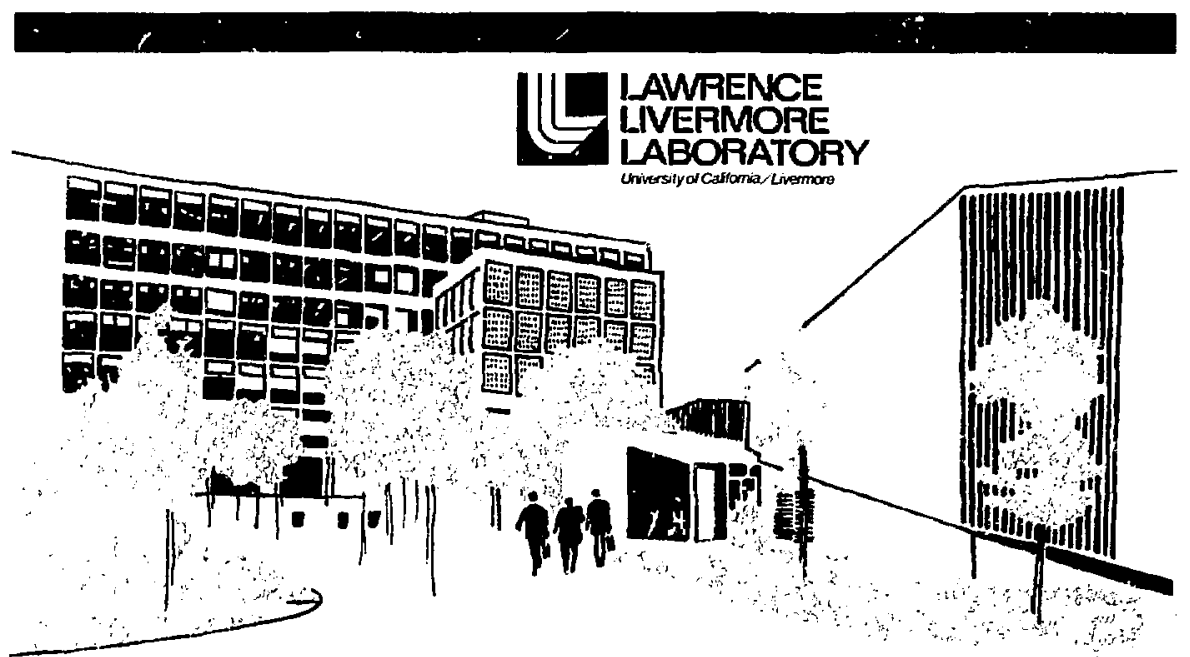




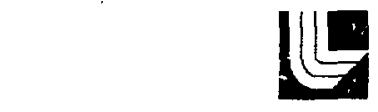

I_AWRENCE IIIVERMORE I_ABORATORY

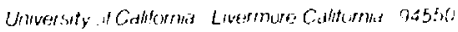

UC.RL 52506

THE EFFECTS OF TORLS WALL FIEXIBILITY ON FORCES IN

THE MARK I BOILING WATER REACTOR PRESSLRE

SI PPRESSION SYSTEM-PART I

R. M. Martin

I: it. Meciuley

MS. date: Seprember 1977 


\section{EOREWORD}

This work was supported by the U.S. Nuclear Regulatory Commission under Interagency Agreement DOE 40-550-75 with the U.S. Department of Energy. The NRC Project Iojentification Sequence is BtR 20100402 FIN A0208, "Hydrodynamic/Structural Interaction in the Mark I BWR Pressure Suppression Systen." 


\section{CONTENTS}

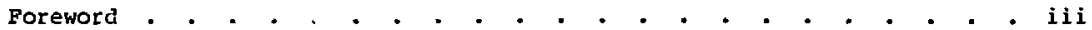

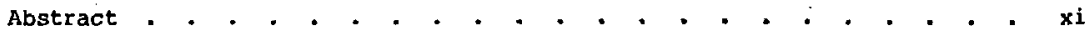

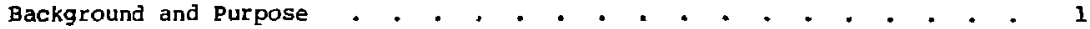
Problem Definiticn . . . . . . . . . • . • • . . . . . . 6

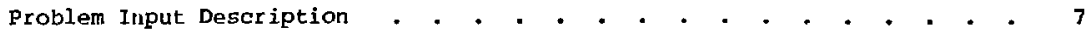
Summary of Major Findings . . . . . . • . • . . . . . . 12

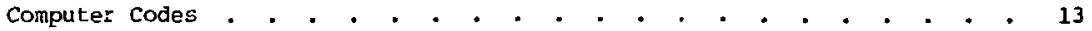
Work Completed . . . . . . . . . . . . . . . . . . . . 16

SRV Discharge--Generalized Results . . . . . . . . . . . 17 LOCA Chug--Generalized Resulies . . . . . . . . . . . . . 21 Conclusions and Reromendations . . . . . . . . . . . . . . . 26

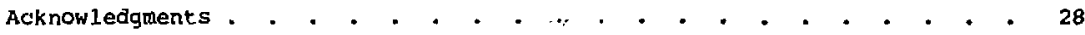
References . . . . . . . . . . . . . . . . . . . . . 29 APPENDIX A. Description of pinite Element Code DTVIs2 . . . . . . . 31 APPENDIX B. SRV Discharge: Detailed Results . . . . . . . . . 33 APPENDIX C. LOCA Chug: Detailed Resuits . . . . • . . . . . . . 69 
2. An interior photo of the Monticello torus. A vent line, the ringheader and downcomers, anc ring stiffeners at the mitered joints are clearly visible . . . . . . . . . . . . . . . . . . . . . 2

2. Artist's rendering of a Mark I boiling water reactor, showing the essential elements of the pressure suppression system

3. Schematic section of a Mark I drywell and torus, showing the steam flow path in a loss-of-coolant accident (LOCA) - . . . . . . . . . 4

4. Schematic plan view of Mark I torus, showing mitered joints and SRV discharge ramsheads with steam flow paths. . . . * . . . . . 5

5. Schematlc diagram and reference dimensions for the Monticello Brit torus

6. Idealized torus quadrant with a plan view showing section line for the quadrant

7. Input pulse for LOCA chugging problem

8. Input pulse for SRV discharge problem . . . . . . . . . . 11

9. Pressure at pool bottom ( $D / t=300--S R V$ discharge) with comparison of results between CHAMP and the finite element code DTVIS2 . . . . . 15

10. Wall displacement ai pool bottom (D/t = 300--SRV discharge) with comparison of results between CHAMP and the finite element code DTris2 .

11. Effect of torus shell thickness on the pressure history at the pool bottom (SRV discharge) . . . . . . . . . . . . . . . . 18

12. Effect of torus shell thickness on total vertical reaction force history (SRV discharge) . . . . . . . . . . . . . . . . 19

13. Effect of torus shell thickness on normalized peak overpressure (SRV discharge)

14. Effect of torus shell thickness on normalized peak vertical reaction force (SRV discharge)

15. Effect of torus shell thickness on pool bottom pressure history (LOCA chug) . . . . . . . . . . . . . . . . . . . . 23

16. Effect of torus shell thickness on total vertical force (LOCA chug) 24

17. Effect of torus shell thickness on normalized peak pressure at pool bottom (LOCA chug) . . . . . . . . . . . . . . . . . 25

18. Effect of torus shell thickness on normalized vertical reaction force (rock chug) 


\section{APPENDIX B FIGURES--SRV Discharge}

E-1. Typical finite element mesh for the SRV discharge

problem $(\mathrm{D} / \mathrm{t}=300)$

B-2. Pressure on shell wall (A-90 9 ; $60^{\circ}$;

$\mathrm{C}-30^{\circ}$ ) (see Fig. 6) $(\mathrm{D} / \mathrm{t}=0$ )

B-3. Pressure on shell wall $\left(A-90^{\circ} ; \mathrm{B}-60^{\circ} ; \mathrm{C}-30^{\circ}\right)$

(see Fig. 6) $(\mathrm{D} / \mathrm{t}=300)$

B-4. Pressure on shell wall $\left(\mathrm{A}-90^{\circ} ; \mathrm{B}-60^{\circ} ; \mathrm{C}-30^{\circ}\right.$ )

(see Fig. 6) $(\mathrm{D} / \mathrm{t}=600)$

B-5. Presssure on shell wall $\left(\mathrm{A}-75^{\circ}, \mathrm{B}-45^{\circ}, \mathrm{C}-15^{\circ}\right.$ )

(see Fig. 6) $(D / t=0)$

B-6. Pressure on shell wall $\left(\mathrm{A}-75^{\circ} ; \mathrm{B}-45^{\circ} ; \mathrm{C}-15^{\circ}\right.$ )

(see Fig. 6) $(\mathrm{D} / \mathrm{t}=300)$

8-7. Pressure on shell wall $\left(\mathrm{A}-75^{\circ} ; \mathrm{B}-45^{\circ} ; \mathrm{C}-15^{\circ}\right)$

(see Eig. 6) $(\mathrm{D} / \mathrm{t}=600)$

B-8. Pressure in fluid at $r=r_{m}$ (see Fig. 6) $\left\langle A-90^{\circ}\right.$;

$\left.\mathrm{E}-60^{\circ} ; \mathrm{C}-30^{\circ}\right)$ (D/t $=0$ )

B-9. Pressure in fluid at $r=r_{m}$ (see Fig. 6) $\left(A-90^{\circ}\right.$;

$\left.\mathrm{B}-60^{\circ} ; \mathrm{C}-30^{\circ}\right)(\mathrm{D} / \mathrm{t}=300)$

$B-10$. Pressure in fluid at $r=r_{m}$ (s $\geq$ Fig. 6) $\left(A-90^{\circ}\right.$; $\mathrm{B}-60^{\circ} ; \mathrm{C}-30^{\circ},(\mathrm{D} / \mathrm{t}=600)$

$B-11$. Pressure in fluid at $r=r_{m}$ (see Fig. 6) $\left(A-75^{\circ} ; \mathrm{B}-45^{\circ}\right.$;

$\left.\mathrm{C}-15^{\mathrm{o}}\right)(\mathrm{D} / \mathrm{t}=0)$

B-12. Pressure in fiuid at $r=r_{m}$ (see Fig. 6) $\left(A-75^{\circ} ; B-45^{\circ}\right.$;

$\left.\mathrm{C}-15^{\circ}\right)(\mathrm{D} / \mathrm{t}=300)$

B-13. Pressure in fluid at $r=r_{m}$ (see Fig. 6) $\left(A-75^{\circ} ; B-45^{\circ}\right.$;

$\left.c-15^{\circ}\right)(\mathrm{D} / \mathrm{t}=600)$

B-14. Shell displacement at $90^{\circ}(D / t=300)$

B-15. Shell displacement at $90^{\circ}(D / t=600)$

$\mathrm{B}-16$. Shell velocity at $90^{\circ}(\mathrm{D} / \mathrm{t}=300)$

B-17. Shell velocity at $90^{\circ}(\mathrm{D} / \mathrm{t}=600)$

$B-18$. Free surface displacement at vertical centerline $(D / t=0)$ 50

B-19. Free surface displacement at vertical centerline $(D / t=300)$

51

$B-20$. Free surface displacement at vertical centerline $(D / t=600)$ 
B-21. Free surface velocity at vertical centerline $(D / t=0) \quad . \quad . \quad 54$

B-22. Free surface velocity at vertical centerline $(D / t=300) \cdot$, 55

B-23. Free surface velocity at vertical centerline $(\mathrm{D} / \mathrm{t}=600) \quad . \quad, 56$

B-24. Bubble displacement at $A$ and $B$ (see Fig. B-1) (D/t = 0) . . . 57

B-25. Bubble displacewent at $A$ and $B$ (see Fig. B-1) $(D / t=300)$. . . 58

B-26. Bubble displacement at $A$ and B (see Fig. B-1) $(D / t=600)$. . 59

B-27. Bubble displacement at C (see Fig. B-1) (D/t = 0) . . . . . 60

B-28. Bubble displacement at C (see Fig. B-1) $(D / t=300)$. . . . 61

B-29. Bubble displacement at $C$ (see Fig. B-1) $(D / t=600)$. . . . . 62

B-30. Bubble velocity at $A$ and $B$ (see Eig. B-1) $(D / t=0)$. . . . . 63

B-31. Bubble velocity at $A$ and $B$ (see Fig. $B-1)(D / t=300)$. . . . 64

B-32. Bubble velocity at $A$ and $B($ see Fig. $B-1)(D / t=600)$. . . . 65

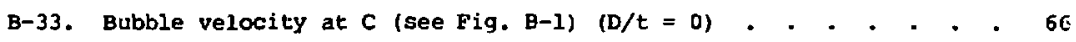

B-34. Bubble velocity at $C$ (see Fig. B-1) $(D / t=300) \quad . \quad . \quad . \quad . \quad 67$

B-35. Bubble velocity at C (see Pig. B-1) (D/t =600) . . . . . . 68 


\section{APPENDIX C EIGURES--LOCA Chug}

C-1. Typical finite element mesh for the LOCA chug problem (D/t = 300) $\quad 70$ $\mathrm{C}-2$. Pressure on shell wall $\left(\mathrm{A}-90^{\circ} ; \mathrm{B}-60^{\circ} ; \mathrm{C}-30^{\circ}\right)$

(see Fig. 6) $(\mathrm{D} / \mathrm{t}=0$ )

C-3. Pressure on shell wall $\left(\mathrm{A}-90^{\circ} ; \mathrm{B}-60^{\circ} ; \mathrm{C}-30^{\circ}\right)$

(see Fig, 6) $(\mathrm{D} / \mathrm{t}=300)$.

$\mathrm{C}-4$. Pressure on shell wall $\left(\mathrm{A}-90^{\circ} ; \mathrm{B}-60^{\circ} ; \mathrm{C}-30^{\circ}\right)$

(see Fig. 6) $(D / t=600)$.

$\mathrm{C}-5$. Pressure on shell wall $\left(\mathrm{A}-75^{\circ} ; \mathrm{B}-45^{\circ} ; \mathrm{C}-15^{\circ}\right.$ )

(see Fig. 6) $(D / t=0$ )

$\mathrm{C}-6$. Pressure on shell wall $\left(\mathrm{A}-75^{\circ} ; \mathrm{B}-45^{\circ} ; \mathrm{C}-15^{\circ}\right)$

(see Fig. 6) $(D / t=300)$

$\mathrm{C}-7$. Pressure on shell wall $\left(\mathrm{A}-75^{\circ} ; \mathrm{B}-45^{\circ} ; \mathrm{C}-15^{\circ}\right.$ )

(see Fig. 6) $(\mathrm{D} / \mathrm{t}=600)$.

C-8. Pressure in fluid at $r=r_{m}$ (see Fig. 6) $\left(A-90^{\circ}\right.$;

$\mathrm{B}-60^{\circ} ; \mathrm{C}-30^{\circ},(\mathrm{D} / \mathrm{t}=0)$

C-9. pressure in fluid at $r=r_{m}$ (see Fig, 6) $\left(A-90^{\circ}\right.$;

$\left.\mathrm{B}-60^{\circ} ; \mathrm{C}-30^{\circ}\right)(\mathrm{D} / \mathrm{t}=300)$

$\mathrm{C}-10$. Pressure in $\mathrm{fJuid}$ at $\mathrm{r}=\mathrm{r}_{\mathrm{m}}$ (see Fig. 6) $\left\{\mathrm{A}-90^{\circ}\right.$;

$\left.\mathrm{B}-60^{\circ} ; \mathrm{C}-30^{\circ}\right)(\mathrm{D} / \mathrm{t}=600)$

$\mathrm{C}-11$. Pressure in fluid at $\mathrm{r}=\mathrm{r}_{\mathrm{m}}$ (see Fig. 6) $\left(\mathrm{A}-75^{\circ}\right.$;

$\mathrm{B}-45^{\circ} ; \mathrm{C}-15^{\circ},(\mathrm{D} / \mathrm{t}=0)$

$\mathrm{C}-12$. Pressure in fluid at $\mathrm{r}=\mathrm{r}_{\mathrm{m}}$ (see Fig. 6) $\left(\mathrm{A}-75^{\circ}\right.$;

$\left.\mathrm{B}-45^{\circ} ; \mathrm{C}-15^{\circ}\right)(\mathrm{D} / \mathrm{t}=300)$

$\mathrm{C}-13$. Pressure in fluid at $r=r_{m}$ (see Fig. 6) (A-75 ${ }^{\circ}$;

$\left.\mathrm{B}-45^{\circ} \mathrm{C}-15^{\circ}\right)(\mathrm{D} / \mathrm{t}=600)$

C-14. Shell displacement at $90^{\circ}(\mathrm{D} / \mathrm{t}=300)$

C-15. Shell displacement at $90^{\circ}(\mathrm{D} / \mathrm{t}=600)$

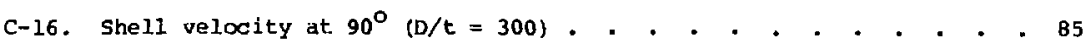

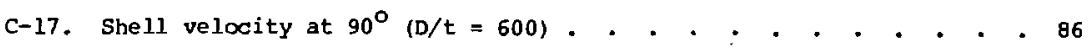

C-18. Free surface displacement (A-bubble centerline;

B-shell centerline $(\mathrm{D} / \mathrm{t}=0)$. . . . .

C-19. Free surface displacement (A-bubble centerline;

B-sheil centerline) $(D / t=300)$ 
C-20. Free surface displacement (A-bubble centerline;

B-she11 centerline $(D / t=600)$. . . . . . . . . . . . . 89

C-21. Free surface velocity (A-bubble centerline;

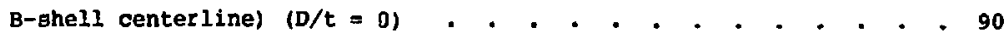

C-22. Eree surface velocity (A-bubble centerline;

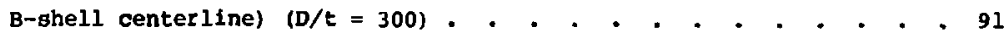

C-23. Eree surface velocity (A-bubble centerline;

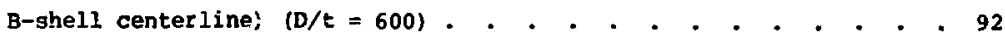

C-24. Bubble displace. st at $A$ and $B$

(see Fig. C-1) (D/t = 0) . . . . . . . . . . . . . . . . 93

C-25. Bubble displacement at $A$ and $B$

(see Fig. C-1) (D/t = 300) . . . . . . . . . . . . . . . . 94

C-26. Bubble displacement at $A$ and $B$ (see Fig. C-1) (D/t $=600) \cdot . \quad .95$

C-27. Bubble displacement at $A^{\prime \prime}$ and $B^{\prime}$ (see Fig. C-1) (D/t = 0) . . . 96

C-28. Bubble displacement at $A^{\prime}$ and $B^{\prime}$ (see Fig. C-1) (D/t = 300) . .97

C-29. Bubble displacement at $A^{\prime}$ and $B^{\prime}$ (see Fig. C-1) $(D / t=600)$. .98

C-30. Bubble velocity at $A$ and $B$ (see Fig. C-1) $(D / t=0)$. . . . . . 99

C-31. Bubble velocity at $A$ and $B$ (see Fig. C-l) $(D / t=300) . . \quad . \quad .100$

C-32. Bubble velocity at $A$ and $B$ (see Fig. C-1) $(D / t=600)$. . . . 101

C-33. Bubble velocity at $A^{\prime}$ and $B^{\prime}$ (see Fig. C-l) $(D / t=0)$. . . . 102

C-34. Bubble velocity at $A^{\prime}$ and $B^{\prime}$ (see jig. $\left.C-1\right)(D / t=300) . . .103$

C-35. Bubble velocity at $A^{\prime}$ and $B^{\prime}$ (see Fig. C-1) $(D / t=600) \quad . \quad . \quad 104$ 
ABSTKACT

We investigated the effects of torus wall flexibility in the pressure suppression system of a Mark I boiling water reactor (BWR) when the torus wa?l is subjected to hydrodynamic loadings. Using hypothetical models, we examined these flexibility effects under two hydrodynamic loading conditions: (1) a steam relief val.ve (SRV) discharge pulse, and (2) a loss-of-coolant accidert (LOCA) chugcing pulse. In our analyses of these events we used a recently developed two-dimensional finite element computer code. Taking the basic geometry and dimensions of the Monticello Mark I BWR nuclear power plant (in Monticel1o, Minnesota, U.S.A.), we assessed the effects of flexibility in the torus wall by changing values of the inside-diameter-bo-wall-thickness ratio. Varying the torus wall thicisness (t) with respect to the inside diameter (D) of the torus, we assigned values to the ratio $\mathrm{D} / \mathrm{t}$ ranging $\mathrm{from} 0$ (infinitely rigid) to 600 (highly flexible). In the case of a modeled steam relief valve (SRV) discharge pulse, we found the peak vertical ceaction force on the torus was reduced from that of a rigid wall response by a factor of 3 for the most highly flexible, plant-simulated wall $(\mathrm{D} / \mathrm{t}=600)$. The reduction factor for a modeled loss-of-coolant accident (LOCA) chugging pulse was shown to be 1.5 .

The two-dimensional analyses employed overestimate these reduction factors but have provided, as intended, definition of the effect of torus boundary stiffness. In the work planned for FY79, improved morieling of the structure and of the source is expected to result in ractors more directly applicable to actual pressure suppression systems. 
BACY.GROUNT; AND PURPOSE

The Mark I boiling wacer reactor (BWR) pressure suppression cor-tainment system was designed to absorb pressures generatej in a loss-of-coolant accident (LOCA) or in steam relief valve (isRV) discharges. In either of these events, reactor primary coolant in the form of steam or hot water travels to a partially water-filled toroidal-like shell surcounding the drywell, thereby dissipating pressure. (See Figs. 1 and 2.)

The LOCA event, which is hypothetical-man accident of that kind has never cccurred in a plant--involves a rupture or break in the primary coolant circulation system. Such a break would allow the coolant in the form of stean or hot water to escape into the reactor drywell where, without some provision for dissipation, the pressures might increase to the point of sniangering the reactor's structural integrity, thus allowing primary coolant to reach the atmosphere. An SRV cischarge, on the other hand, is a normally occurring event in the operation of a BWR plant; when the primary coolant reaches a point of overpressure the excess pressure is relieved through a valve. In a Mark I BWR the steam exiting this valve is conducted by piping to the torus suppression pool suzrounding the reactor's drywell. The steam conduits for SRV discharges are independent of the ven: lines that would : nduct steam Erom the orywell to the torus in a LOCA event. (See Figs. 3 and 4,)

Many analytical and experimental approaches toward understanding the pressure forces in LOCA's or SRV discharges treat the torus shell as a rigid body. But the shell is, in fact, flexible and its elastic response to fluid injectad into the pool may significantly affect the total loads on the containmint system and its attendant structure. We therefore devised a study to provide qualified understanding of the effects torus wall flexibility mignt have on hydrodynamic loazings within the totus. $A_{i}$ we wera interested in the 


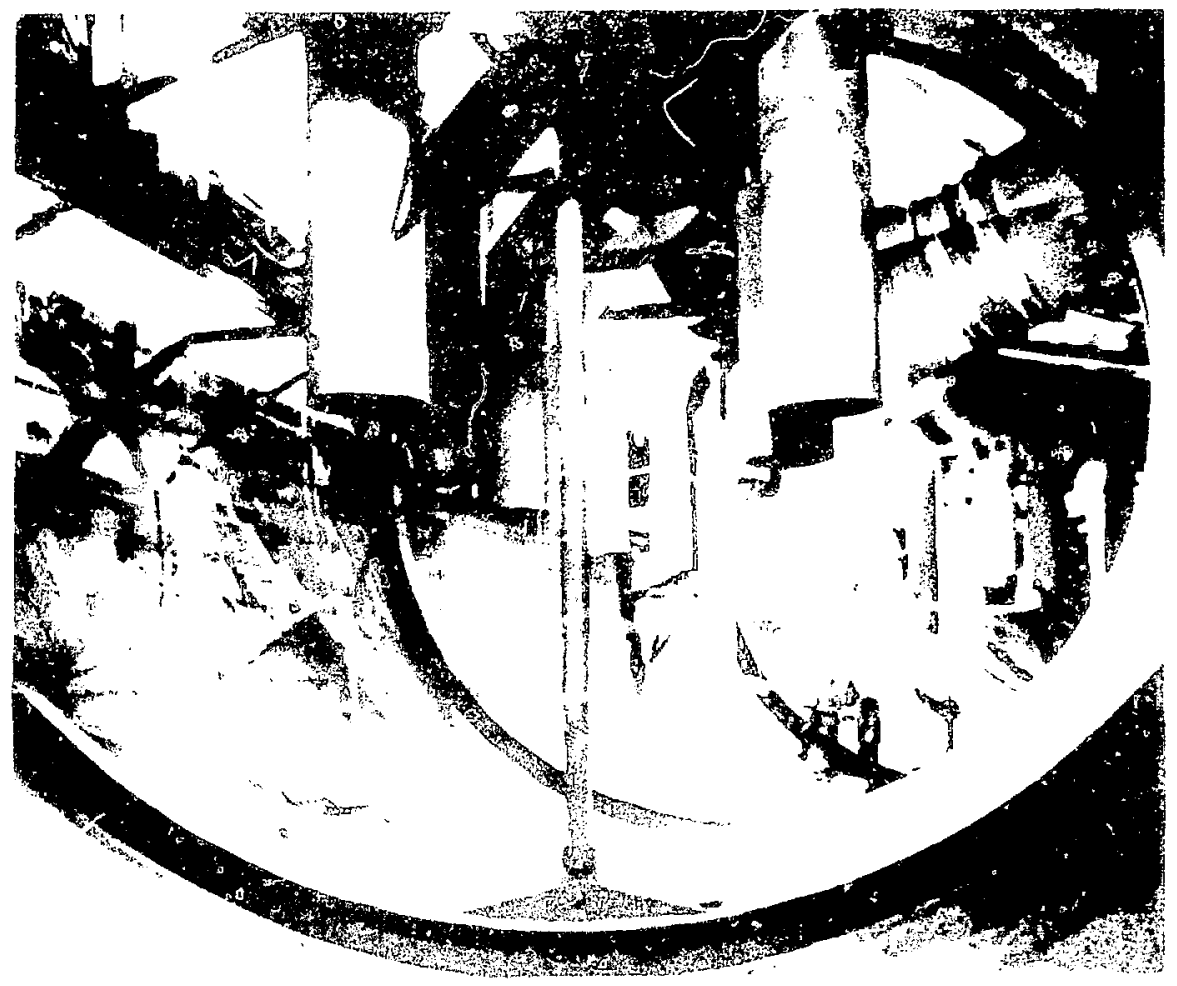




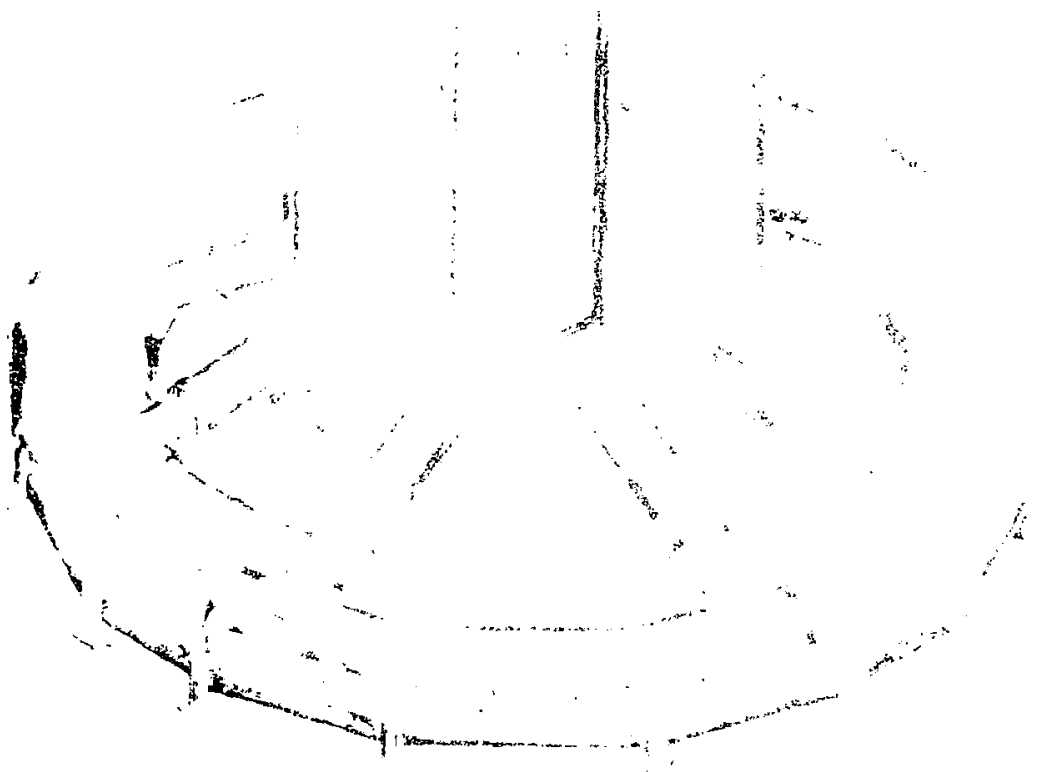


degree of flexibility in toruses of varying diameters and wall thicknesses -the thinner the torus wall with respect to 1 ts di umeter, the greater the flexibility--we chose to vary, in our calculations, ihe shell-diameter-tothlckness ratio (D/t) from 0 (infinitely rigid) to 600 (highly flexible). (The actual zatio of our model plant's suppression system, Monticello in Minnesota, is 568.5.) In this mannet, we coild determine shel 1 boundary and in-pool pressures for toruges of different flexiblities.

$4=$ Path of steam in a LOCA

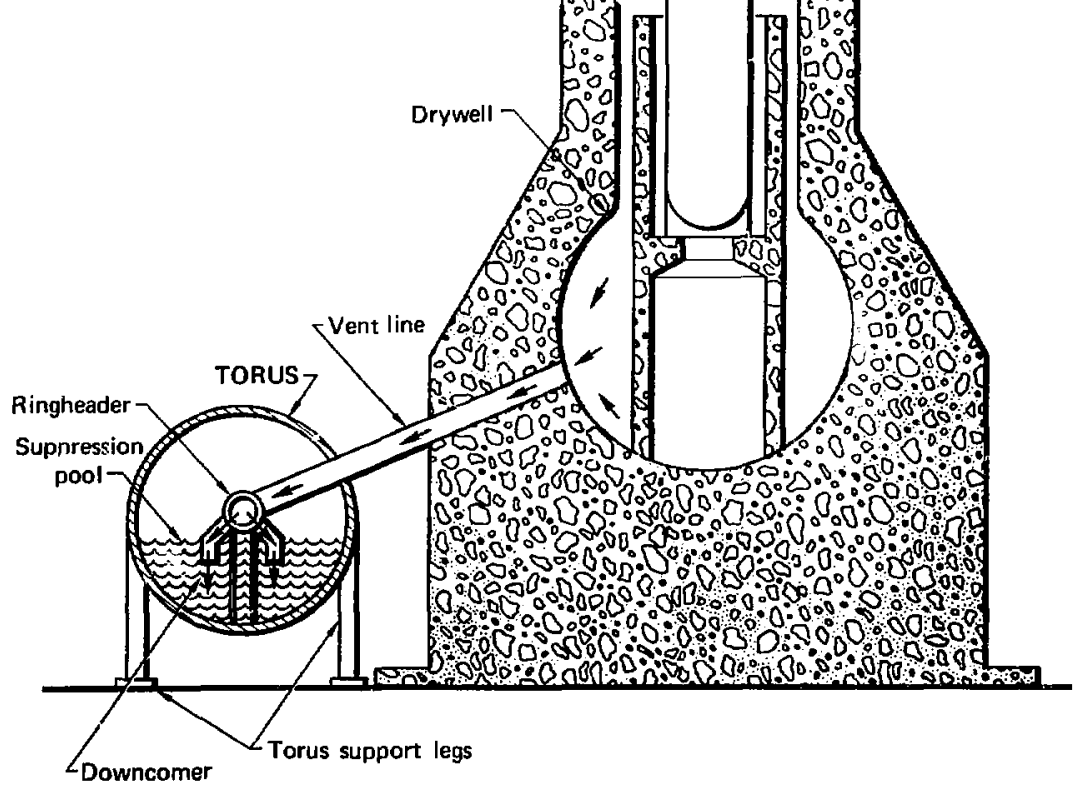

FIG. 3. Schematic section of a Mark I drywell and torus, showing the steam flow path in a loss-ot-coolant accident (LOCA). 


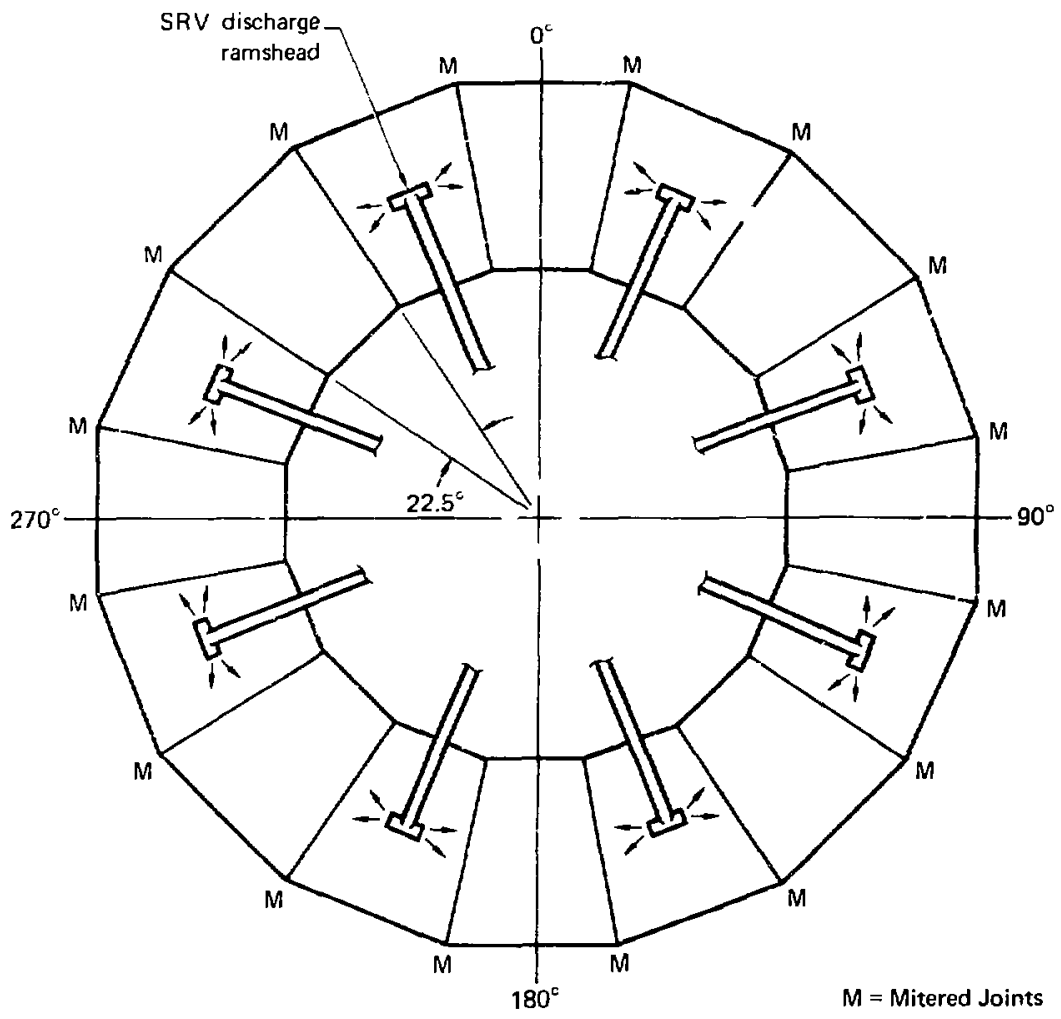

FIG. 4. Schematic plan view of Mark I torus, showing mitered joints and SRV discharge ramsheads with steam flow paths. 
Three classes of problems were and are of interest in studying torus wall flexiblitty. Pirst is the hypothetical loss-of-coolant accident, or LOCA downcomer clearing problem, characterlzed by large $f l o w$ rates and consequent large pool motions. In this problem, a break in the primary coolant circulation system causes air, followed by stean, to travel from the drywell throligh vent lines into the ringheader, ultimately injecting the air and steam into the torus pool through palrs of downcomers. (See Fig. 3.)

The second problem concerns the phenomenon of LOCA chugging. This occurs during the later stages of a LOCA and is caused by rapid, randoin condensation of the steam fets formed at the submerged downcomer exits. These random chugs, or pulses, may repeat hundreds of times before pressures have finally subsided.

The third problem is that of afs and steam discharged from lines connected to the reactor pressure rellef valves (SRV) and terminating near the botton of the suppression pool in ramsheads vents, which as we have already indicated are discrete from the venting system for LOCA's. (See Fig. 4.) Steam relief valve discharges are normally occurring phenomena in the BWR operation. 
In this report, Part I of the continuing study of the effects of hydro/ structure interaction, we examined the effect torus wall flexibility has on presstres and forces in the suppression pool for problems two and three for D/t ratios ranging fron 0 to 600." All analyses were done in two dimensions. Part II of this study will provide more realistic three-dimensional assessments of these problens.

We used the pressure suppression containment geometry of the Monticello plant in Minnesota because it is typical of the Mark I plants and because in-plant testing has been performed there. Figure 5 shows the significant dimensions of Monticello's pressure suppression system.

To simplify our computations, we treated the three-dimensional geometry as a two-oimensional plane and limited our study to a single lower quadrant of the torus, disregarding any motion that inight occur in the entire upper half. The aica we chose to exanine is located midway between mitered joints with their ring stiffeners; the plane section of our quadrant is shown in Fig. 6 . We decided to allow no motion at the shell waist (see Figs. 5 and 6), a reasonable structural boundary condition, as the forces exiting the downcomers and the SRY ranshead ports are directed at the pool botton and the lower sides of the torus. Moreover, the relative shortness of span between mitered joints would tend to limit motion at the shell waist.

LOCA DOWNCOMER CLEARING

As we have said, a loss-of-coolant accident (LOCA) has never occurred in an actual plant, and, lacking any empirical data, one is therefore constrained to model this event using theoretical-analytical methods, which can be expedited with a systers model conputer code. In consultation and agreenent with the NRC re obtained such a modeled calculation from Idaho Nuclear Engineering Laboratory that had been prepared for other purpases. The modeled event was

\#As we explain later in this report, we could not complete our study of problem one--LOCA downcomer clearing-because the computer code was inadequate to LOCA calculations. However, we do provide here our data source for problem one. 


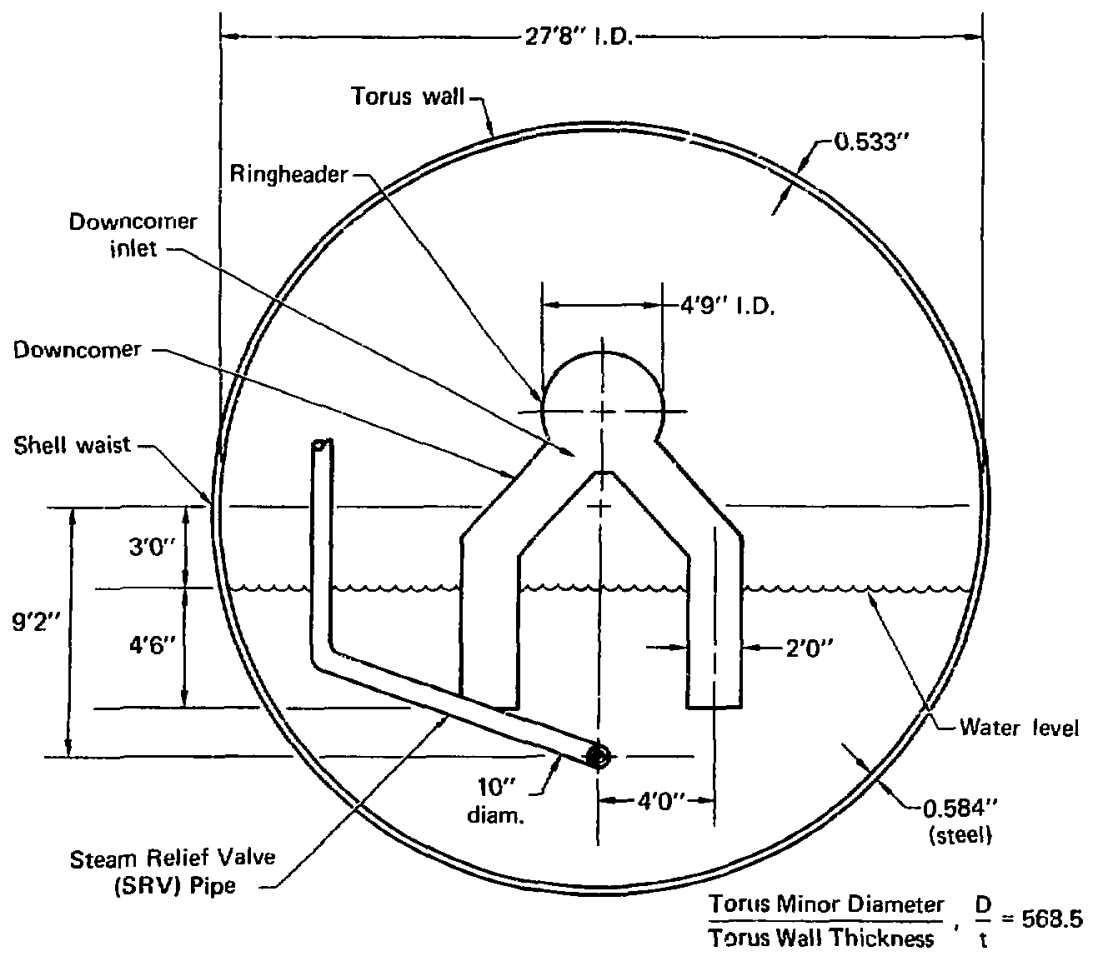

FIG. 5. Schematic diagram and reference dimensions for the Monticello BWR torus. 


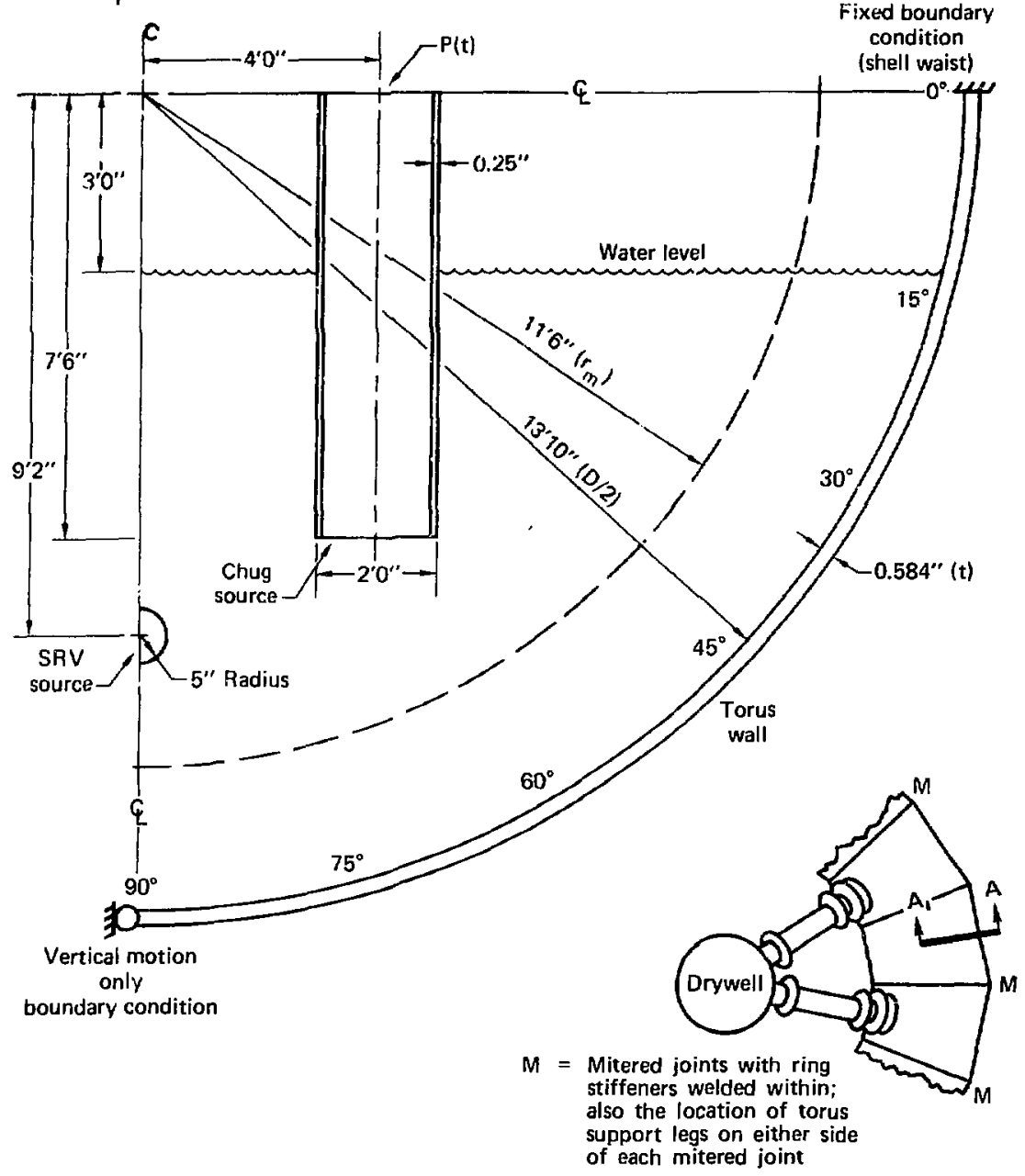

FIG. 6. Idealized torus quadrant with a plan view showing section line for the quadrant. 
calculated on the Brown's Ferry plant's dimensions, which are sufficiently close to Monticello's dimensions, and it proviáes values for pressures, temperatures, and flow-rates at the inlets to the lowncomers in a LOCA event (Bee Fig. 5).

\section{IOCA CHUGGING PULSE}

There is very little quantitative information available on the shape and frequency of chugging pulses that occur as a result of stean bubble condensation during the later phase of a LOCA, particularly for geometries and submergences of the Mark I torus, Therefore, using best judgment and in consultation with the NRC, we assigned a single triangular pulse value having a peak magnitude of 1.38 bars and a duration of 80 as as the driving force for this problem. Figure 7 shows the pulse used in tne chugging analyses.

\section{STEAM RELIEF VALVE DISCHARGE}

The pressure pulse selected to investigate the SRV discharge problen was taken from Ref. 1. The pulse is theoretical, has an amplitude of 10.35 bars, and is derived using Rayleigh bubble arguments. The frequency of the pulse was taken as $10 \mathrm{~Hz}$. Figure 8 shows the pulse used in the SRV analyses. 


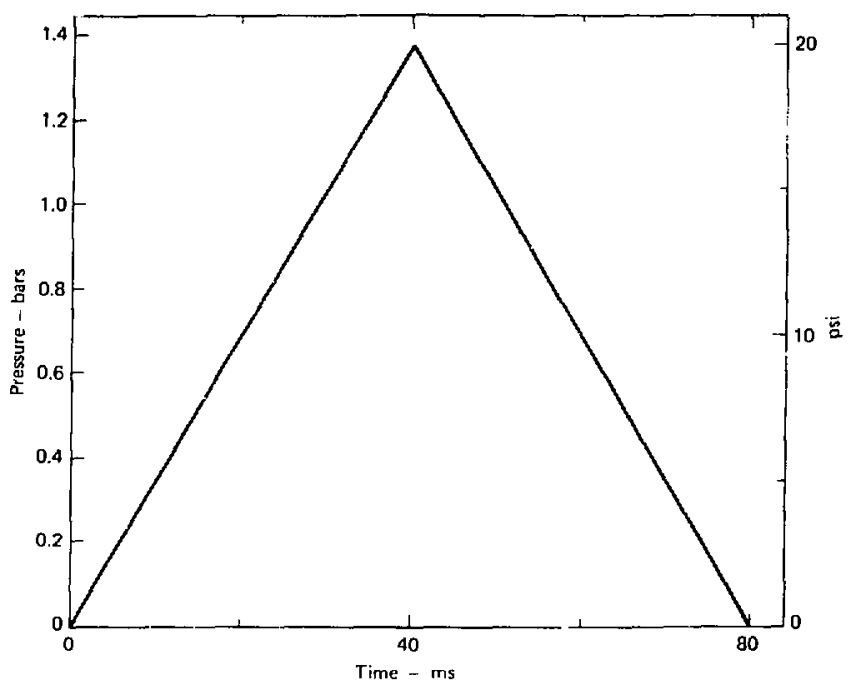

FIG. 7. Input pulse for LOCA chugging problem.

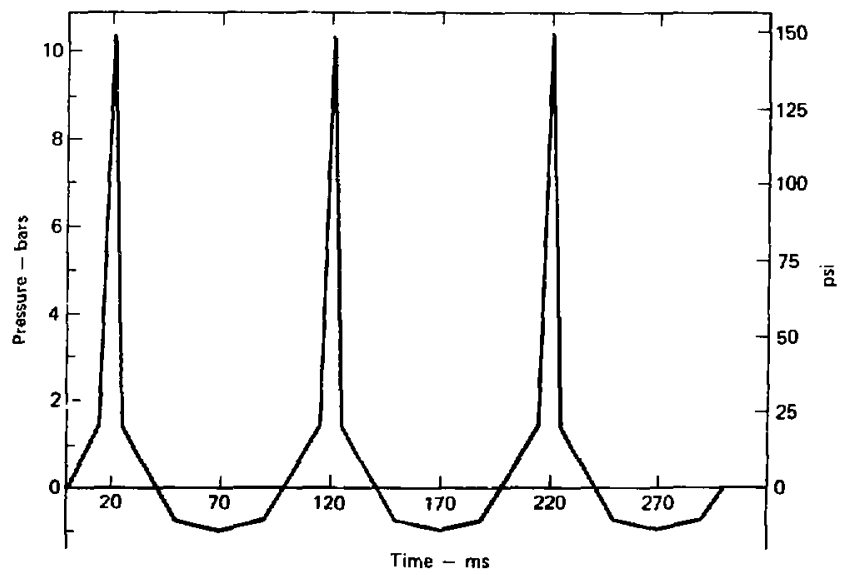

FIG. 8. Input pulse for SRV discharge problem. 
In the case of a modeled stean relief valve discharge pulse, we found the peak vertical reaction force on the torus was reduced from that of a rigid wall response by a factor of 3 for the nost highly flexible, plant-simulated wall $(D / t=600)$. The reduction $f$ actor for a modeled loss-of-coolant accident chugging pulse was shown to be 1.5 .

The two-dimensional analyses we used are appr sximate and as a consequence overestimate the reduction factors; however, the analyses do successfully demonstrate the effects of torus boundary flexibility. In the work planned for FY79, improyed modeling of the structure and of the hydrodyinamic forces is expected to result in factors more directly applicable to actual pressure suppresision systems. 


\section{CONPUTER CODES}

We had originally anticipated using the computer code cramp for the three problems of interest. This code, described as a two-dimensional finite Jifference coupled compressible Eulerian-Lagrangian code, is still under separate development for $I_{1} O C A$ and similar problems at Lawrence Livermore Laboratories. ${ }^{2,3}$ An Eulerian fluid dynamics formulation is necessary when the problem is characterized by significant fluid flow or when fluid motions are large relative to the size of the problem under consideration. Since this is clearly the case in a LOCA downcomer clearing situation, and so that we could have a common calculational base, we decided initially to use the champ code for all of the problems.

Therefore, prior to firm definition of the various problem input descriptions, two test calculations using the CHAMp code were run in Fehruary 1977. These two problems represented a hypothetical SRV discharge for both a rigid $(D / t=0)$ and a flexible-walled $(D / t=300)$ torus section, and their purpose was to assess the CHAMP code's ability to perform correct fluid dynamics. calculations. We chose an SRV event rather than a LOCA downcomer clearing event because the latter involved longer computational time. The code performed our two trials satisfactorily but with running times longer than anticipated. To verify the code further, other CHAMP applications were repor ted in May 1977 as part of a separate NRC water hammer investigation. ${ }^{4}$ Despite the early promise of the chaMp code, its developmental nature, together with its long running tinies in problel. completion, persuaded us that 
other methods would be required and also that we should limit our wurk to the small displacement SRV and LOCA chug problems.*

Recent developments in fluid finite element techisiques by the Methods Development Group of Mechanical Engineering at LLL provided us with an alternative method of calculating SRV discharge and LOCA chugging, the two problems having relatively small deformations and no appreciable flow. This new method is a finite element code. ${ }^{\dagger}$ The running times of tinis code for the limited class of SRV discharge and LOCA ching problems proved to be 30 to 50 times faster than the compressible Eulerian CHAMP code, Appendix A describes the finite element code.

We compared our new finite element code with CHAMp by running a test problem on it that CHAMP had already conputed--the SRV discharge pulse with a $D / t$ ratio of 300 . It can be sees from figs. 9 and 10 that the results are in reasonable agreement.

\#At this writing, the CHAMP code can calculate SRV discharge and LOCA chugging problems, but it cannot yet perform satisfactorily the calculations involved in LOCA downcomer clearing. Moreover, isntinuing restrictions involving Langrangian zoning will not permit acceptable modeling of a very thin shell with CHAMP; the iimit currently corresponds to a minor-diameter-to-wallthickness (D/t) ratio of about 300. Work is continuing on the CHAMP code by its authors, particularly in regard to downcomer clearing.

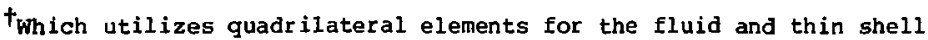
elements for the torus wall. A zero gap element which permits a sliding interface is present between the fluid and the structure. 


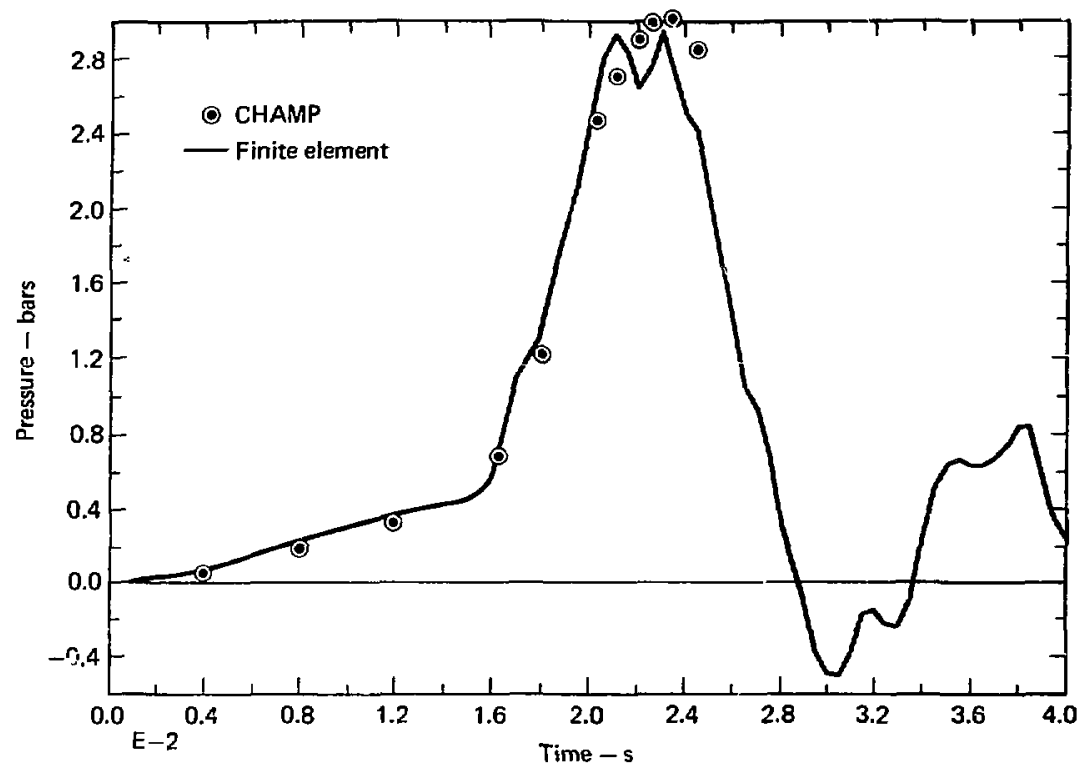

FIG. 9. Pressure at pool bottom (D/t = 300--SRV discharge) with comparison of results between CHAMP and the finite element code DTVIS2.

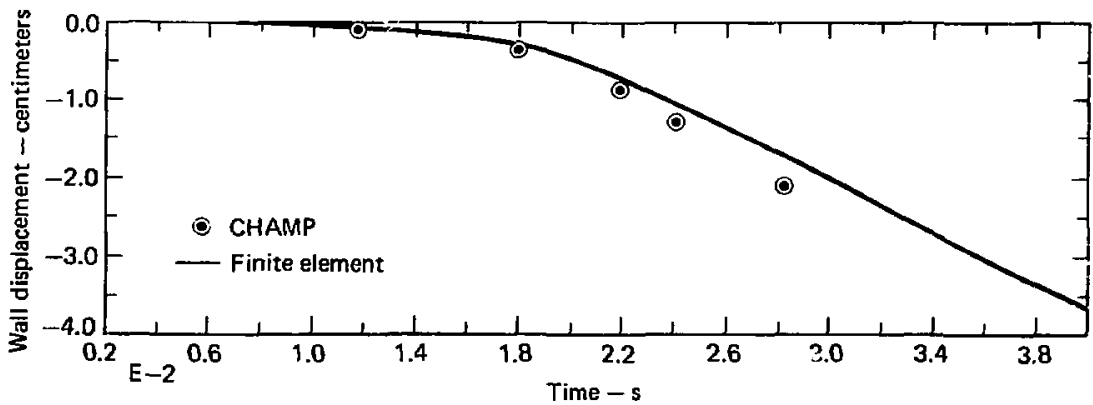

FIG. 10. Wall displacement at pool botton (D/t = 300--SRV discharge) with comparison of results between ChAMP and the finite element code DTVIs2. 
WORR COMPLETED

One of the original tasks in this contract was to demonstrate a computer code's ability to calculate acsurately a dynamic fluid-structure problem such as obtains in a Mark I torus pool. One can select or design a code and by using theoretical data make it wark. Ultimately, however, one should verify the capability of a code by comparing calculated results with experimental data. In conjunction with the NRC, it was agreed to use our code to calculate the results derived in experiments at the Monticello plant. The available experimental data ${ }^{5}$ were for an SRV discharge, but our review of that data revealed that the source pressure in the ramshead had not been measured, and also that the pressures measured on either side of the ramshead in the torus pool were markedly assymetrical, for which no explanation was provided. Therefore, because of insufficient data, the intended code verification was not completed. A limited verification was performed earlier, to which the reader is referred. 4

As for completed work, the steam relief valve (SRV) discharge and LOCA chugging problems were calculated with the two-dimensional finite element core DTVIS2 for diameter-to-wall-thickness (D/t) ratios of 0 (rigid), 300, and 600 . Material properties used in these analyses are given in Table 1.

TABLE 1. Material properties.

\begin{tabular}{|c|c|c|c|c|c|}
\hline \multirow[b]{2}{*}{ Mater IaI } & \multicolumn{3}{|c|}{ Modulus (bars) } & \multirow[b]{2}{*}{ Poisson ratio } & \multirow[b]{2}{*}{ Density $\mathrm{gm} / \mathrm{cm}^{3}$} \\
\hline & Bulk & Shear & Elastic & & \\
\hline Water & $2.18 \times 10^{4}$ & 0.1 & - & .49999 & 1.0 \\
\hline Steel & - & - & $2.05 \times 10^{6}$ & .318 & 8.0 \\
\hline
\end{tabular}

Generalized results for SRV discharge and LOCA chugging follow, along with comments about the specified forcing functions. Detailed results appear in Appendices $B$ and $C$. 
The SRV discharge problem was run using a single pulse having a total width of $40 \mathrm{~ms}$ and a peak overpzessure of $150 \mathrm{psi}$ (10.35 bars).* (The reasons for using only a single pulse will be discussed later in this section.) Figure ll shows the pressure history for the pulse chosen in the fluid adjacent to the shell at the bottom centerline for three cases of differing flexibility: $D / t=0$, 300, and 600. It can be seen from this figure that along with the decrease in peak pressure with increasing $\mathrm{D} / \mathrm{t}$, the pulse shape is both shifted in time and broadened. The temporal shift is caused by both the short transit time (order of $1 \mathrm{~ms}$ ) for the signal to travel between source and shell wall and by motion of the wall itself. As flexibility increases, earlier motion of the shell wall is responsible for the lag time seen in the rising portion of the pulse. The broadening of the pulse is a result of momentum conservation; i.e., the total impulse of the signal is apportioned between the shell and the fluid.

The total vertical force on the shell resulting from the SRv pulse is shown in $\mathrm{Fig}$. 12 for the $\mathrm{D} / \mathrm{t}$ ratios considered. The general characteristics of these curves follow those of the above-mentioned pressure histories.

Figure 13 shows a plot of peak overpressure, thormalized to the peak source pressure versus the $D / t$ ratio. Figure 14 shows the variation in peak vertical reaction force (nomalizec to the infinitely rigid case) with the $D / t$ ratio. Increased shell flexibility results in reduced net vertical force acting on the shell.

The arguments for using only a single SRV pulse for this analysis will be discussed at this point. An examination of the pulse (Fig. 8) reveals that the positive portion of the pulse contains approximately 1.85 times the impulse carried by the negative portion. Separate calculations were carried

*Data taken from Ref. 1 .

${ }^{+}$At the shell/fluid interface at the pool bottom. 


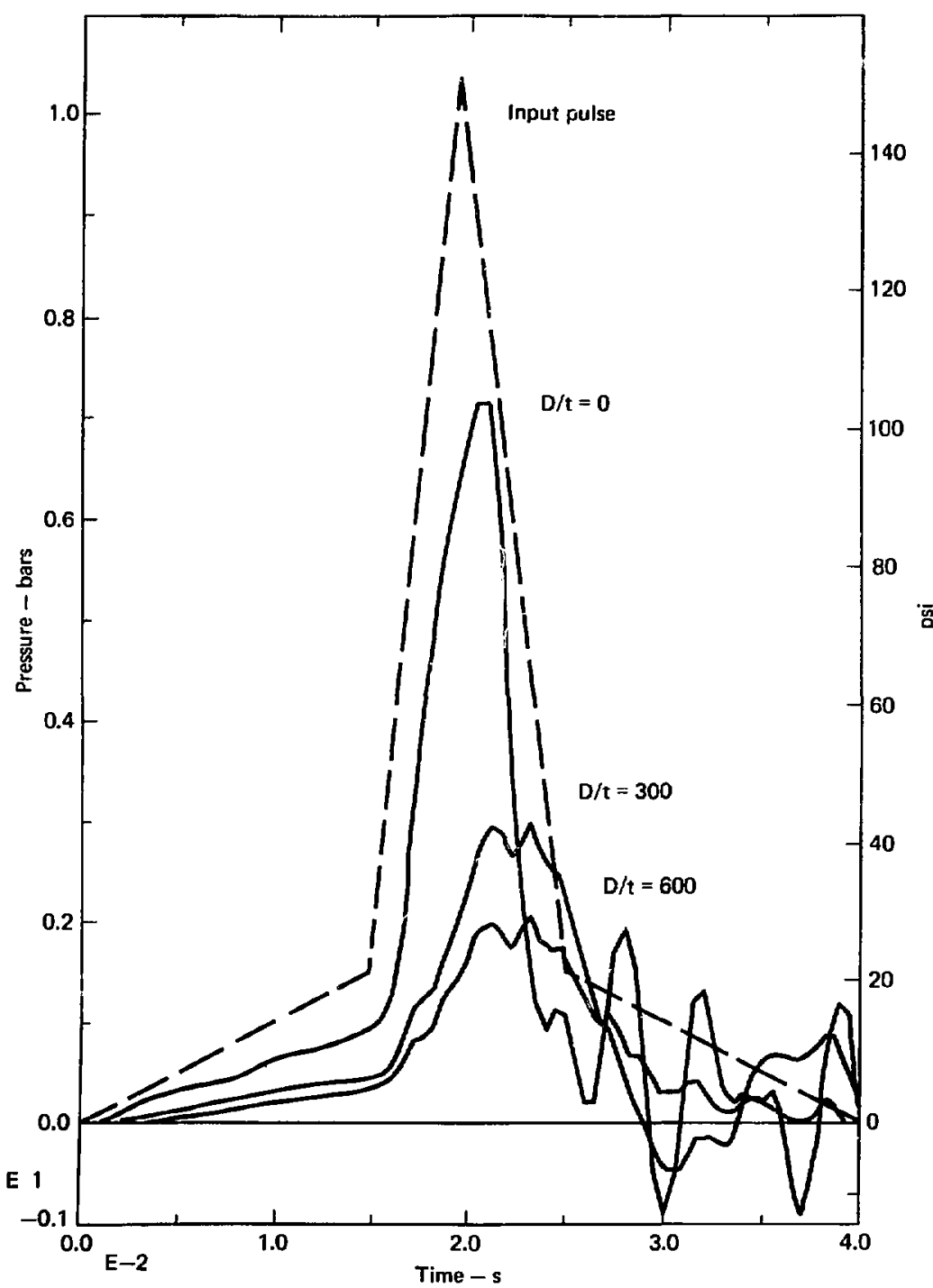

FIG. 11. Effect of torus shell thickness on the pressure history at the pool bottom (SRU dibcharge). 


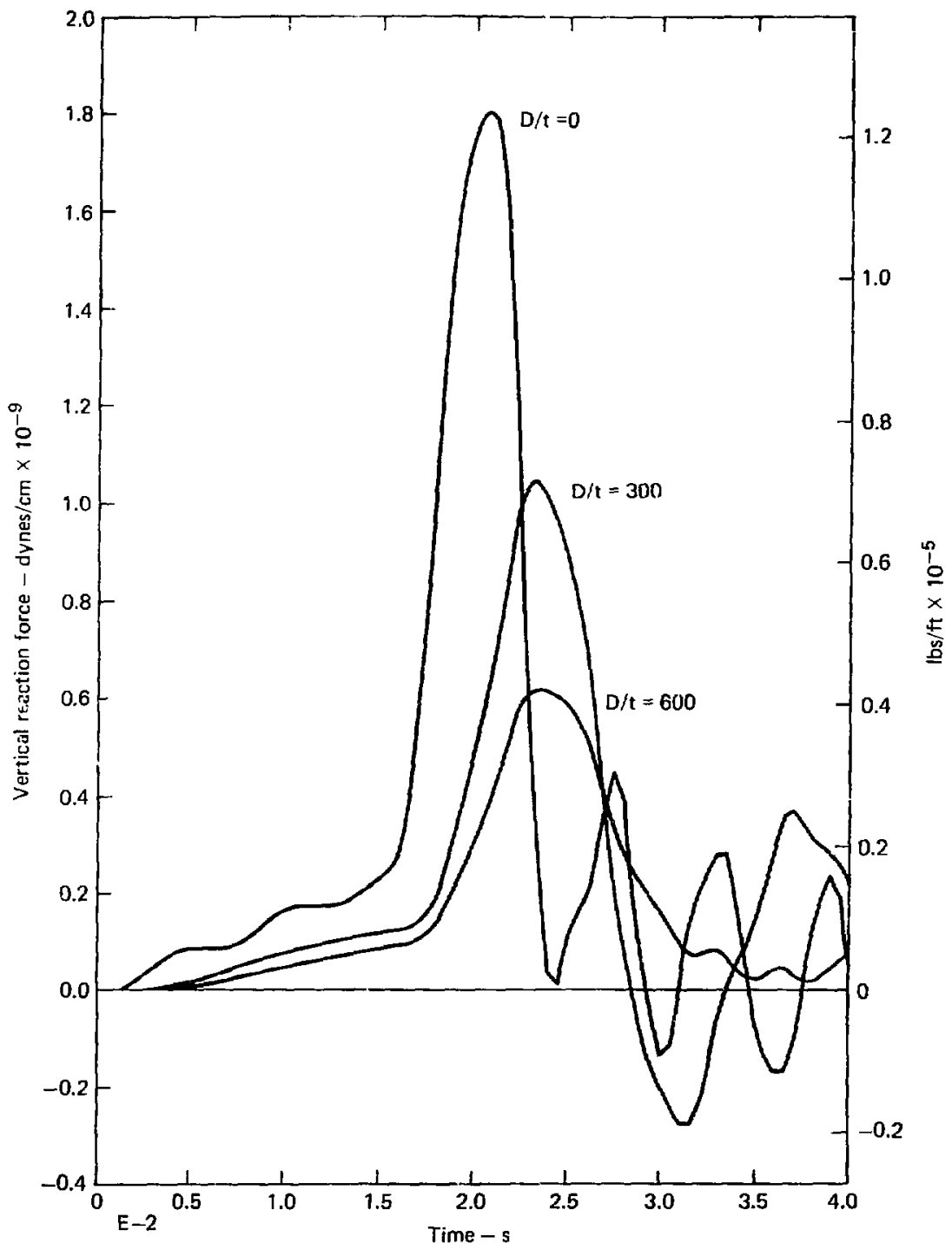

FIG. 12. Effect of torus shell thickness on total vertical reaction force history (Sr:' discharge). 


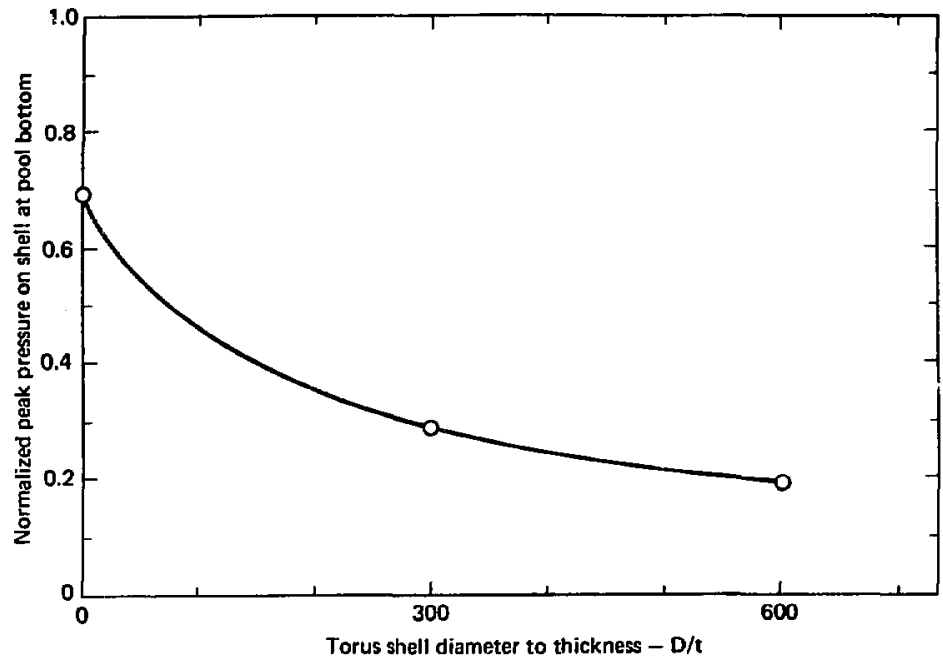

FIG. 13. Effect of torus shill thickness on normalized peak overpressure (SRV discharge).

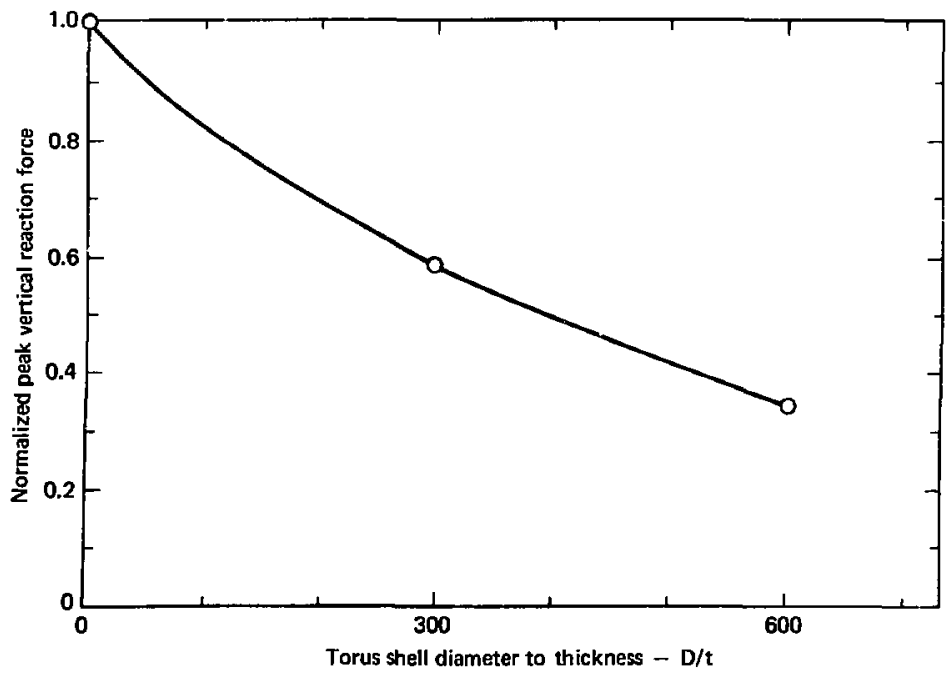

FIG. 14. Effect of torus shell thickness on normalized peak vertical reaction force (SRV discharge). 
out for times in excess of $100 \mathrm{~ms}$ with the result that bubble growth continued to increase even at late times; i.e., the initiation time of the second pulse. It follows that an equal amount of negative impulse would be required just to reurn the bubble to its original position. The effect of continuing the calculation past the point of a single pulse would be analogous to that of applying an increasing pressure to an already enlarged surface, resulting in the physically incorrect situation of a bubble of ever-increasing, rather than oscillating, radius.

It should also be pointed out that in the plane geometry chosen for this problem, the "bubble" is not spherical but rather a cylinder of infinite length. The lack of geometric limit in the out-of-plane direction served to introduce more energy into the problem than is actually encountered in a real. plant.

These limitations were the determining factors in the decision to limit the calculation to a single, positive pulse.

IOCA CHUG--GENERALIZED RESULTS

Chugging is expected to occur in the later phases of the hypothetical loss-of-coolant accident (LOCA) when steam exiting the downcomer forms a partial bubble that subsequently collapses due to heat transfer in the vent header and in the water of the torus. Complete modeling of this process would require the use of a multiphase computer code. Our model of the LocA chug begins with a "bubble" having the diameter of the downcomer and located below the downcomer exit, the bubble's top being flush with the exit. A pressure history is applied to the bubble's inner surface. The chosen pressure pulse (Fig. 7) has a triangular form with a peak overpressure of $20 \mathrm{psj}$ ( 1.38 bars) and a total duration of $80 \mathrm{~ms}$. While this results in a situation of bubble growth rather than collapse, it is a reasonable first approximation to the problem.

Figure 15 shows the pressure history on the shell at the pool bottom for the three $\mathrm{D} / \mathrm{t}$ ratios investigated. There is a slight temporal shift due to shell motion but it is considerably less noticeable than in the SRV discharge case. 
This is to be expected considering the relatively smaller pulse peak and $r$ ise time, 1.e.. lower shell velocities result. The total vertical force resulting from the chug pulse is shown in Fig. 16. The varlation in peak nornalized presaure on the shell at the bottom of the pool and peak normalized vertical load with shell flexibility $(D / t)$ is shown in Figs. 17 and 18.

It must be remembered that here, too, due to the cholce of plane section modeling, the bubble is actually a cylinder of infinite length. The lack of out-of-plane limits on the source ayain results in the introduction of excess energy into the problem. 


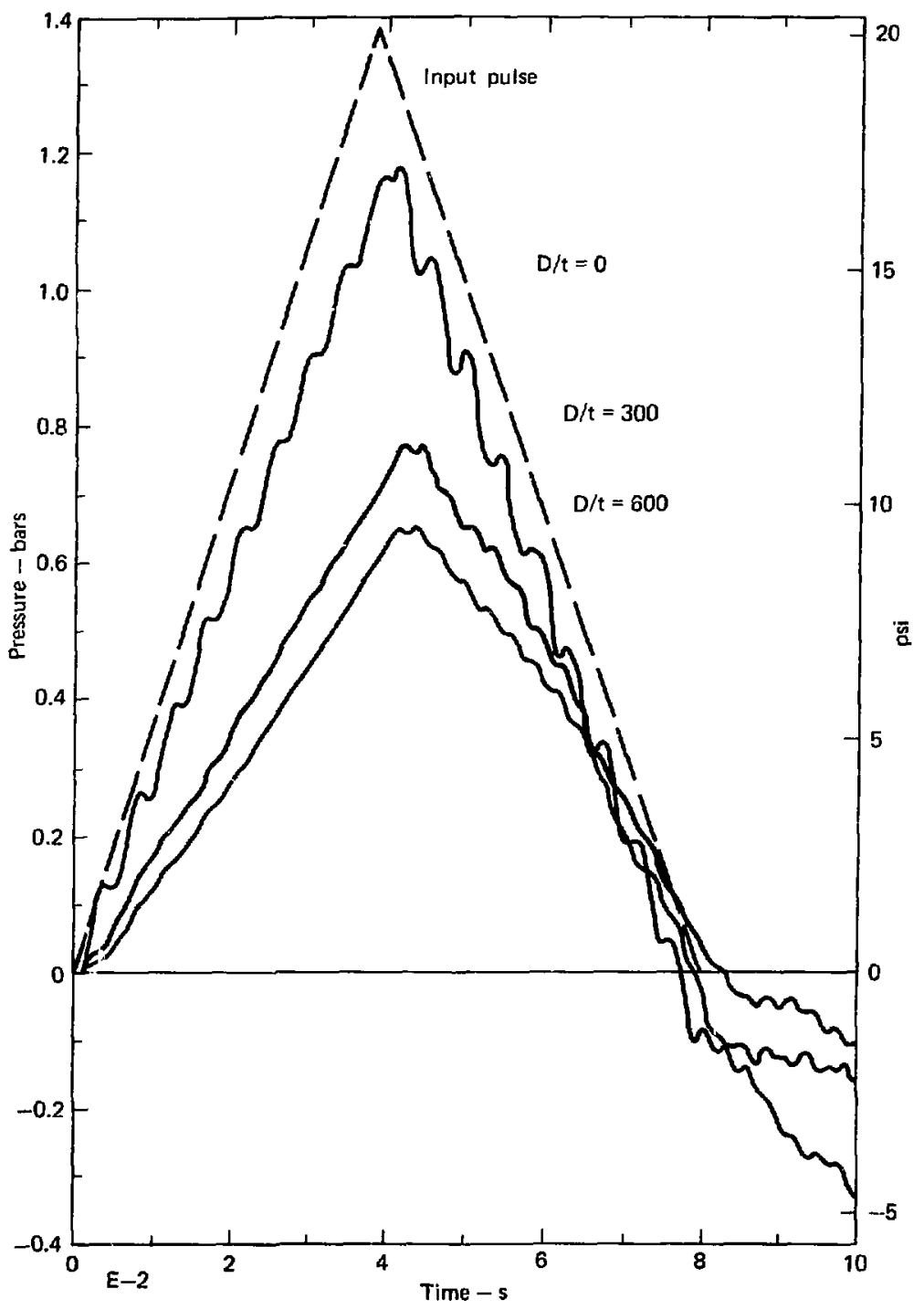

FIG. 15. Effect of torus shell thickness on pool bottom pressure h1story (LOCA chug). 


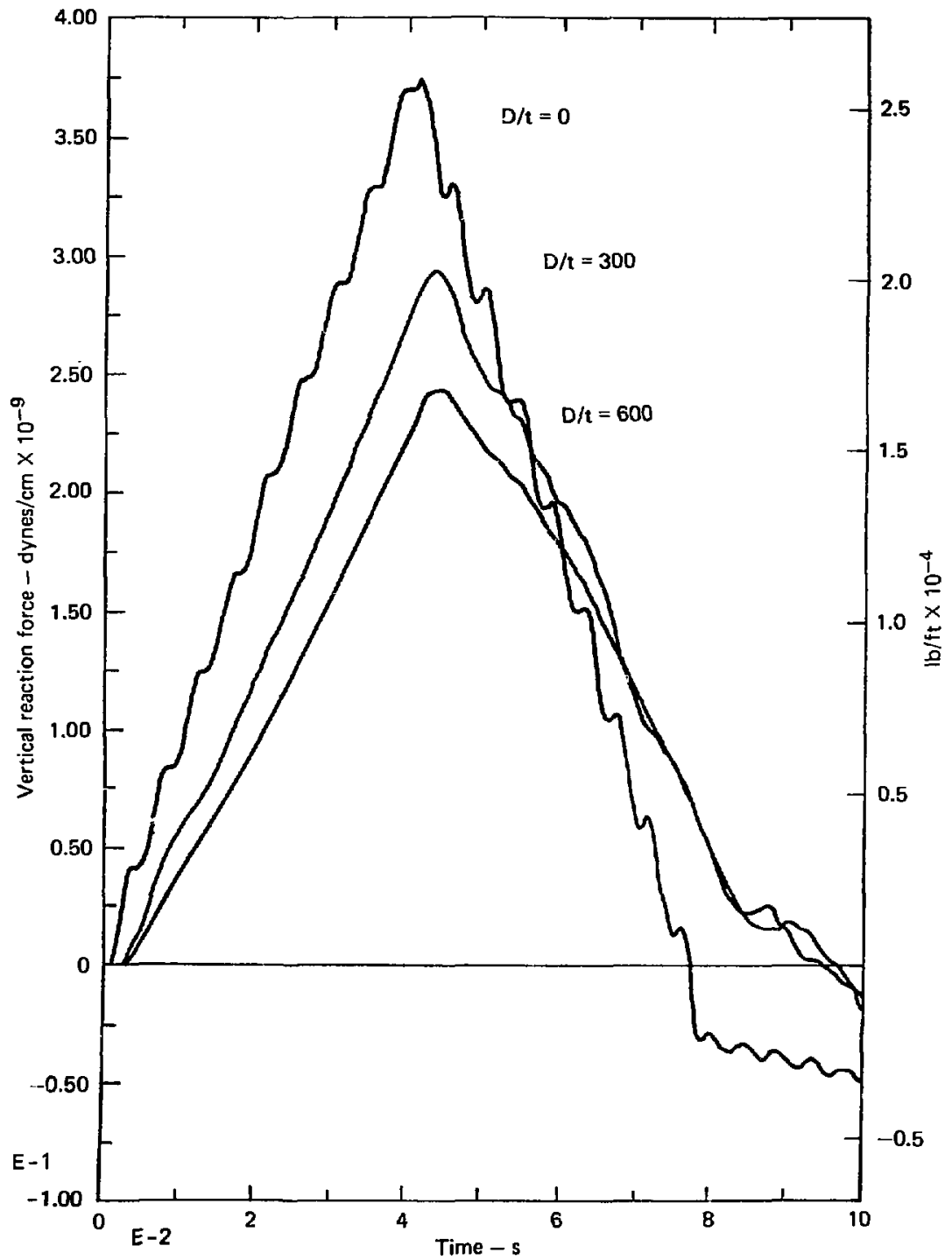

FIG. 16. Effect of torus shell thickness on total vertical force (LOCA chug). 


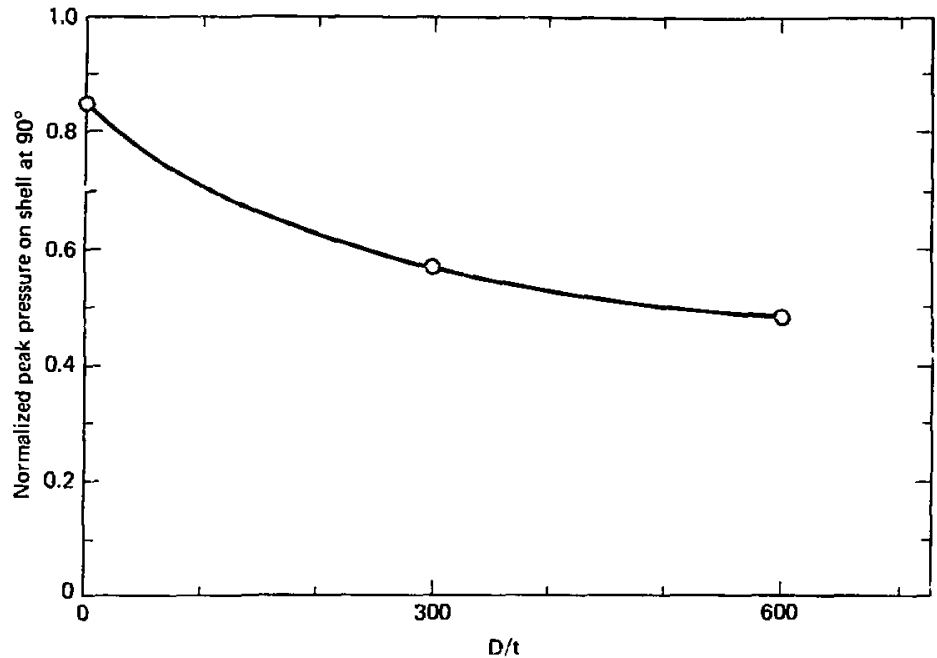

FIG. 17. Effect of torus shell thickness on normalized peak pressure at pool bottom (LOCA chug).

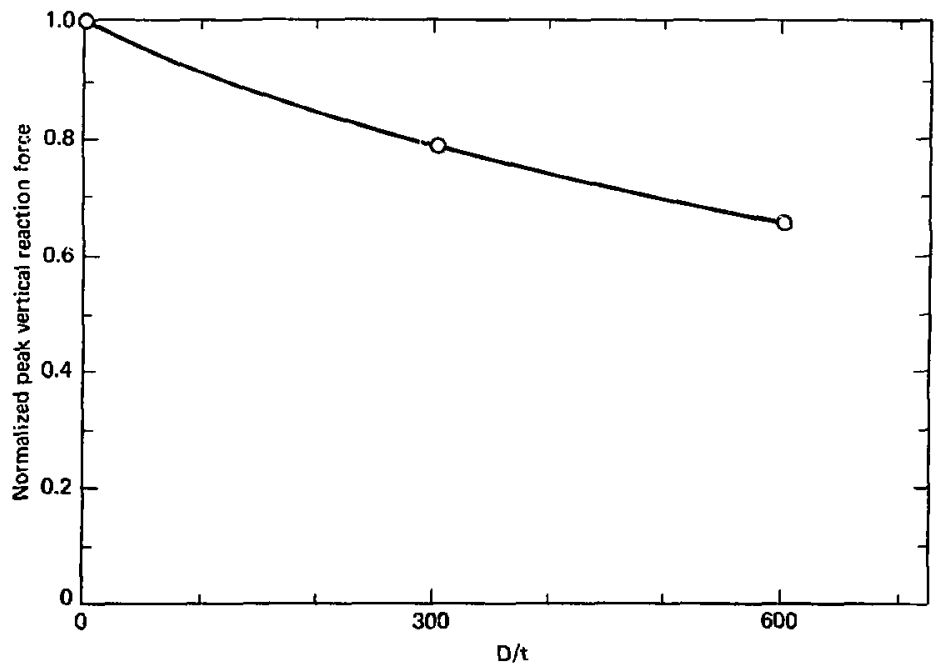

FIG. 18. Effect of torus shell thickness on normalized vertical reaction force (LOCA chug). 


\section{CONCLUSTONS AND RECOMMENDATIONS}

The general conclusion reached from these analyses is that toris wall flexibility will decrease both the maximum pressures induced on the wall and the total vertical load. Theje results are, in principle, those reached earlier by Koch and Karwat. 6

Results from experiments performed on systems having little or no flexibility in the container wall will be conservative when applied to actual high flexibility systems. * The quantification of the magnitude of the reduction experienced by flexible systems is, however, more difficult than simple application of the qualified results produced here.

Consider first that the suppression system modeled here is a flexible cylinder, infinite in extent, whereas a torus-shaped containment system would have an out-of-plane stiffness unaccounted for in these analyses. In addition, the shortness of span between the mitered sections of a Mark I containment system (which is not a true torus) can be expected to contribute additional stiffness over that of a pure toroidal shell.

The second consideration is that the source geometries as calculated in these problems are also cylinders infinite in extent. This lack of limit in the out-of-plane direction leads to the intraduction of excess energy into the problem. Moreover, in the case of spherical sources, a stronger divergence of a pressure wave is experienced over that of a cylindrical wave.

The work reported here has served to verify that increased wall flexibility will, in fact, result in a reduction of both wall pressures and vertical loads experienced by the system. Further work is in progress to arrive at a more detailed three-dimensional qualification and finalls quantification of that reduction.

*Which exhibit D/t ratios of 500 to 600 . 
Several improvements in treating this problem will be considered in future work. The primary goal is a more correctly posed geometrical model, which would still retain the relative simplicity of two-dimenstonal analysis, to be achieved by (1) calculating these probiems in pure toroidal geometry, and (2) by correlating separate structural analyses that could result in modifying the stiffness properties of the torus to account for the ring stiffeners in the mitered joints.

Part II of this investigation will involve the use of a three-dimensional model of a single bay between mitered joints (a $22.5^{\circ}$ sector). Incorporating the entire shell and stiffening structure. Before embarking on significantly more detailed calculations, it would be desirable to have better information on the characteristics of the source, particularly for the case of LOCA chugging. In this regara, it would be useful if future in-plant experiments were designed to provide data directly applicable to the needs of analytical modeling. 
Appreciation is extended to $S$. Sutton of the Thermo-Fluid Mechanics Group for his assigtance in running and analyzing the results of several champ problems. G. Goudreau and w. Mason of the Methods Development Group of Mechanical Engineering were responsible for the timely modifications to the finite element code to include fluid elentents. B. Benda, $M$. Gerhard, and $\mathrm{T}$. wilson of the Engineering Mechanics section performed and processed the fintite element problems. Finally, thanks are expressed to 3 . Hobson and T. Mithels of B-Divisten for their assistance in the use of the CHAMP core, and to Ms. S. Calvert for manuscript preparation. 
REFERENCE;;

1. J. 2. McCready, et al., Steam Vent Cleàring Phenomena and Structural Response of the BWR Torus (Mark I Containment), General Electric Document NEDO-10859, April 1973.

2. B. R. Bowman and L. L. Edwaras, Reactor Containment Anal isis for BWR Suppression Systems (Progress Report for October Through December, 1976), Lawrence Livermore Laboratory, Livermore, Calif.., UCRL-50045-76-4.

3. B. R. Bowman and L. L. Edwa: ds, Reactor Containment Analysis for BHR Suppression Systems (Progres:3 Report for January Through March 1977). Lawrence Livermore Laboratory, Livermore, Calif., UCRL-50045-77-1.

4. S. B. Sutton, An Investigation of Pressurs Transient Propagacion in Pressurized Water Reactor Feedwater Lines, Lawrence Livermore l,aboratory, Livermore, Calif., UCRL-52265.

5. H. C. Chang, Preliminary Report In-Plant Safety/Relief Valve Discharge Load Test--Monticello Plant, General Electric Docunent NEDC-21465, December 1976 .

6. E. Koch and H. Karwat, "Research Efforts in the Area of BWR Pressure Suppression Containment Systems," 4 th Water Reactor Safety Research Meeting, Gaithersburg, Mary] and, September 1976.

FWB $/ e j$ 
DTVIS2 is a two-dimensional plane or axisymmetric implicit Einite element code." It treats quasi-static or dynamic thermoviscoelastic behavior of solids. Its principal development is small deformation linear solids but it has been extended to a limited class of nonlinear elastic materials.

For the purpose of the SRV discharge and LOCA chug calculations, the basic quadrilateral element was converted to a constant pressure fluid element, which worked successfully. The small deformation assumption was adequate because the peak structural reactions occur before deformations become large. At late times the bubble continues to grow, obviating the small deformation condition and requiring both large deformation kinematics and follower pressure. Another implicit finite element code (NSAP2D) treating large deformations and follower pressure is available for solids. ${ }^{+}$This was modified to provide a fluid element too late to impact the LOCA analysis matrix of calculations. A benchmark calculation, however, showed the DrvIS2 results to be adequate.

The spatial discretization for DTVIS2 is accomplished by use of quadrilateral four-node linear isoparametric elements. The usual equations of motion are obtained:

$$
M \underline{u}+k \underline{u}=\underline{P}(t)
$$

$$
\text { with } \quad \begin{aligned}
M & =\int_{V} \rho \Phi^{T_{\Phi} d v} \\
K & =\int_{V} B^{T} D B d v \\
\underline{P} & =\int_{S} \phi^{T} t d s
\end{aligned}
$$

\footnotetext{
"G. L. Goudreau, "DTVIS2 Users Manual," Lawrence Livermore Laboratory, Users Manual in Preparation.

†J. O. Hallquist, "NSAP2D--An Implicit, Finfte Deformation, Finite Element Code for Analyzing the Static and Dynamics Response of 2-D Solids," Lawrerce Livermore Laboratory, Users Manual in Preparation.
} 
where $M_{r} K$, and $\underline{P}$ are the mass and stiffness matrices and load vector, $\rho$ is the denaity, $D$ is the elastic modulus matrix, $t$ is the frescribed surface traction vector, $\Phi$ the basis functions of the usual finite element displacement expanston, and $B$ is the matrix of the gradient of the basis functions. Integration is performed element-wise by appropriate Gauss quadrature.

For the isotropic material consldered,

$$
D=k D_{1}+\mu D_{2}
$$

where $k$ and $\mu$ are the bulk and shear noduli and $D_{1}$ and $D_{2}$ are the appropriate constant matrices.

Time inteyration is accomplished by the unconditionally stable Newmark scheme.

The application of this elenent to Lagranglan fluid problems of the LOCA type leads to the use of a small trace shear modulus $\mu$ to stabilize the grid. The resulting large, nearly incompressible distortions are restricted by a locking of the elements due to excessive kinematic constraints on the element deformation. This results from the multipoint integration of the bulk stiffness." However, one-point integration of the bulk stiffness with $2 \times 2$ integration of the trace shear stiffness overcomes this problem, and results in a successful calculation.

\footnotetext{
T. J. R. Hughes, Callfornia Institute of Technology, Seminar at Lawrence Livermore Laboratory, March 1977 (paper in publication).
} 
APPENDIX B.

SRV DISCHARGE: DETAILED RESULTS 


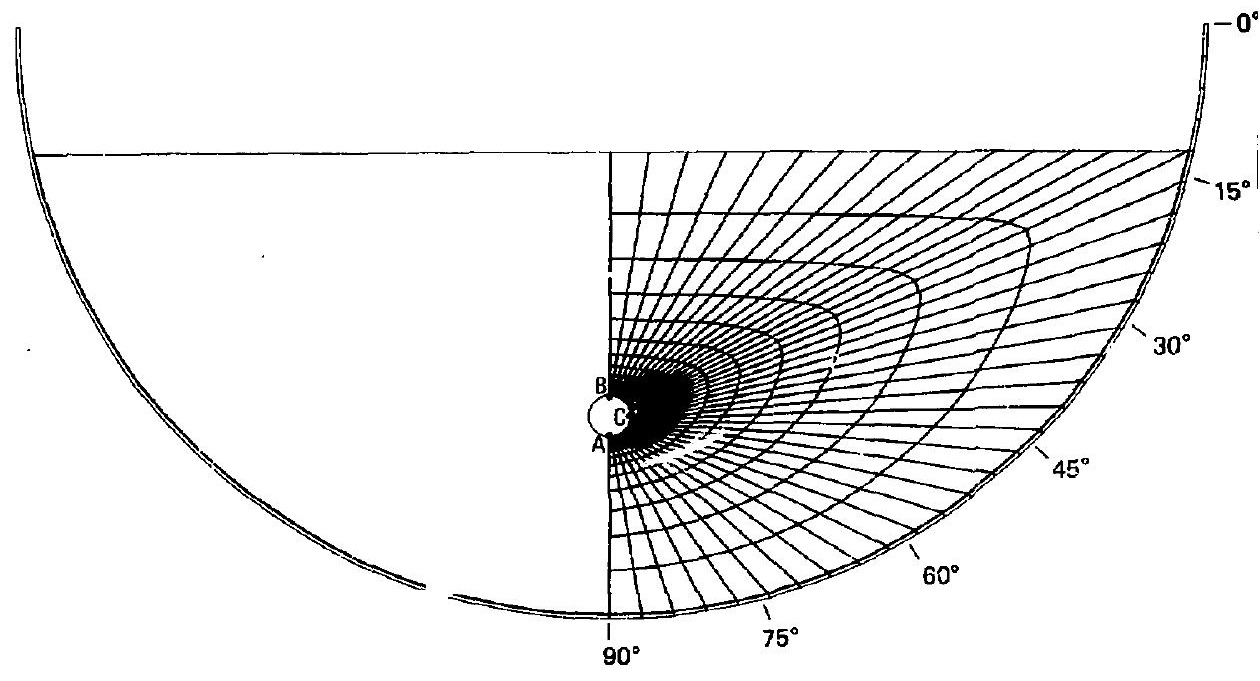

B-1. TYpical finite elewent mesh for the SRV discharge problem $(D / t=300)$. 


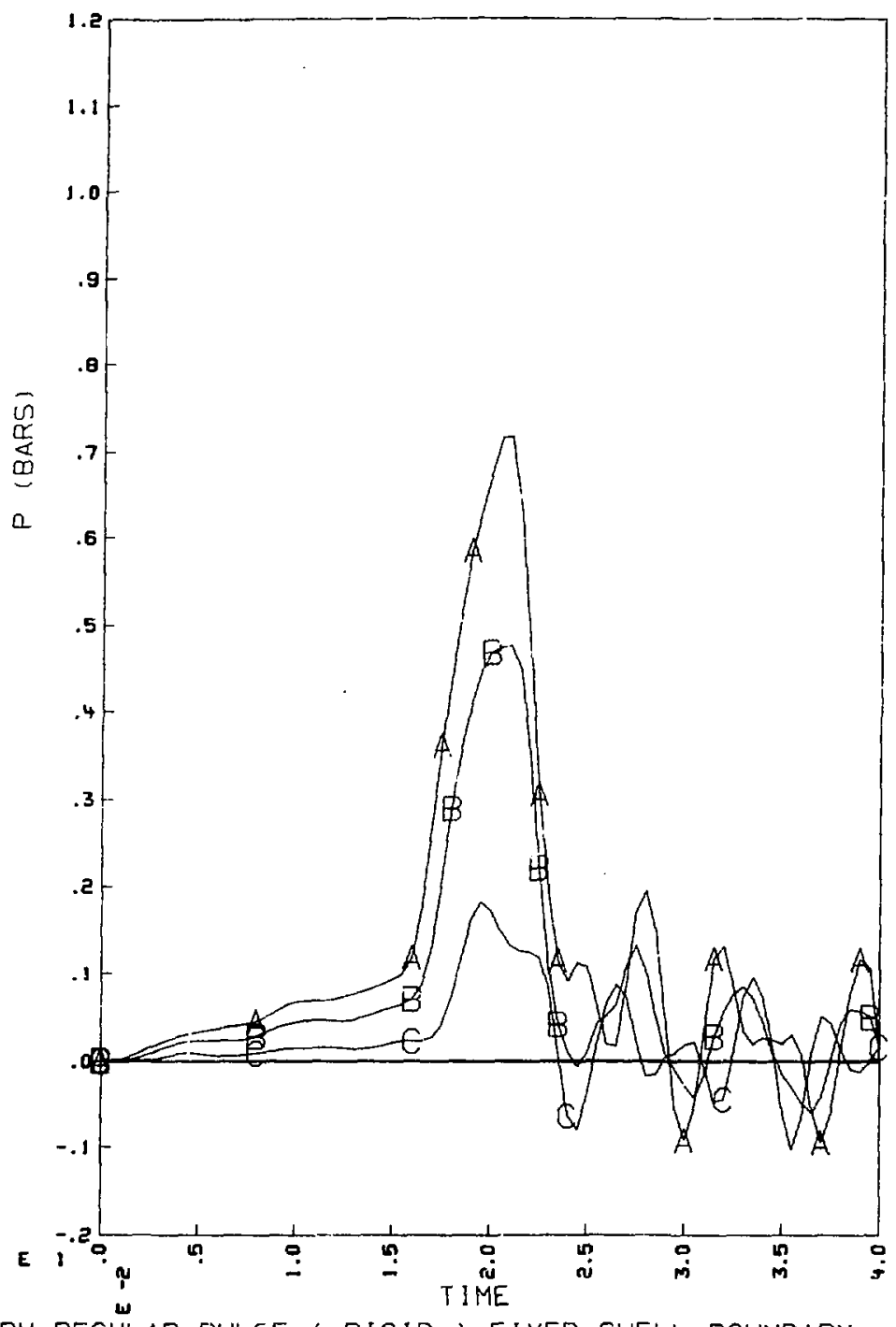

SRV REGÜLAR PULSE ( RIGID) FIXED SHELL BOUNDARY

B-2. Pressure on shell wall $\left(A-90^{\circ} ; B-60^{\circ} ; C-30^{\circ}\right)$ (see Fig. 6) $(D / t=\therefore$. 


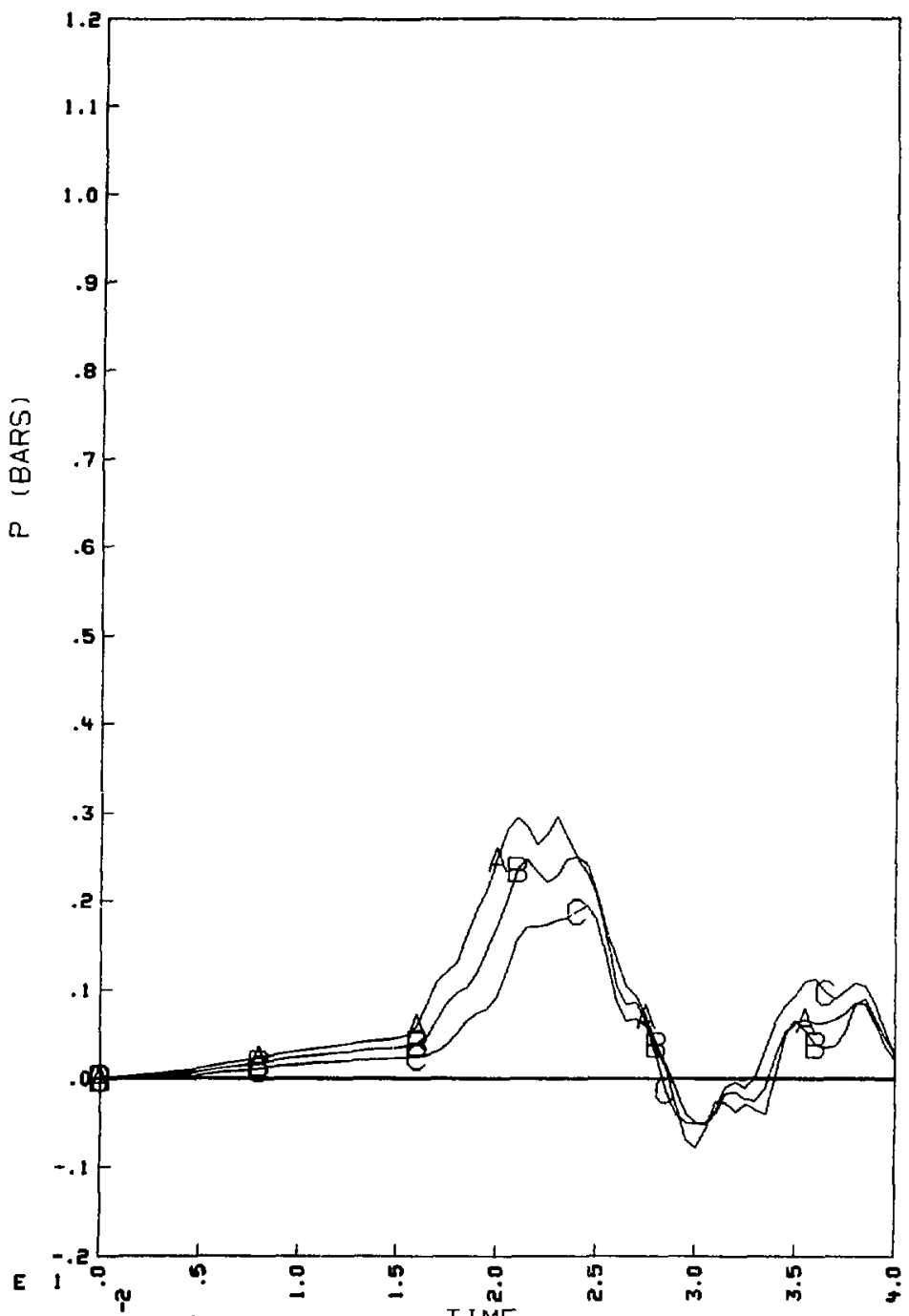

T IME

SRV REGULAR PULSE $(D / T=300)$ FIXED SHELL BOUNDARY

B-3. Pressure on shell wall $\left(A-90^{\circ} ; \mathrm{B}-60^{\circ} ; \mathrm{C}-30^{\circ}\right.$ ) (see Pig. 6) $(D / t=300)$. 


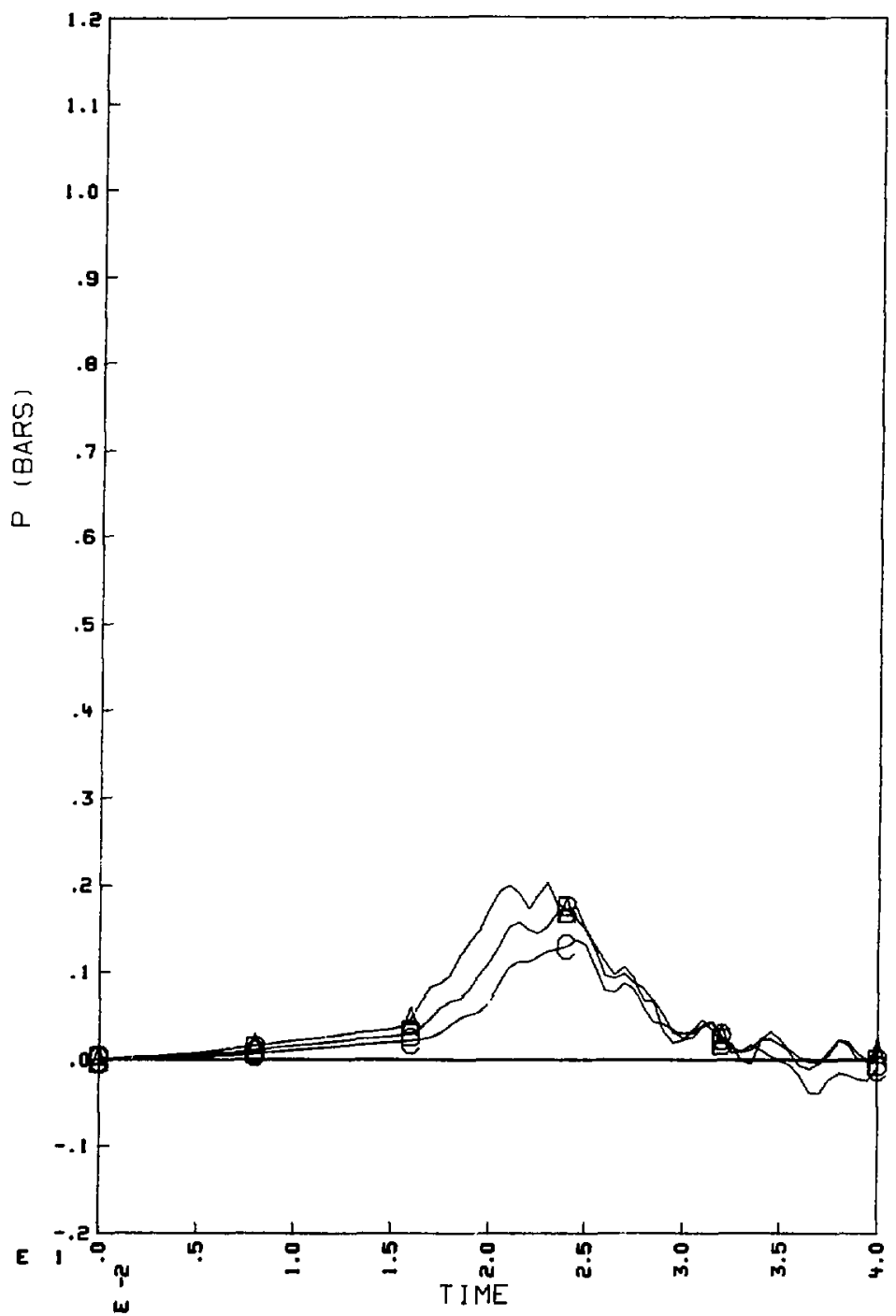

SRV REGULAR PULSE $(0 / T=600)$ FIXED SHELL BOUNDARY

B-4. Pressure on shell wall $\left(\mathrm{A}-90^{\circ}, \mathrm{B}-60^{\circ}, \mathrm{C}-30^{\circ}\right.$ ) (see Fig, 6) $(D / t=600)$. 


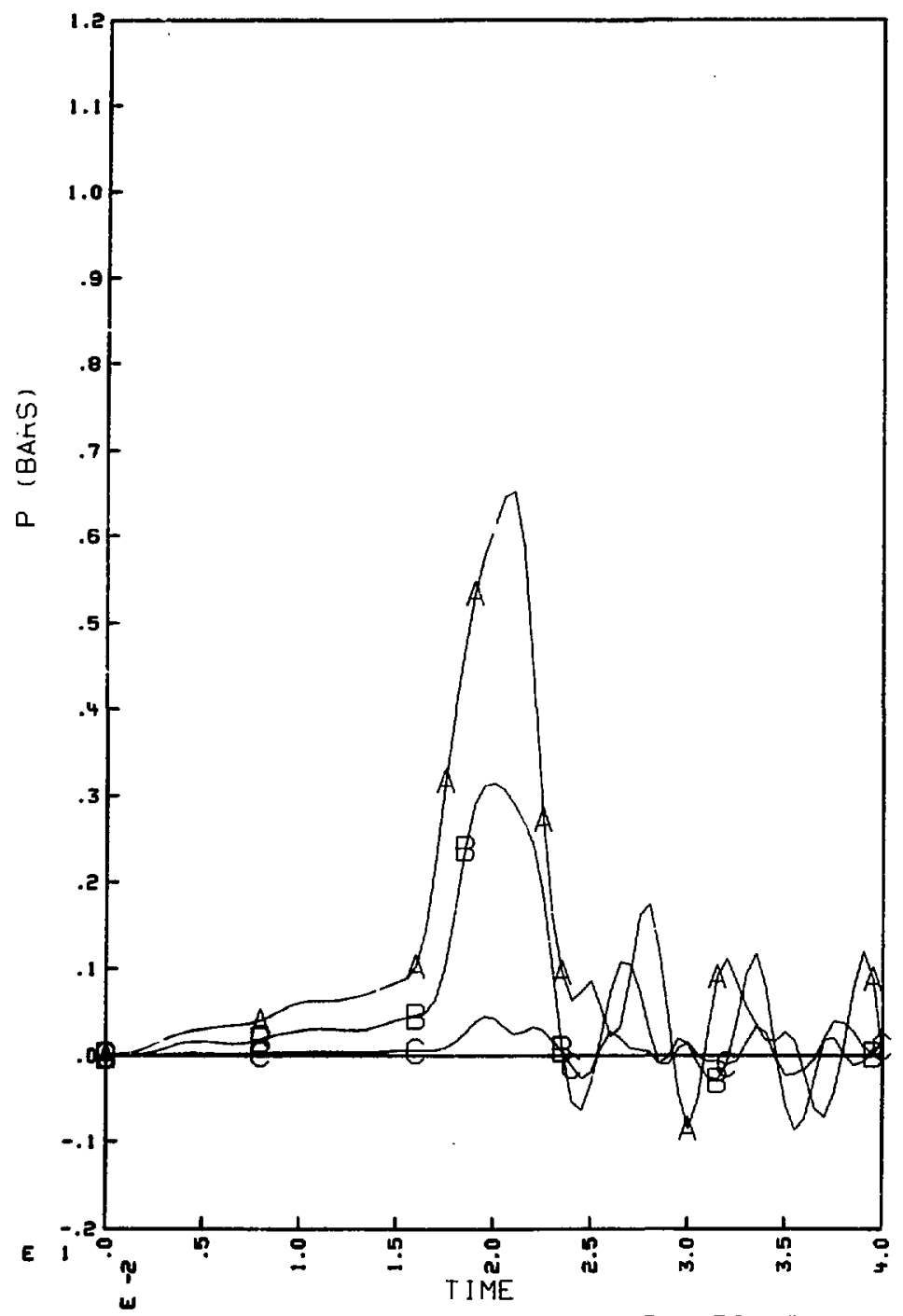

SRV REGULAR PULSE ( RIGID) FIXED SHELL BOUNDARY

B-5. Pressure on shell wall $\left(\mathrm{A}-75^{\circ}, \mathrm{B}-45^{\circ}, \mathrm{C}-15^{\circ}\right)$ (see Fig. 6) $(D / t=0)$. 


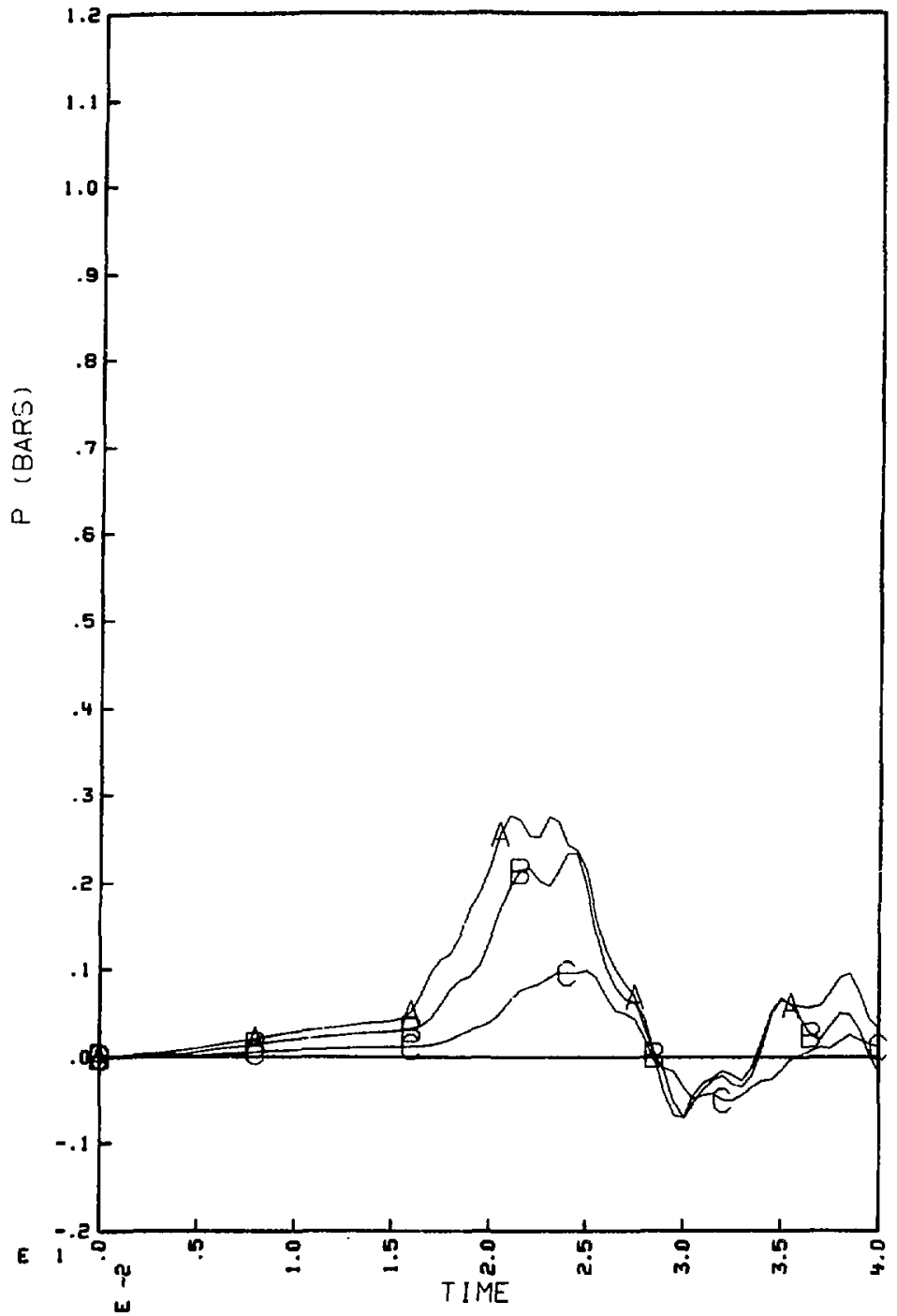

SRV REGULAR PULSE $(D / T=300)$ FIXED SHELL BOUNDARY

B-6. Pressure on shell wall $\left(\mathrm{A}-75^{\circ} ; \mathrm{B}-45^{\circ} ; \mathrm{C}-15^{\circ}\right.$ ) (see Fig. 6) $(D / t=300)$. 


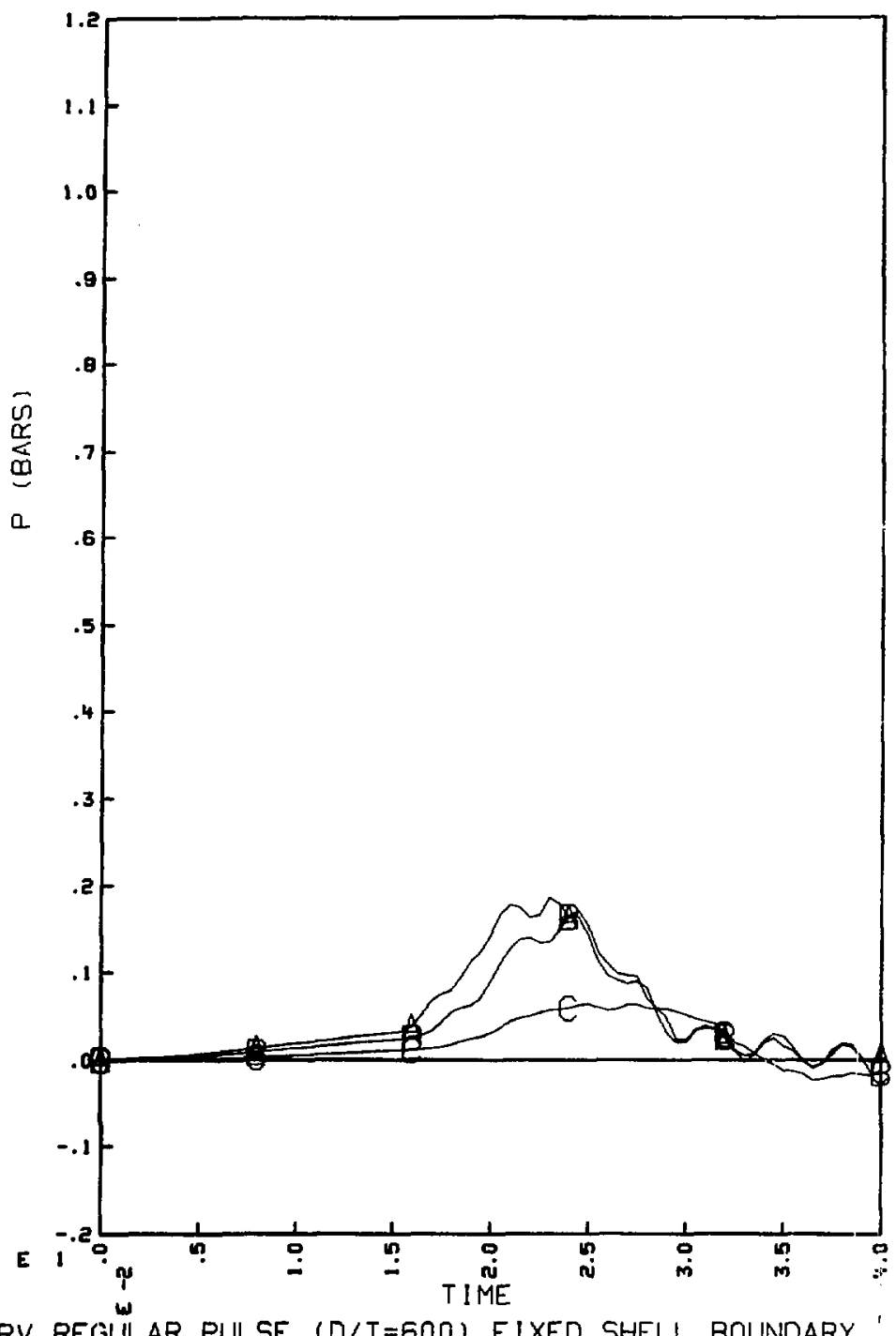

SRV REGULAR PULSE $(D / T=600)$ FIXED SHELL BOUNDARY

B-7. Pressure on ghell wall $\left(\mathrm{A}-75^{\circ} ; \mathrm{B}-45^{\circ} ; \mathrm{C}-15^{\circ}\right.$ ) (nee Fig. 6) $(D / t=600)$. 


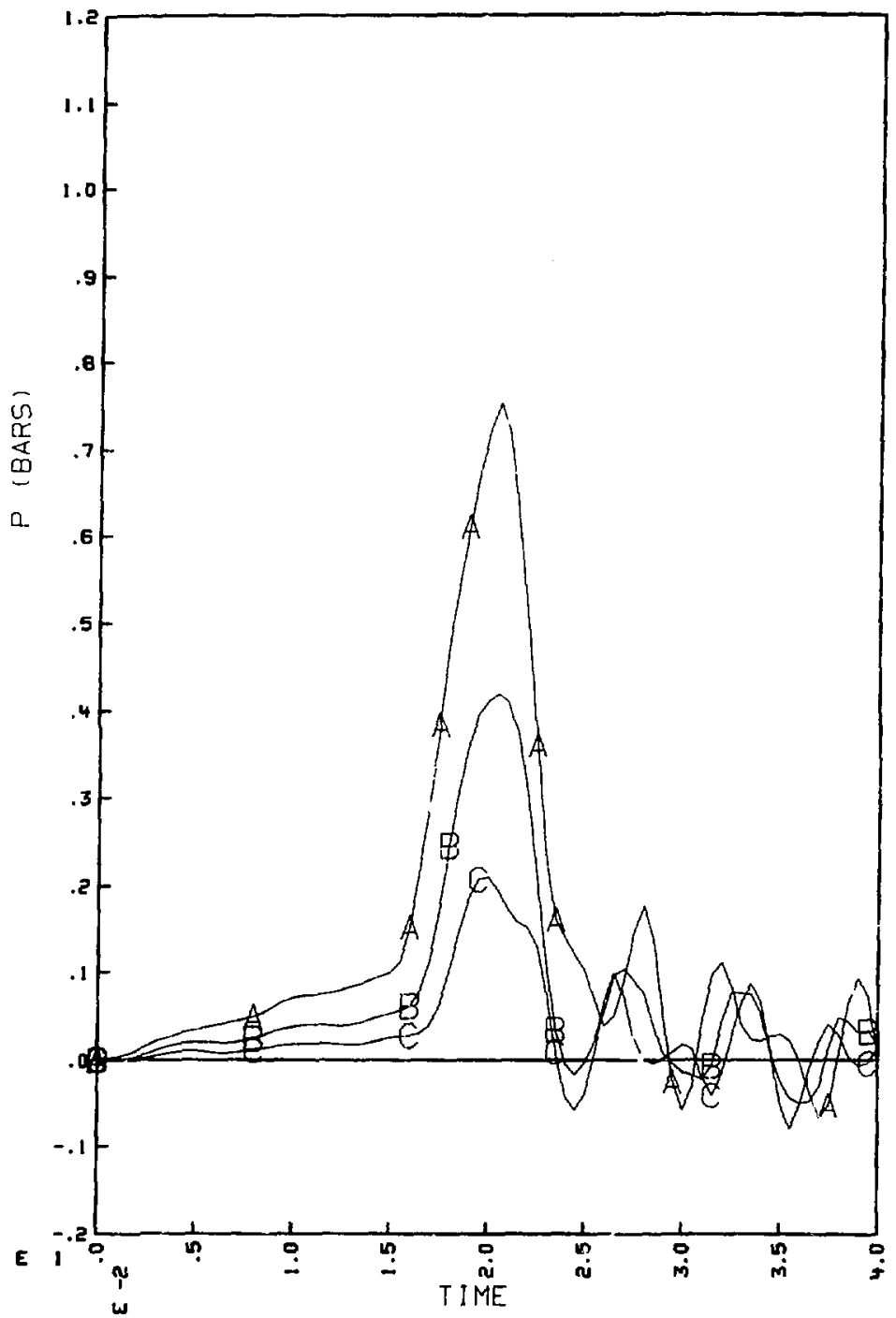

SRV REGULAR PULSE ( RIGID) FIXED SHELL BOUNDARY

B-8. Pressure in flutd at $r=I_{\mathrm{m}}$ (see Fig. 6) $\left(\mathrm{A}-90^{\circ} ; \mathrm{B}-60^{\circ} ; \mathrm{C}-30^{\circ}\right.$ ) $(D / t=0)$. 


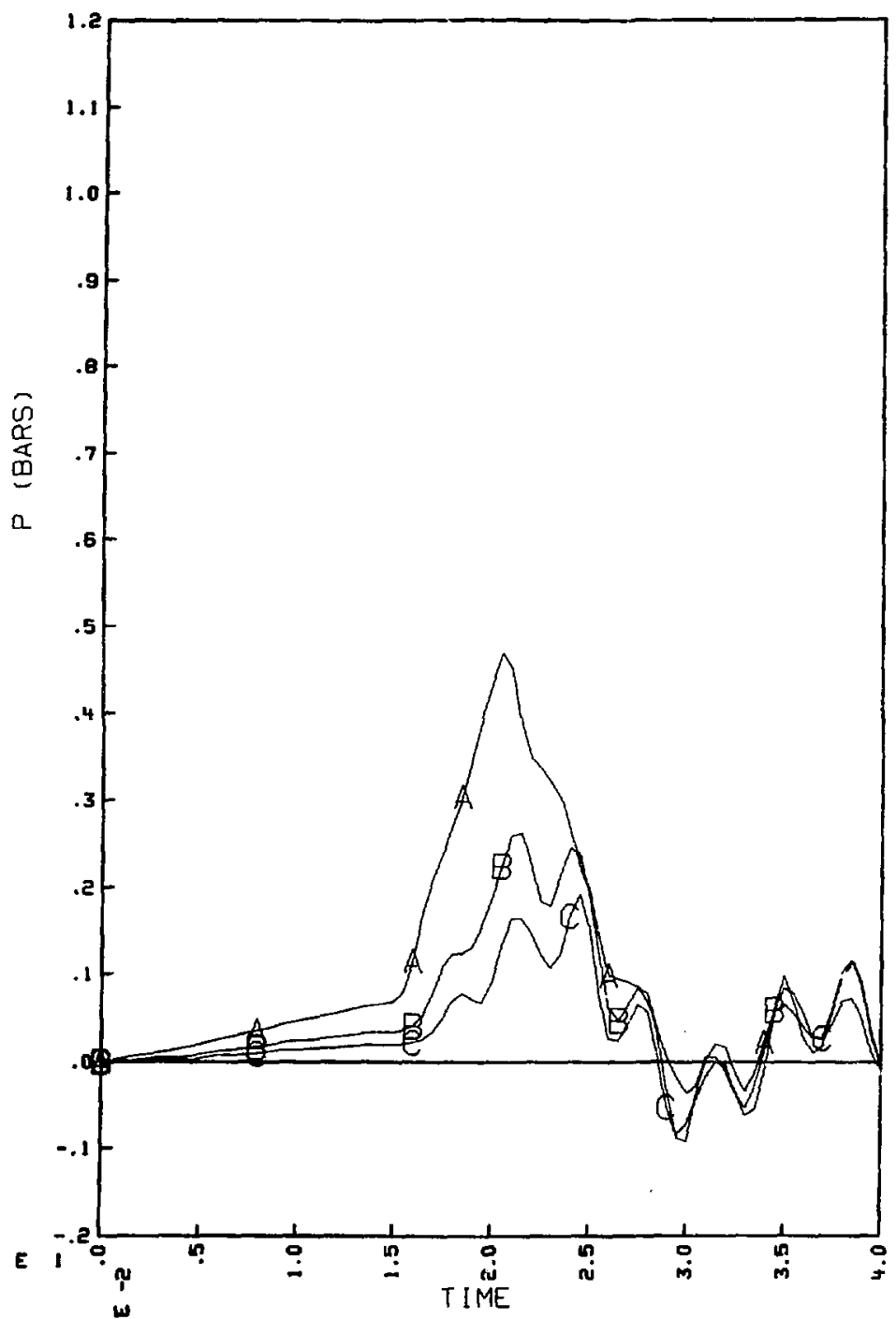

SRV REGULAR PULSE $(D / T=300)$ FIXED SHELL BOUNDARY

B-9. Pressure in fluid at $r=x_{m}$ (see Fig. 6) $\left(A-90^{\circ} ; B-60^{\circ} ; C-30^{\circ}\right.$ ) $(D / t=300)$. 


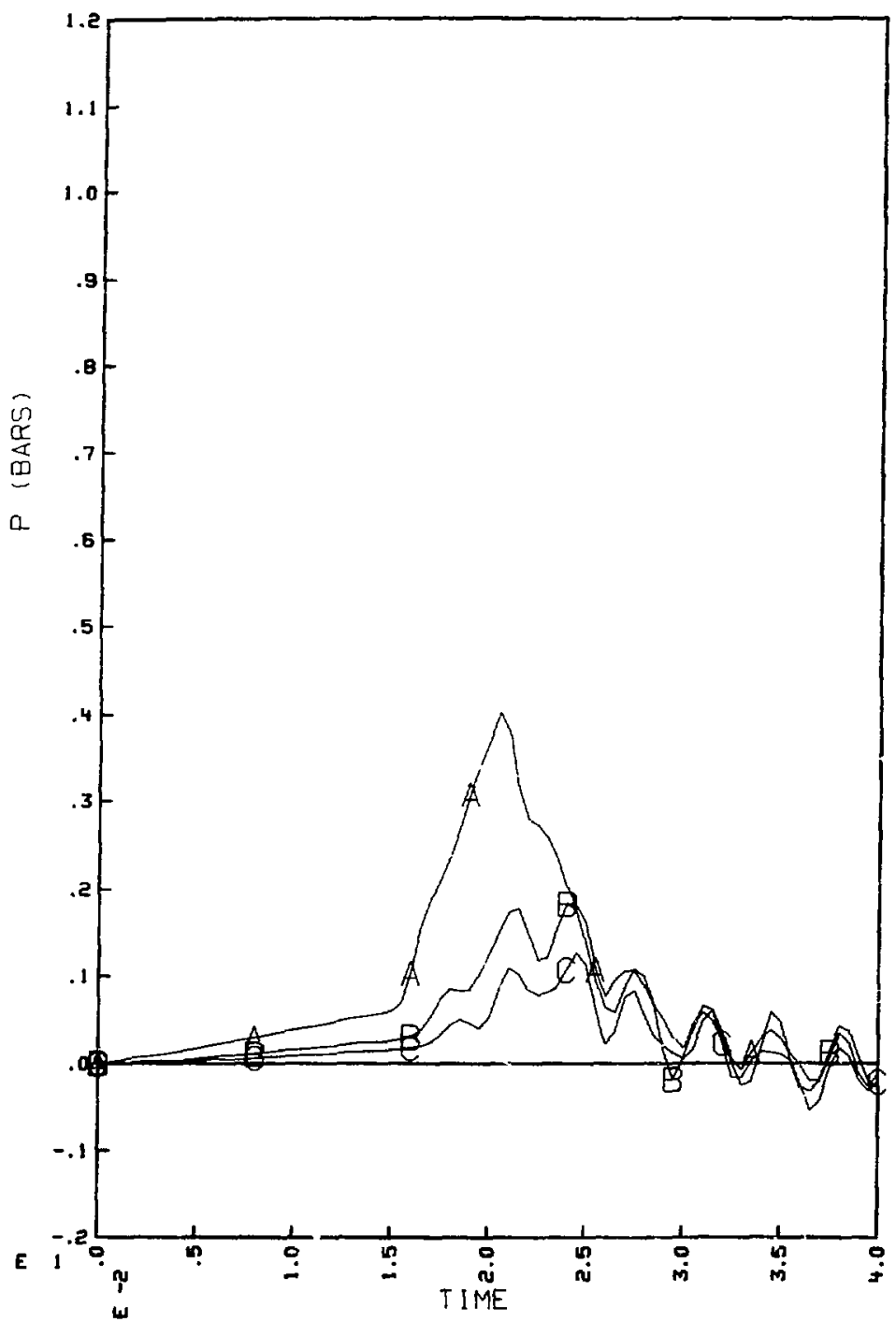

SRV REGULAR PULSE (D/T=600) FIXED SHELL BOUNDARY

B-10. Pressure in fluid at $x=r_{\text {in }}$ (see Fig. 6) $\left(A-90^{\circ} ; 8-60^{\circ} ; C-30^{\circ}\right.$ ) $(D / t=600)$. 


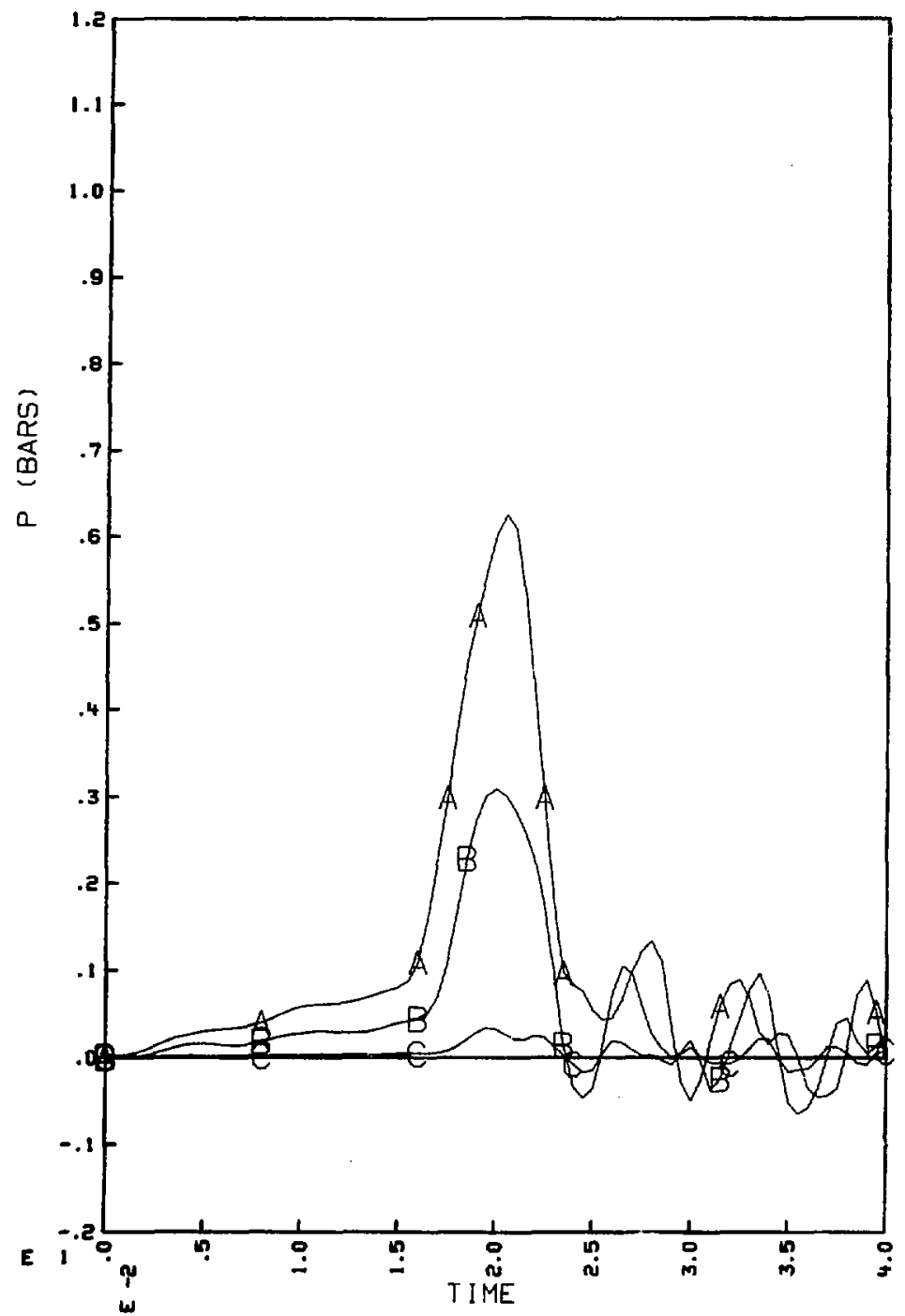

SRV REGULAR PULSE ( RIGID) FIXED SHELL BOUNDARY

B-11. Pregsure in fluid at $r=r_{\mathrm{m}}$ (see Fig. 6) $\left(\mathrm{A}-75^{\circ} ; \mathrm{B}-45^{\circ} ; \mathrm{C}-15^{\circ}\right.$ ) $(D / t=0)$. 


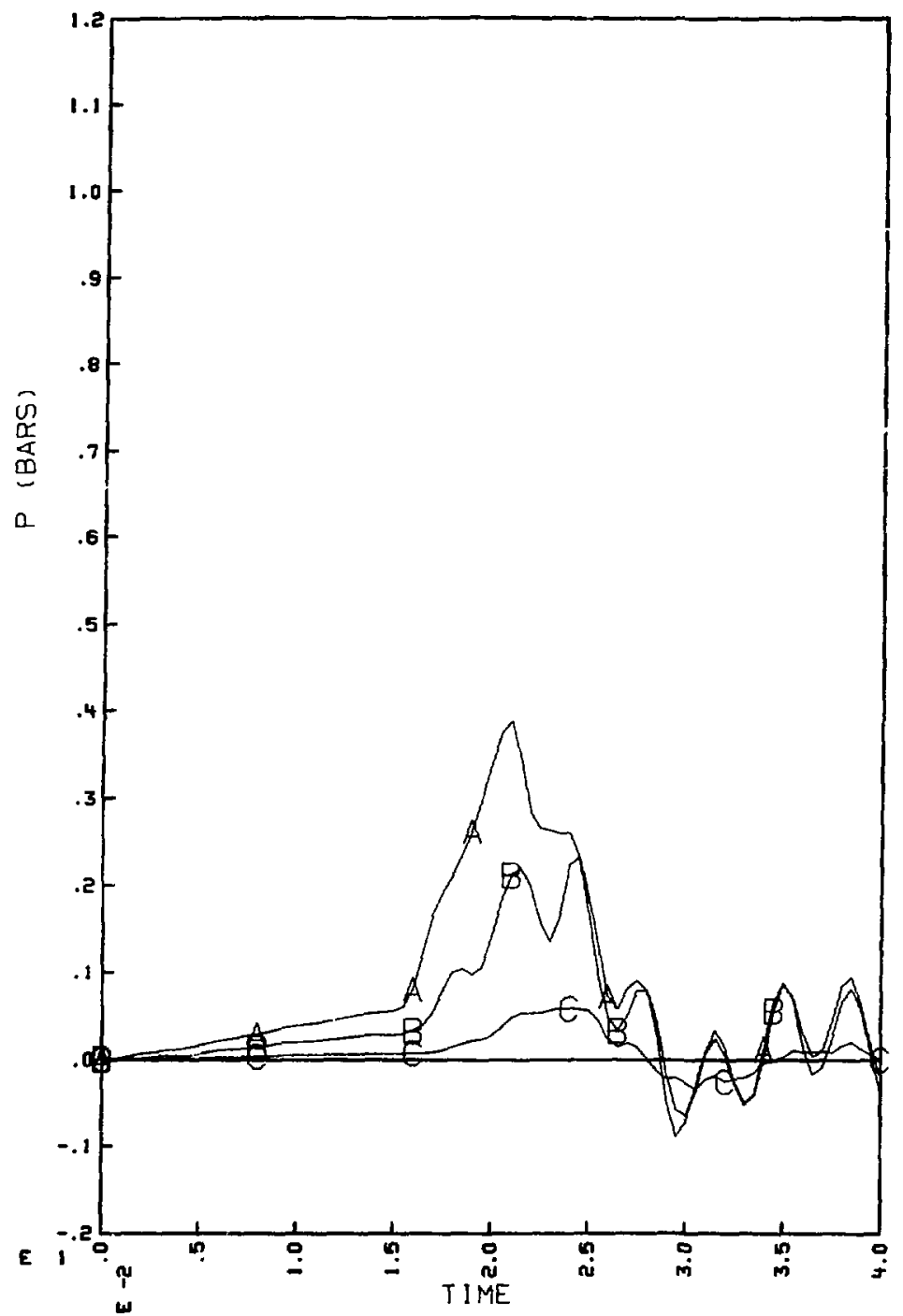

SRV REGULAR PULSE $(D / T=300)$ FIXED SHELL BOUNDARY B-12. Pressure in fluid at $r=r_{\text {do }}$ (see Fig. 6) $\left(A-75^{\circ} ; B-45^{\circ} ; \mathrm{C}-15^{\circ}\right)$
$(D / t=300)$. 


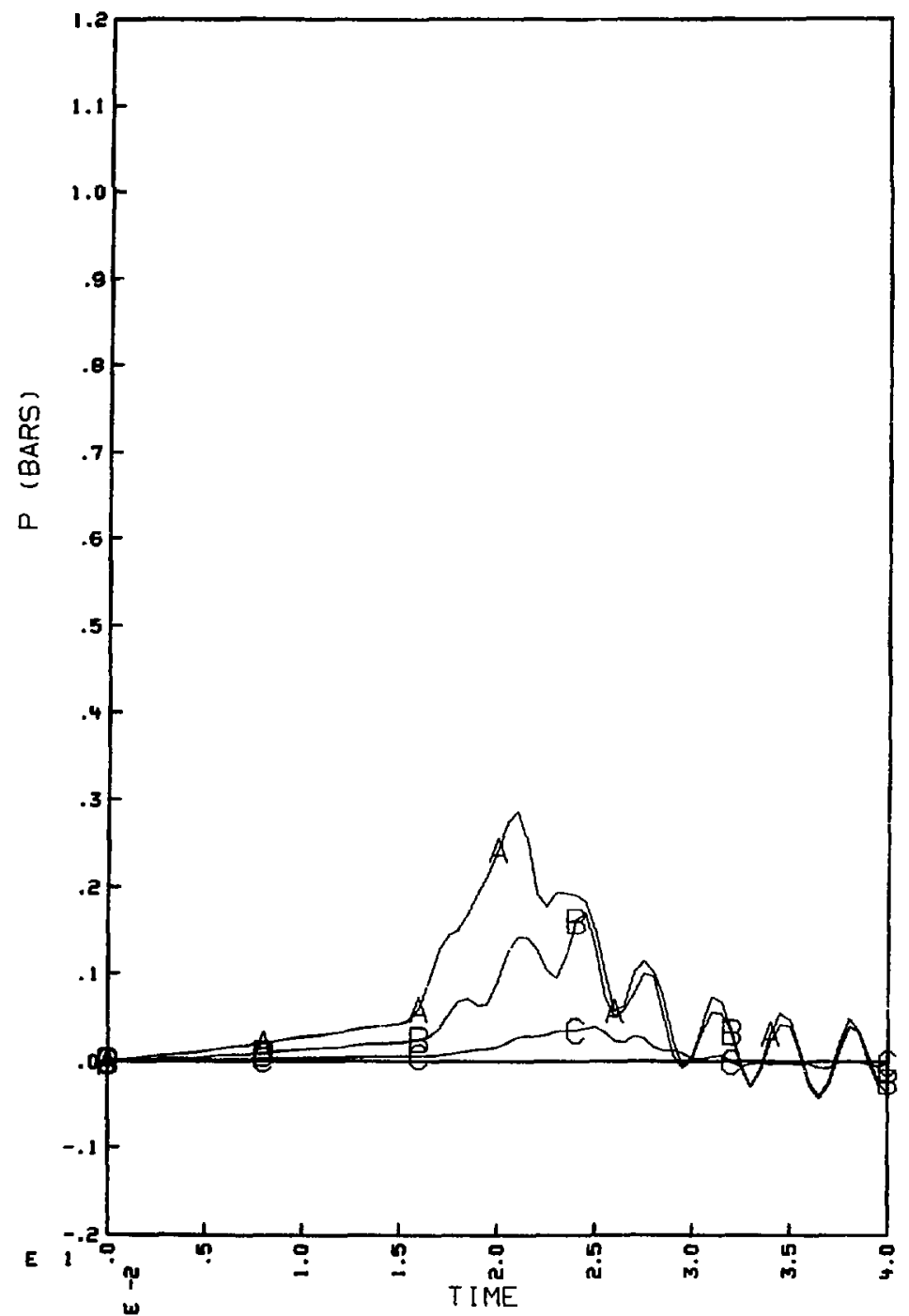

SRI REGULAR PULSE (D/T=60C) FIXED SHELL BOUNDARY

B-13. Pressure in fluid at $\mathrm{r}=\mathrm{r}_{\mathrm{in}}$ (see Fig. 6) $\left(\mathrm{A}-75^{\circ} ; \mathrm{B}-45^{\circ} ; \mathrm{C}-15^{\circ}\right.$ ) $(D / t=600)$.

46 


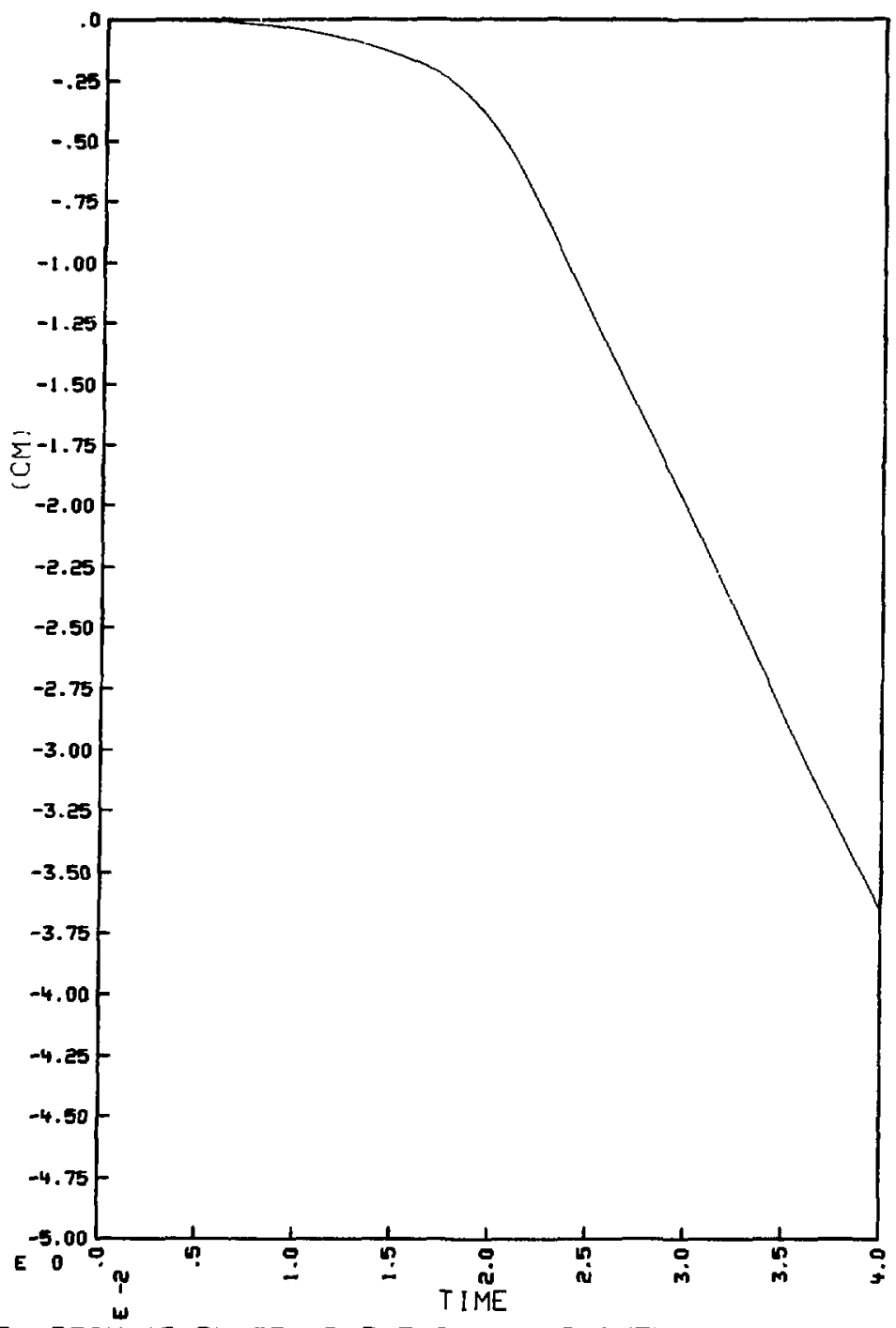

SRV REGULAR PULSE $(D / T=3.00)$ FIXED SHELL BOUNDARY

B-14. Shell alsplacenent at $90^{\circ}(\mathrm{D} / \mathrm{t}=300)$. 


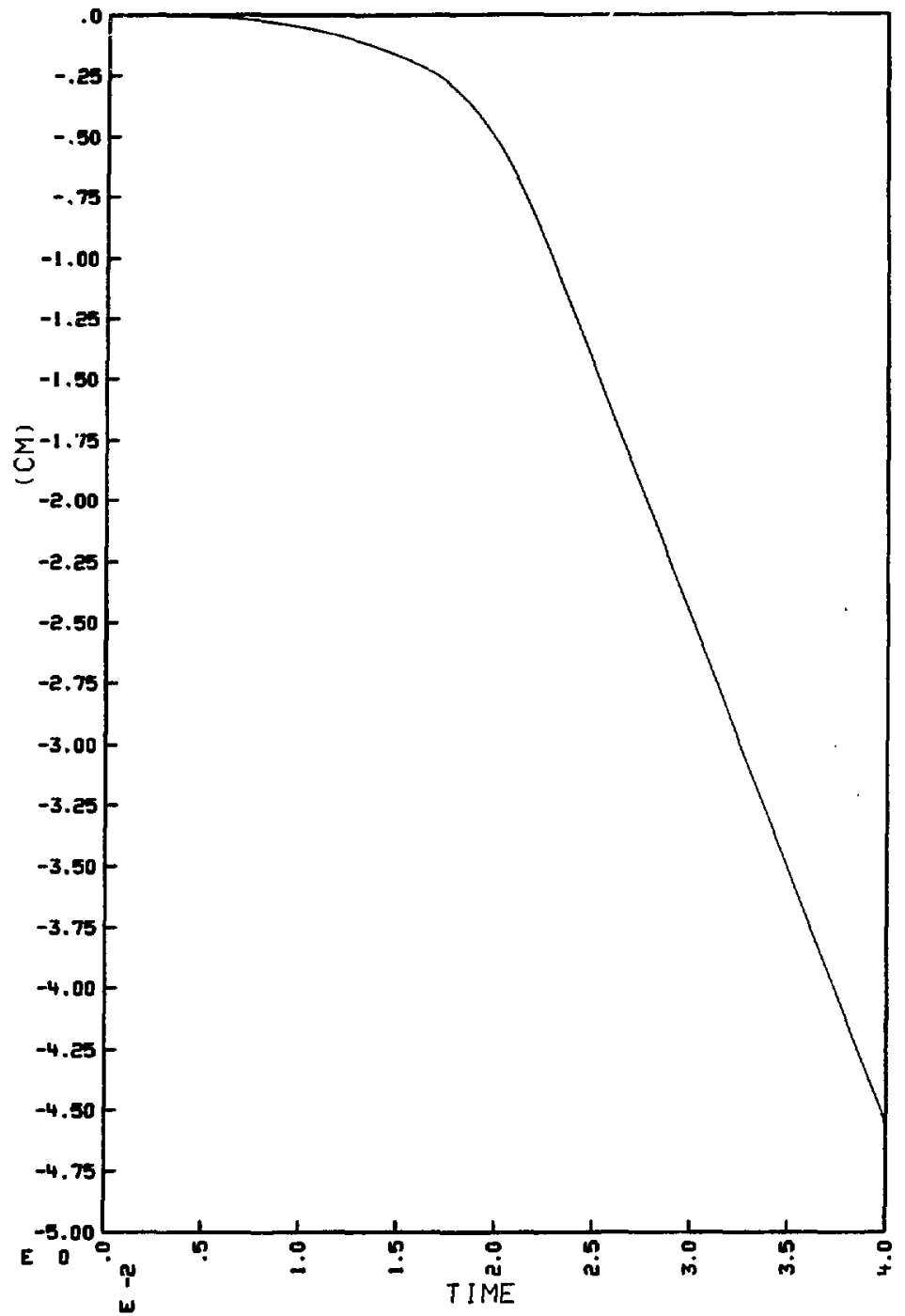

SRV REGULAR PULSE $(D / T=600)$ FIXED SHELL BOUNDARY

B-15. Shell displacenent at $90^{\circ}(D / t=600)$. 


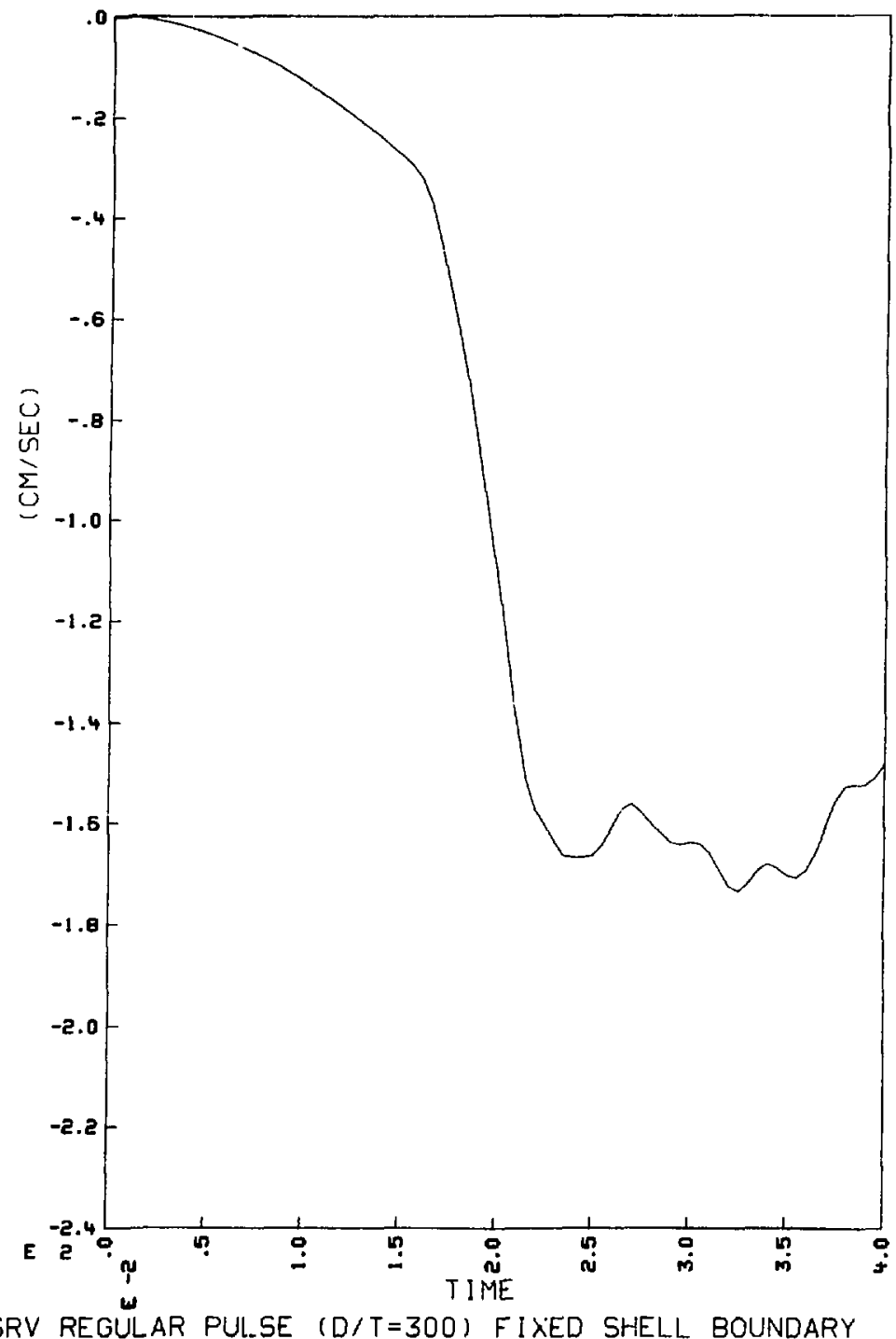

B-16. Shell velocity at $90^{\circ}(\mathrm{D} / \mathrm{t}=300)$.

49 


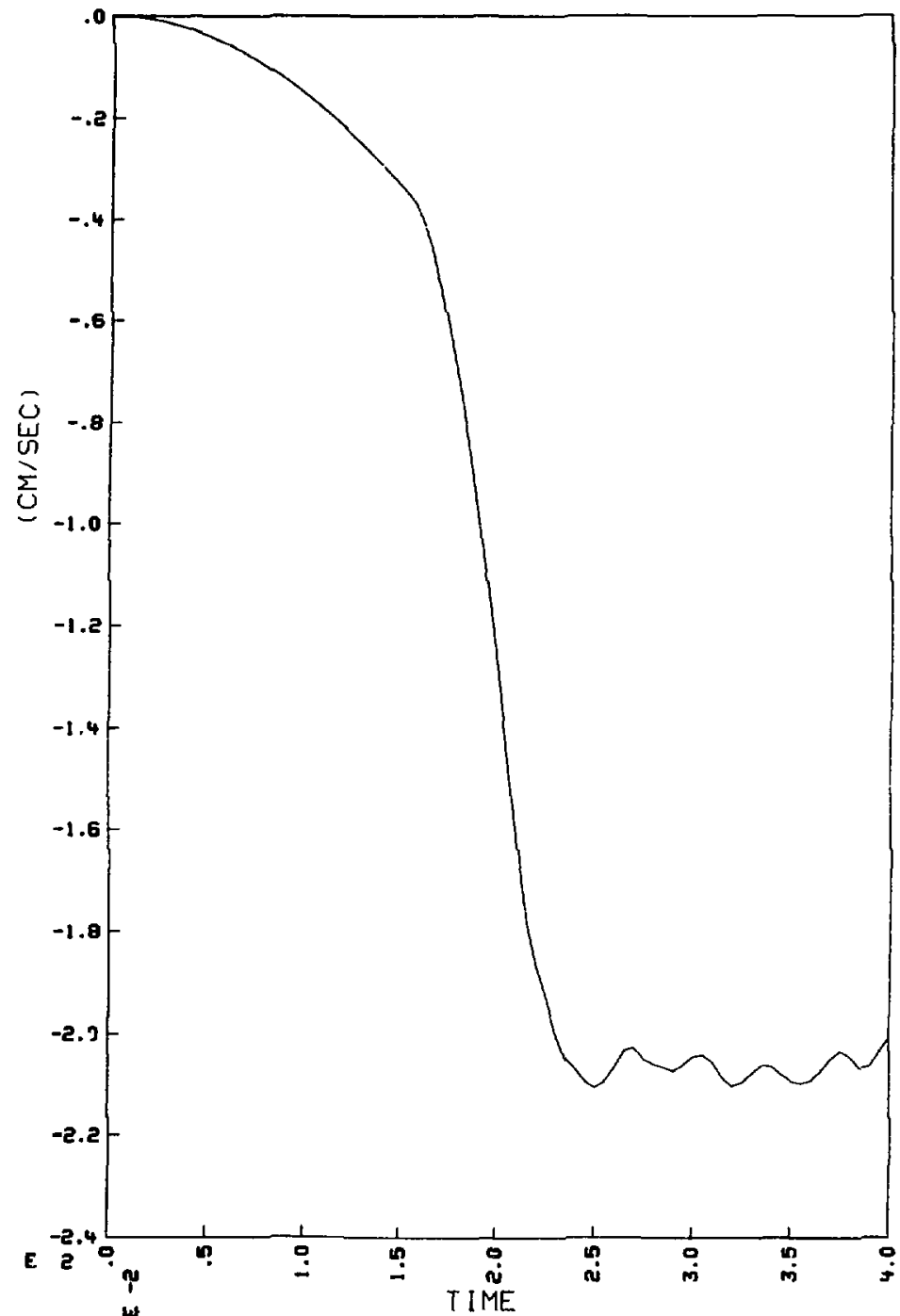

SRV REGULAR PULSE (D/T=600) FIXED SHELL BOUNDARY

B-17. Shell velocity at $90^{\circ}(\mathrm{D} / \mathrm{t}=500)$. 


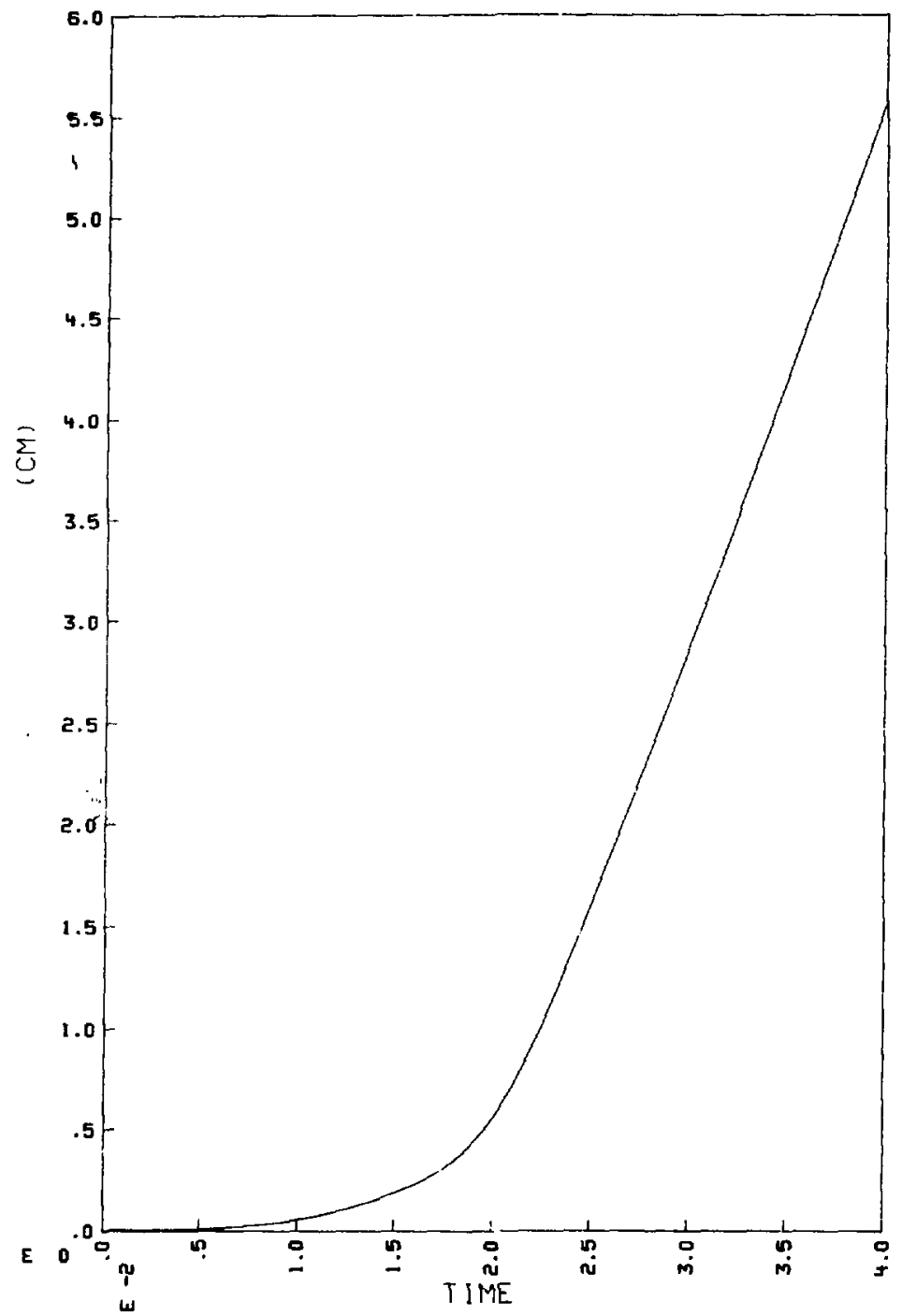

SRV REGULAR PULSE ( RIGID) FIXED SHELL BOUNDARY

B-18. Free surface displacement at vertical centerline $(0 / t=0)$. 


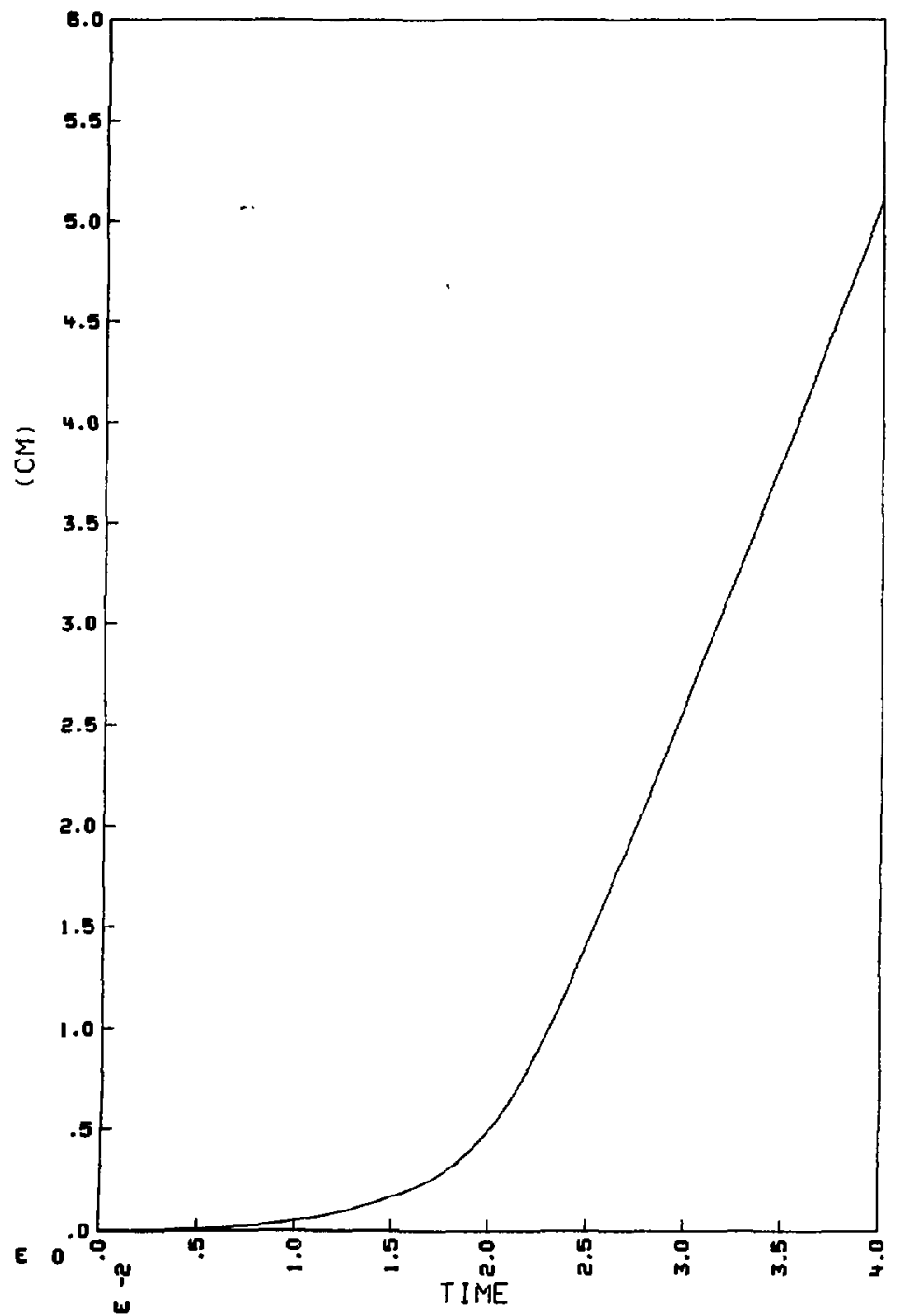

SRV REGULAR PULSE $(D / T=300)$ FIXED SHELL BOUNDARY

B-19. Free surface displacenent at vertical centerline $(D / t=300)$. 


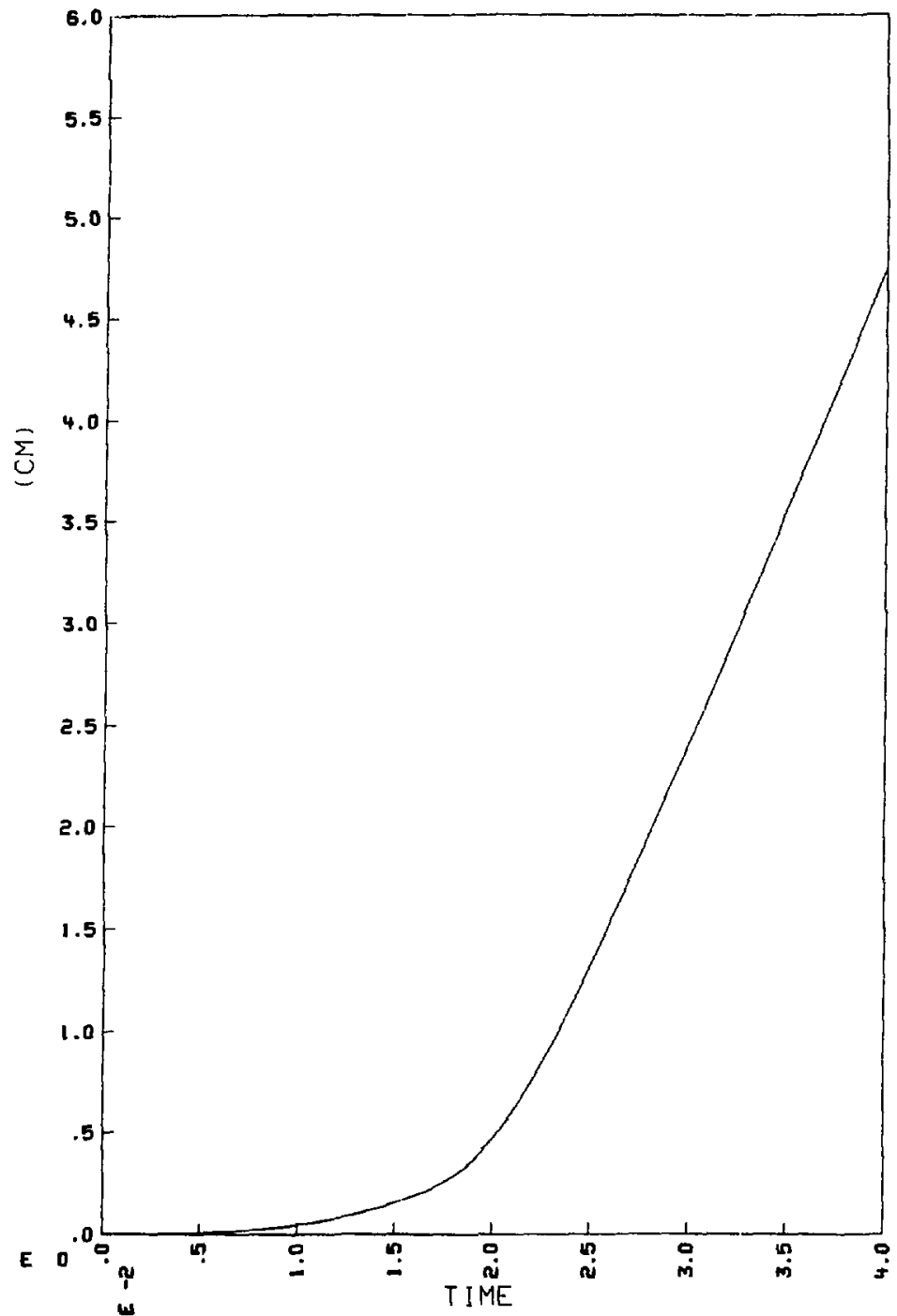

SRV REGULAR PULSE $(D / T=600)$ FIXED SHELL BOUNDARY

B-20. Free surface displacenent at vertical centerline $(D / t=600)$. 


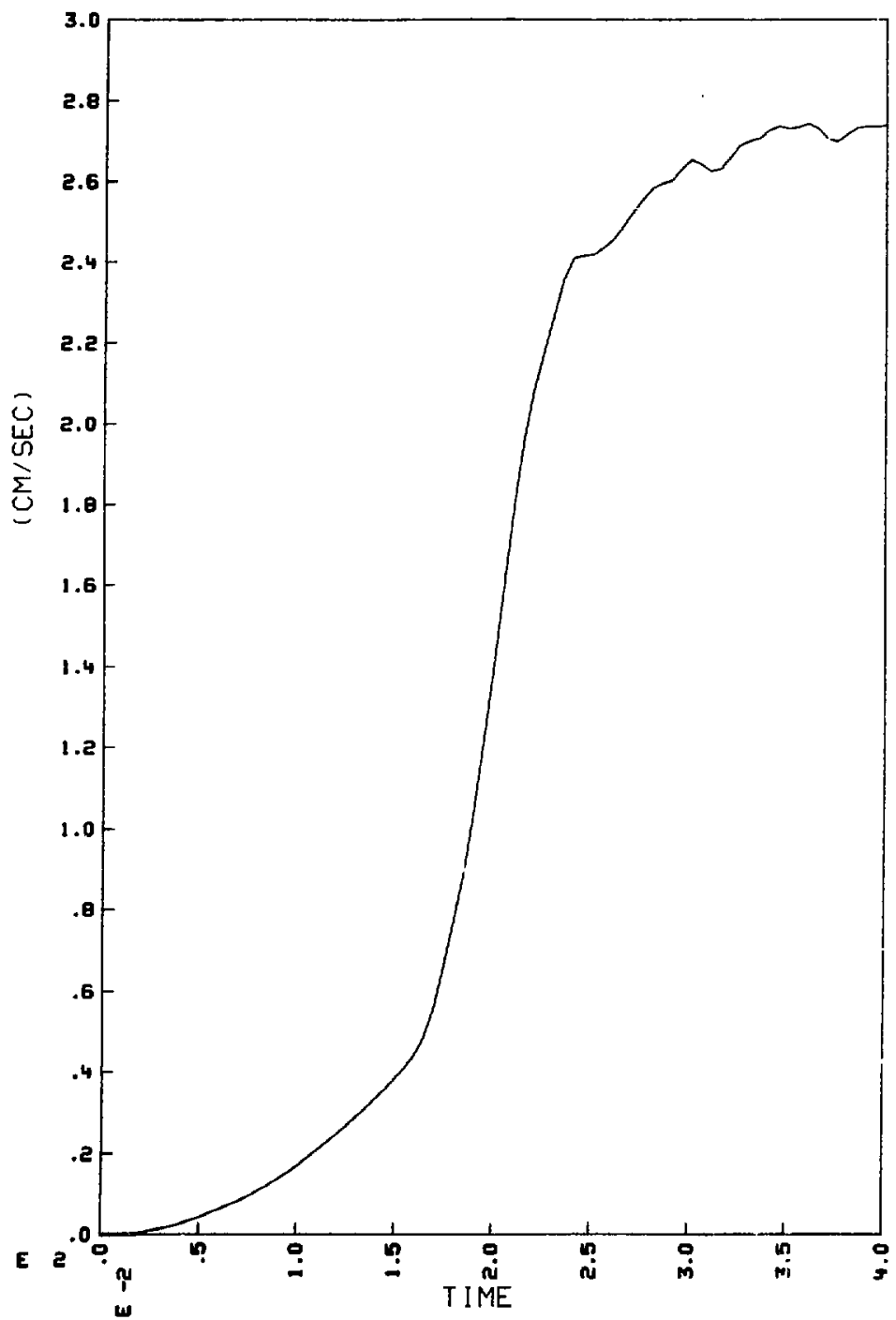

SRV REGULAR PULSE ( RIGID ) FIXED SHELL BOUNDARY

B-21. Free surface velocity at vertical centerline $(D / t=0)$. 


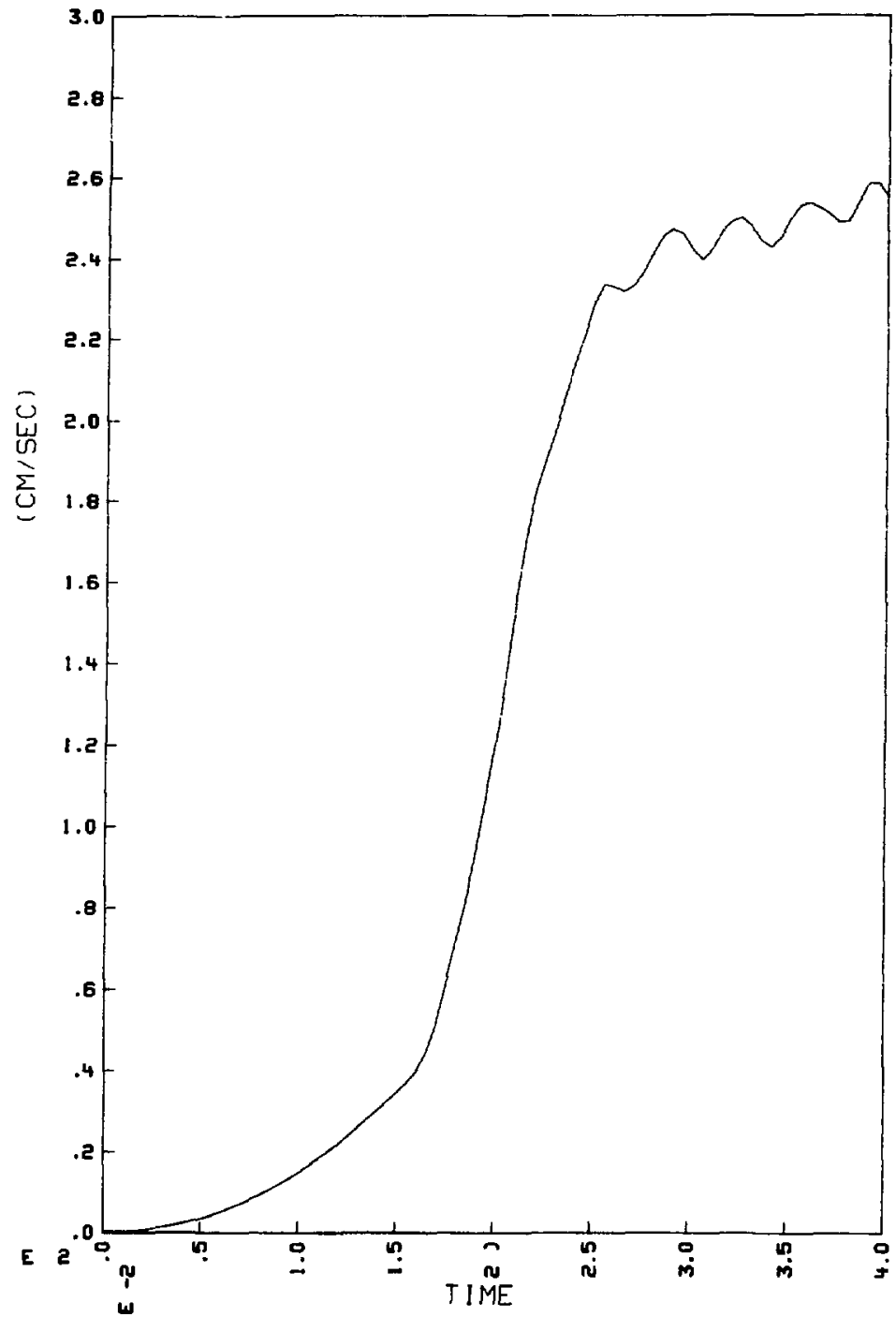

SRV REGULAR PULSE $(D / i=300)$ FIXED SHELL. BOUNDARY

B-22. Free surface velocity at vertical centerline $(D / t=300)$. 


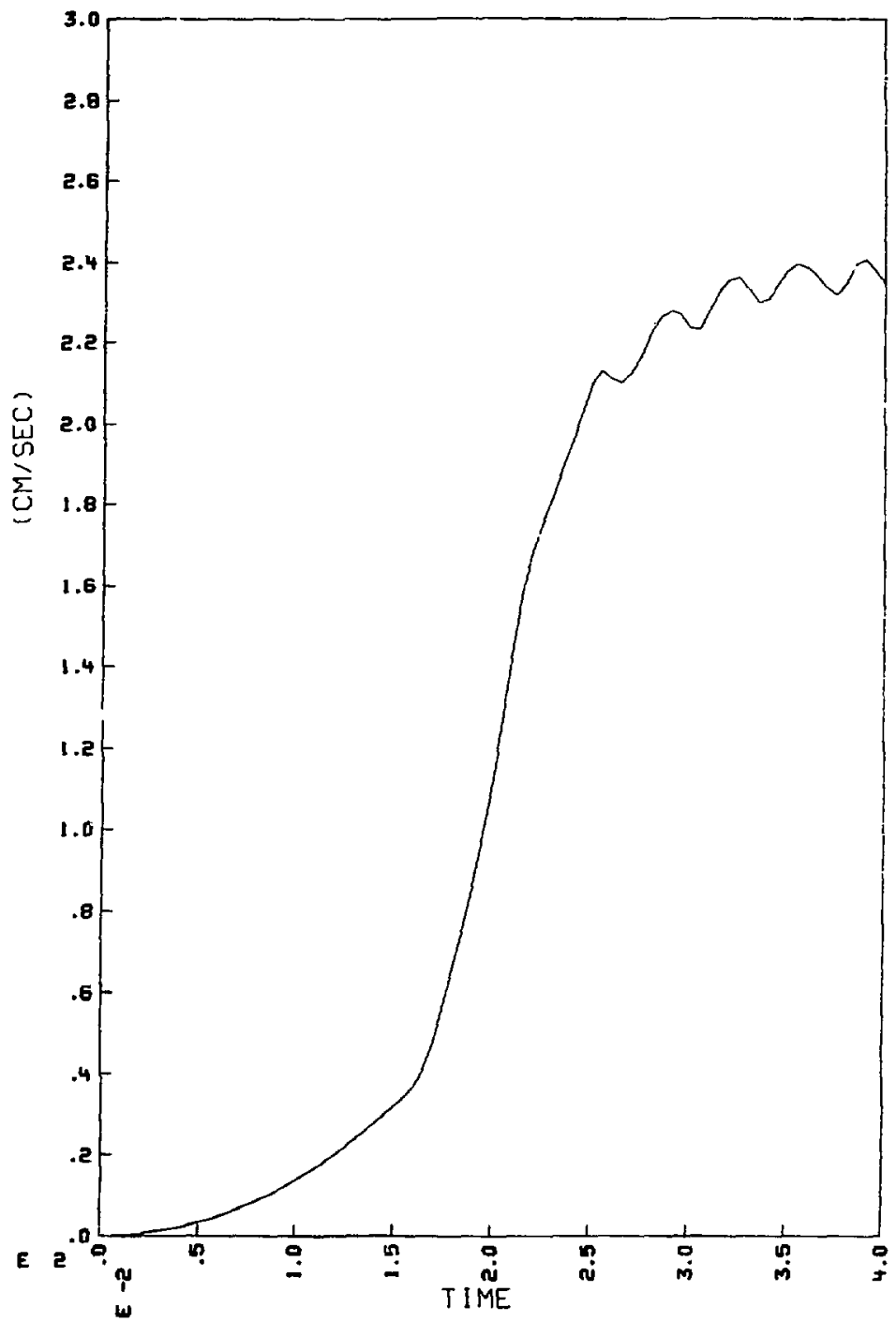

SRV REGULAR PULSE $(D / T=600)$ I IXED SHELL BOUNDARY

B-23. Free surface velocity at vertical centerline $(D / t=600)$. 


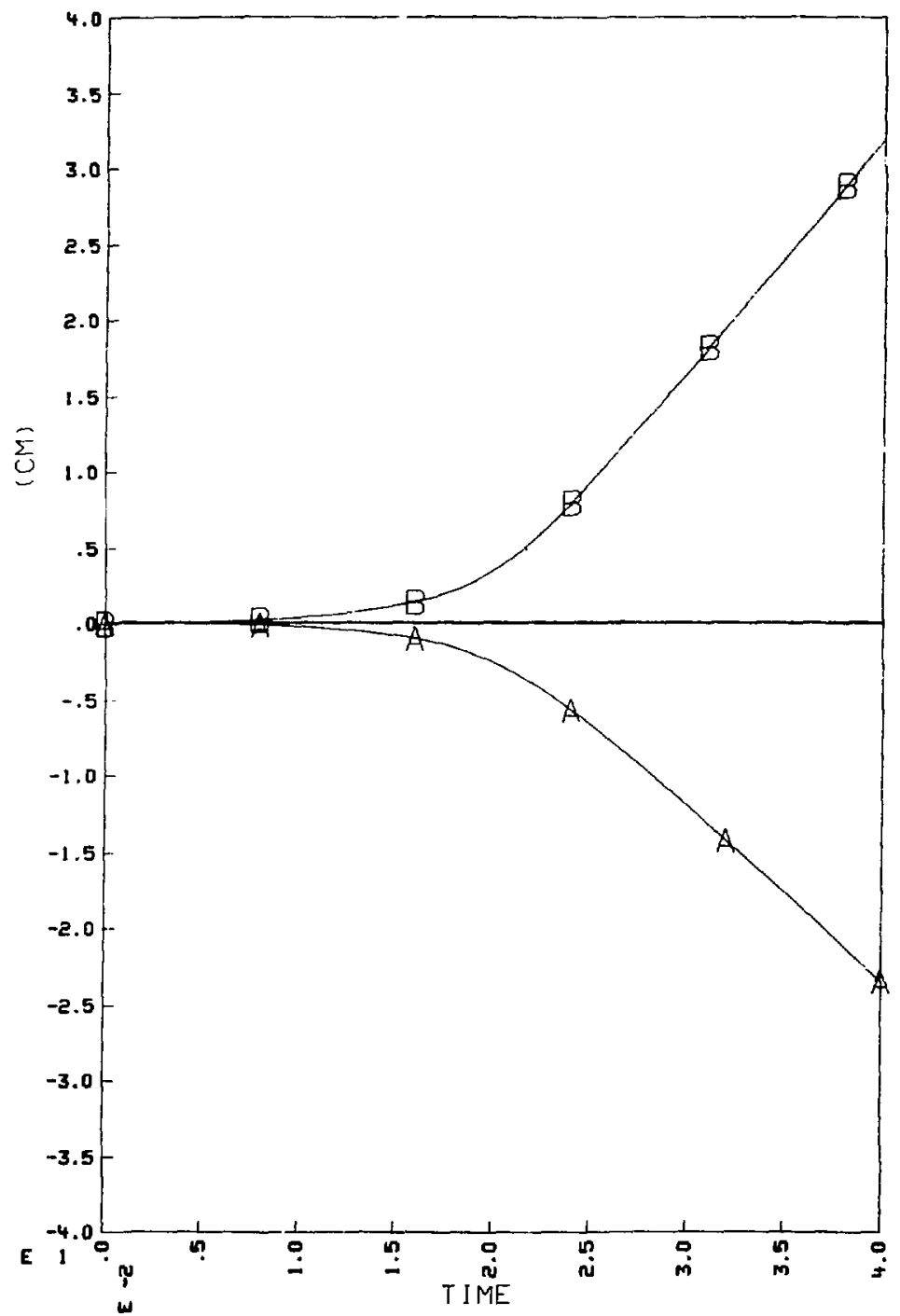

SRV REGULAR PULSE ( RIGID) FIXED SHELL BOUNDARY

B-24. Bubble displacement at $A$ and $B$ (see Fig. B-I) (D/t := 0 ) . 


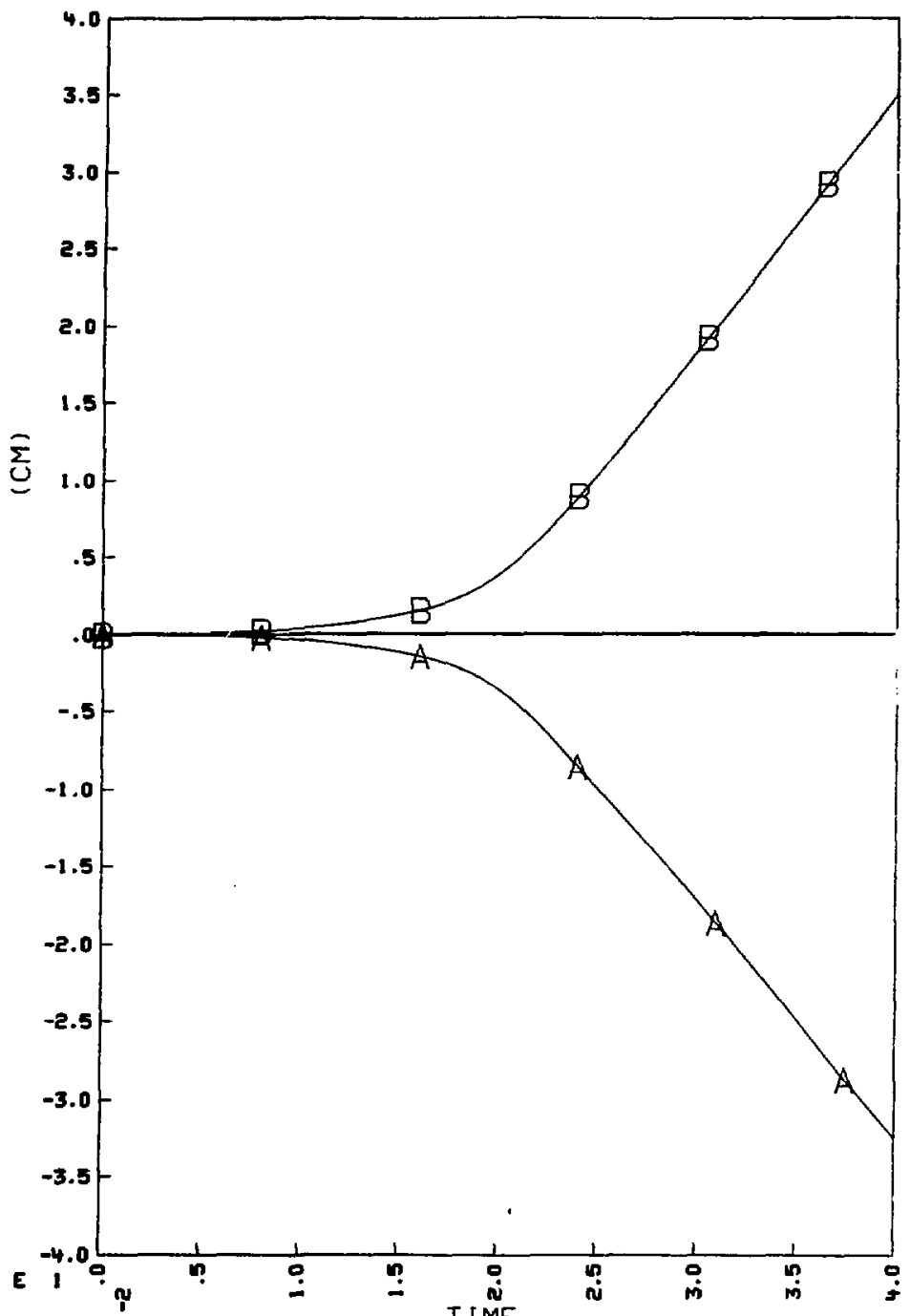

SRV REGULLAR PULSE (D/T $=300)$ FIXED SHELL BOUNDARY

B-25. Bubble displacement at $A$ and $B$ (see Fig. $B-1)(D / t=300)$. 


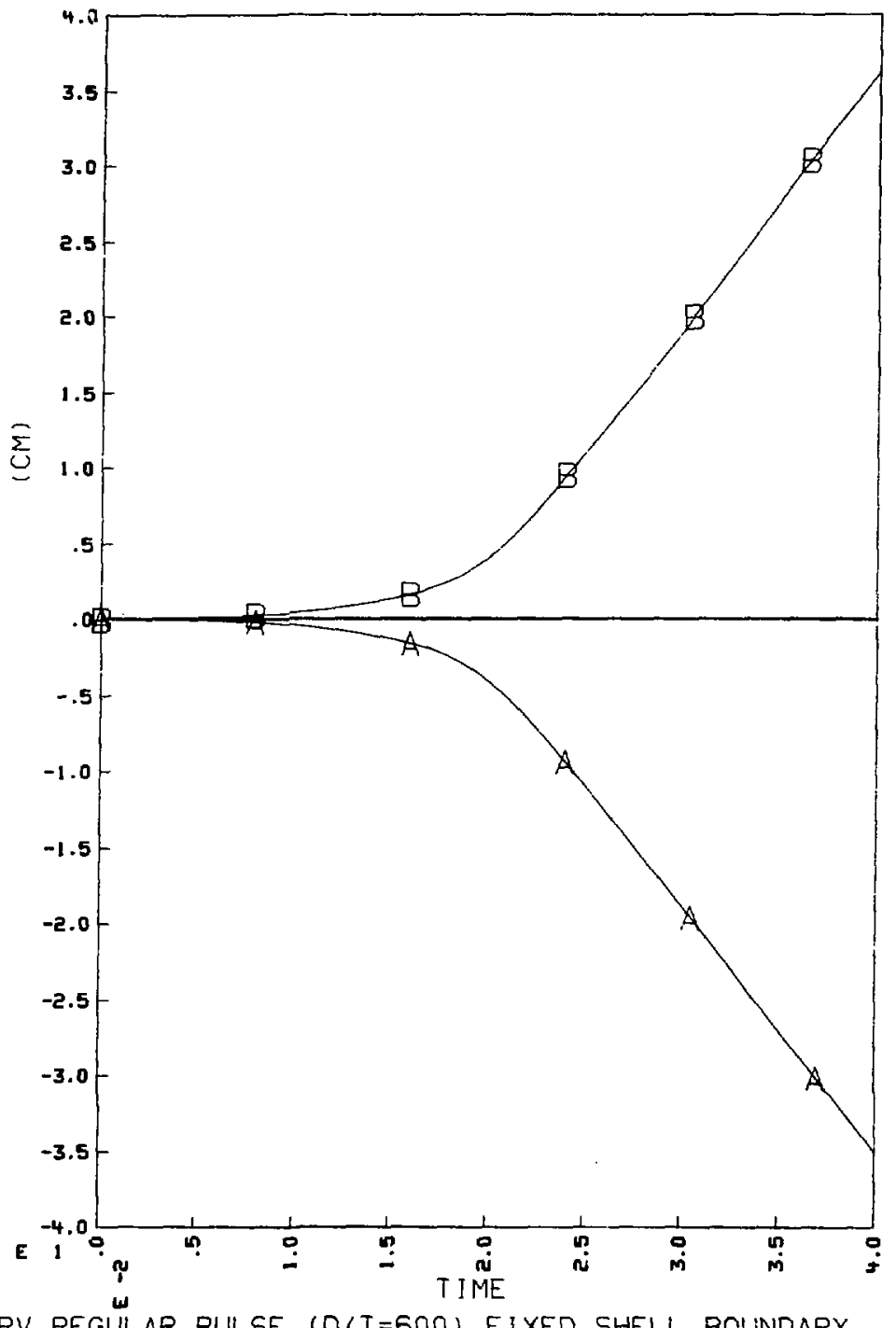

SRV REGULAR PULSE $(D / T=600)$ FIXED SHELL BOUNDARY

B-26. Bubble displacement at $A$ and $B$ (see Fig. B-1) (D/t $=600$ ). 


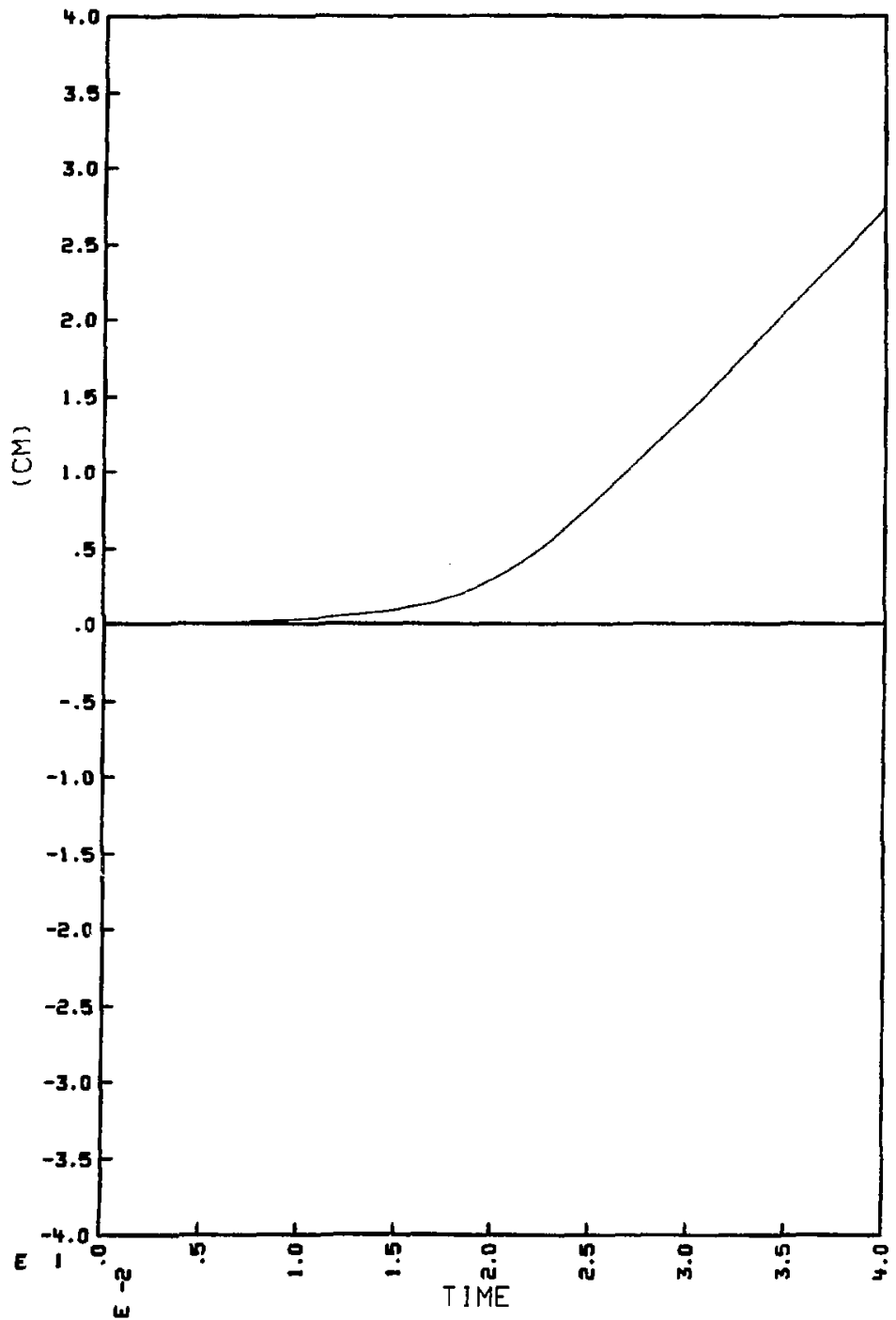

SRV REGULAR PULSE ( RIGID) FIXED SHELL BOUNDARY

B-27. Bubble alsplacenent at C (see Fig. B-l) $(D / t=0)$. 


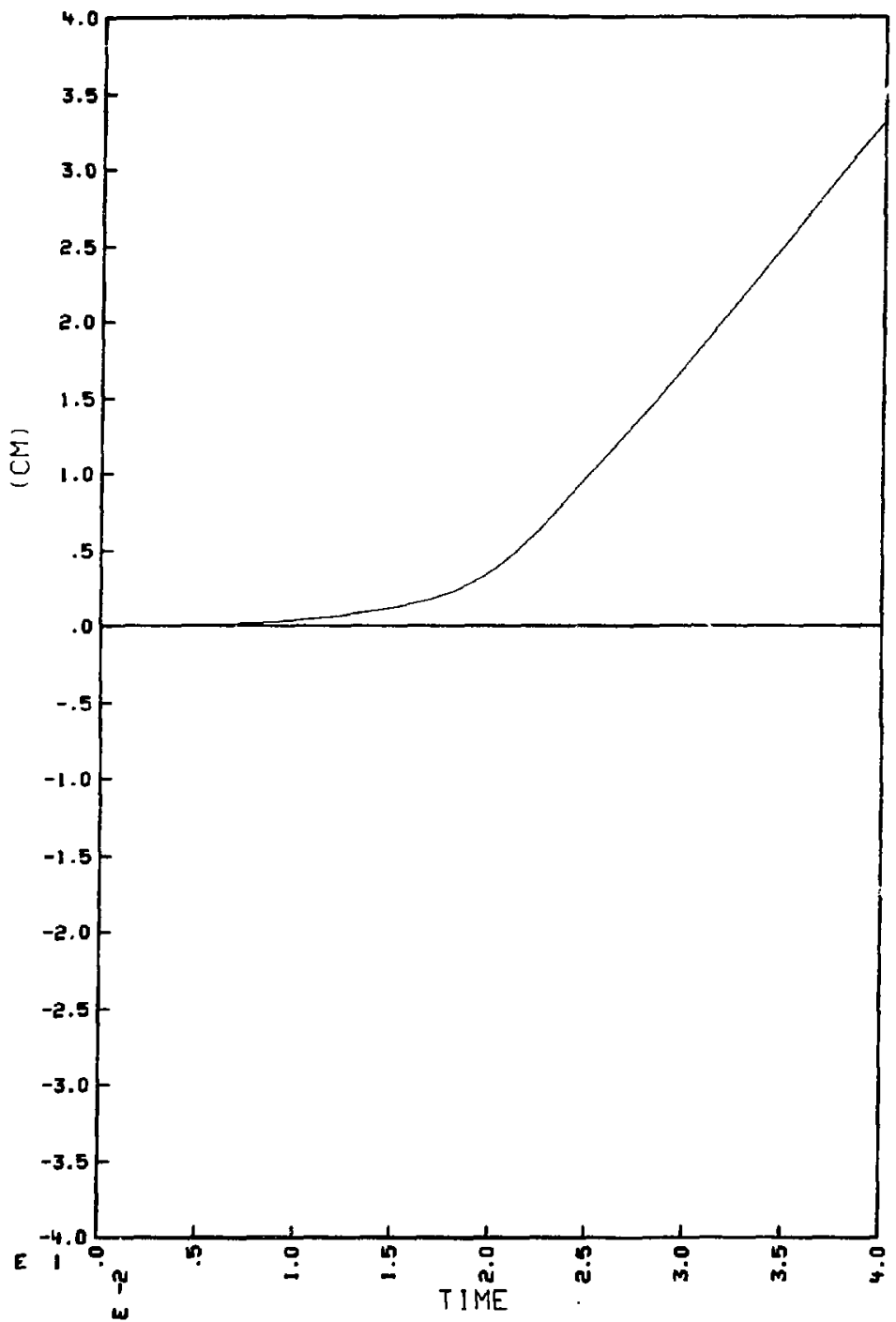

SRV REGULAR PULSE (D/T $=300$ ) FIXED SHELL BOUNDARY

B-28. Bubble displacement at $C$ (see Fig. B-1) (D/t $=300$ ). 


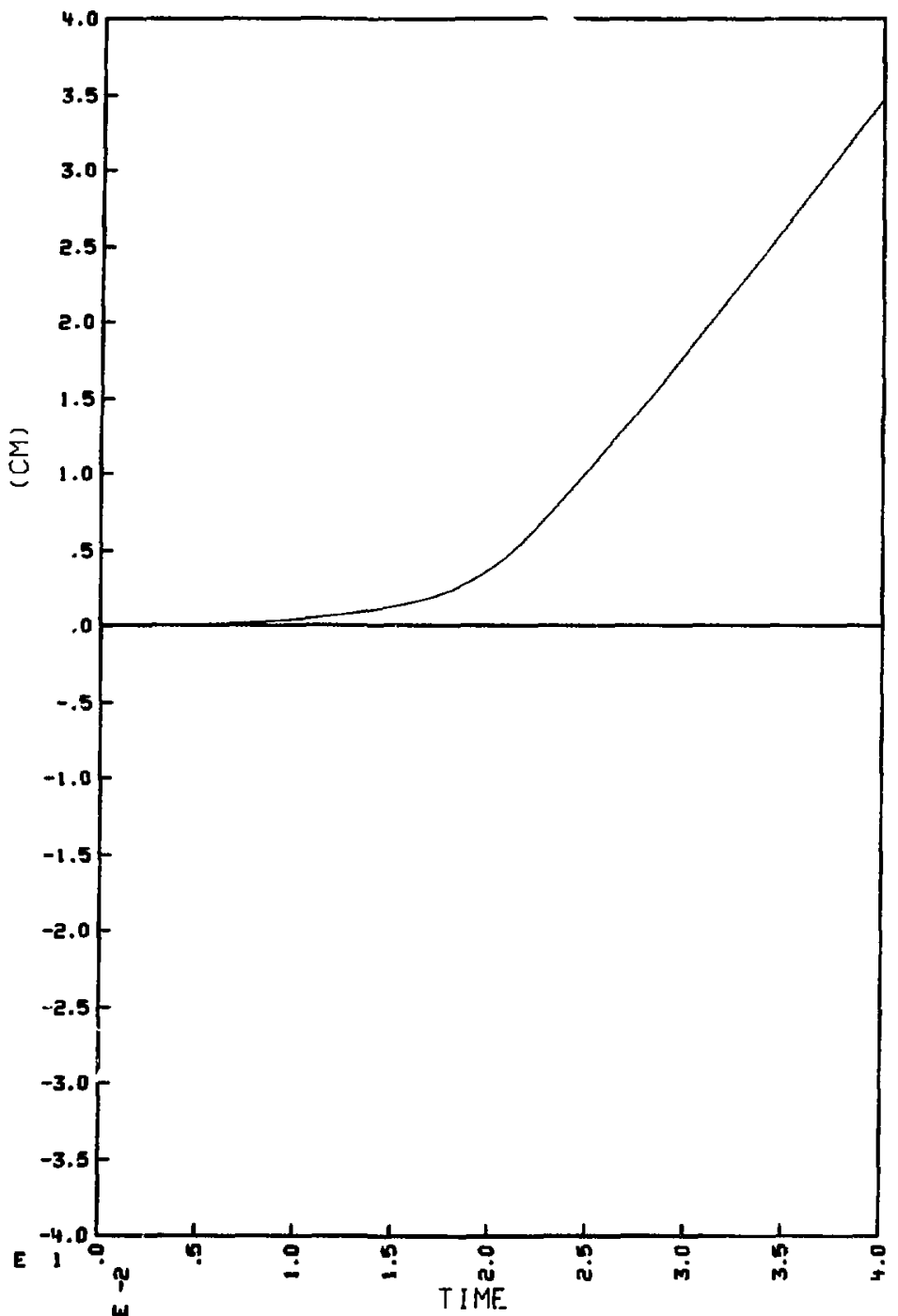

SRV REGULAR PULSE $(D / T=600)$ F IXED SHELL BOUNDARY B-29. Bubble aisplacenent at $\mathrm{C}$ (Bte F1g. B-1) (D/t $=600$ ) 


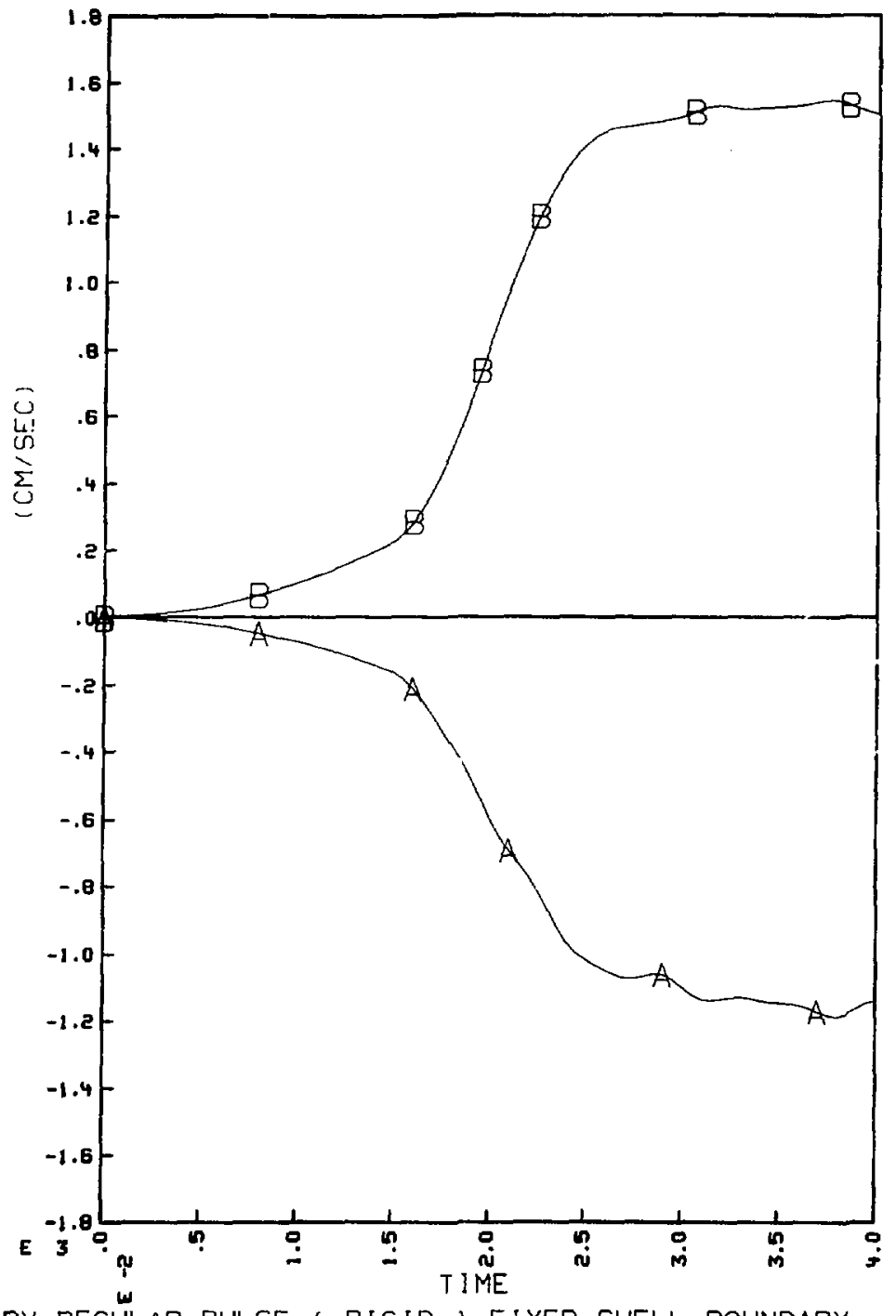

SRV REGULAR PULSE ( RIGID) FIXED SHELL BOUNDARY

B-30. Bubble velocity at $A$ and $B$ (see Fig. $B-1)(D / t=0)$. 


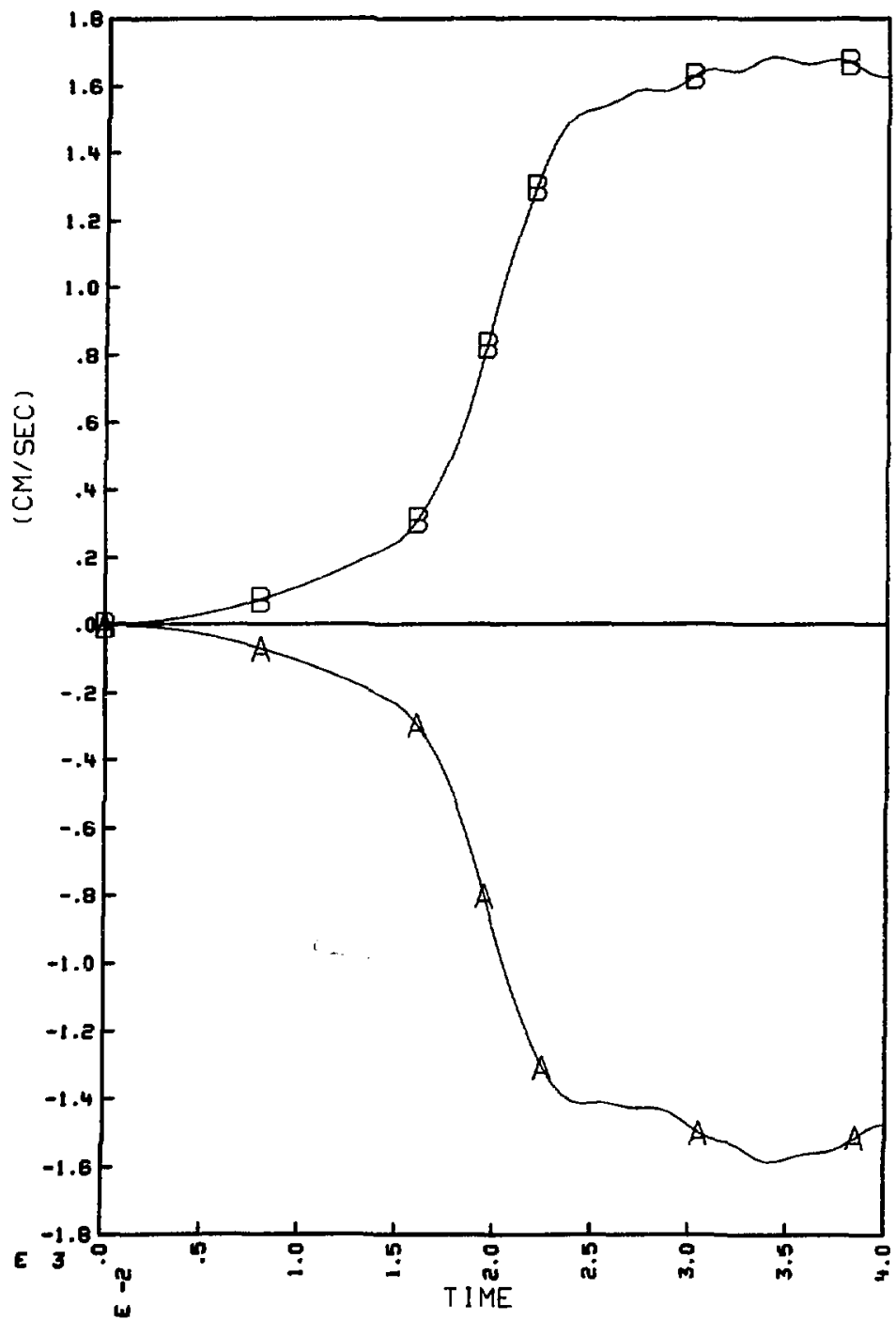

SRV REGULAR PULSE (D/T=300) FIXED SHELL BOUNDARY

B-31. Bubble velocity at $A$ and $B($ see $F 1 g . B-1) \quad(D / t=300)$. 


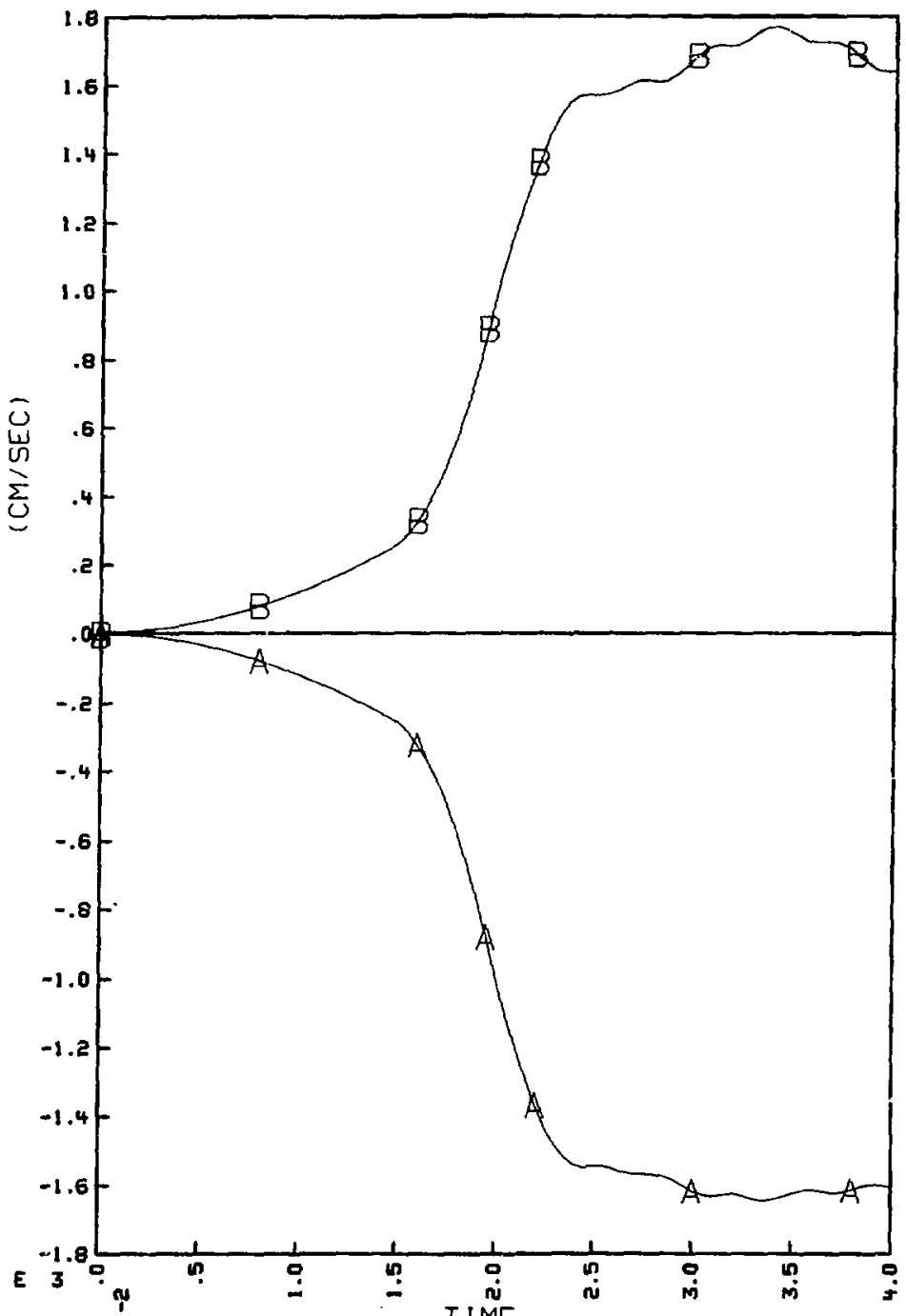

SRV REGULLAR PULSE (D/T=600) FIXED SHELL BOUNDARY

B-32. Bubble velocity at $A$ and $B$ (see Fig. $B-1)(D / t=6,00)$. 


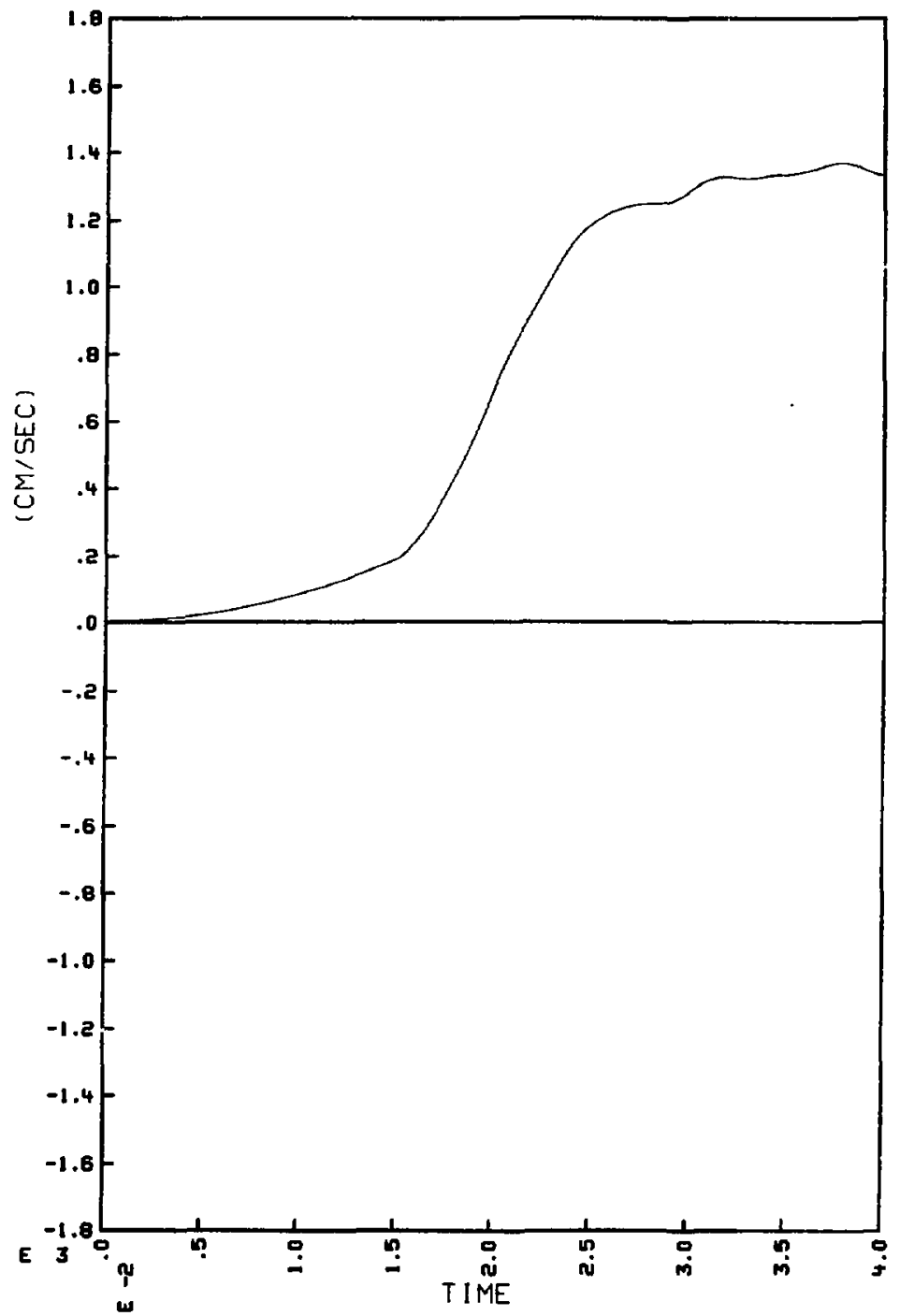

SRV REGULAR PULSE ( RIGID) FIXED SHELL BOUNDARY

B-33. Bubble velocity at $C$ (see Fig. $B-1)(D / t=0)$. 


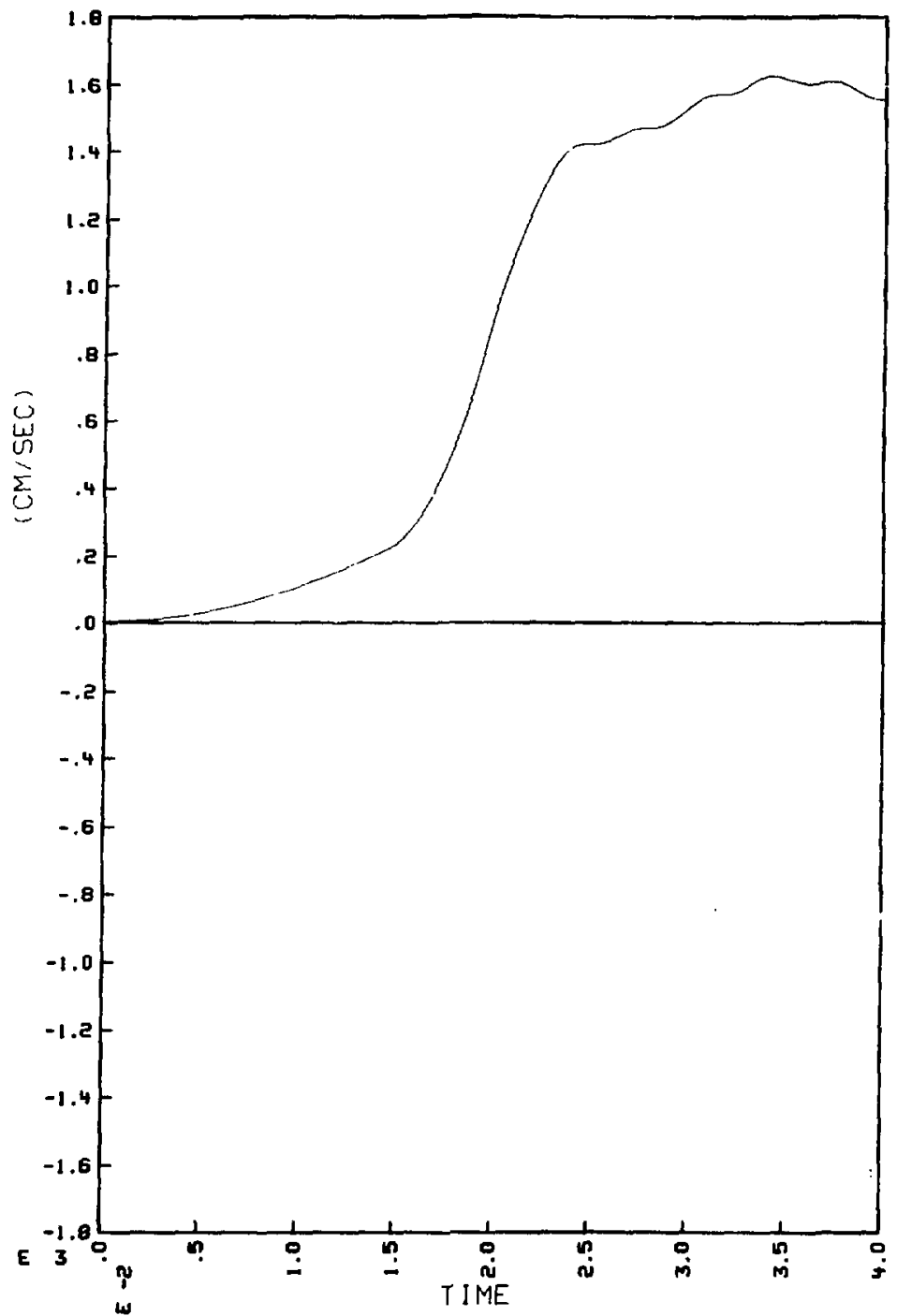

SRV REGULAR PULSE $(D / T=300)$ FIXED SHELL BOUNDARY

B-34. Bubble velocity at $C$ (see Fig. $B-1) \quad(D / t=300)$. 


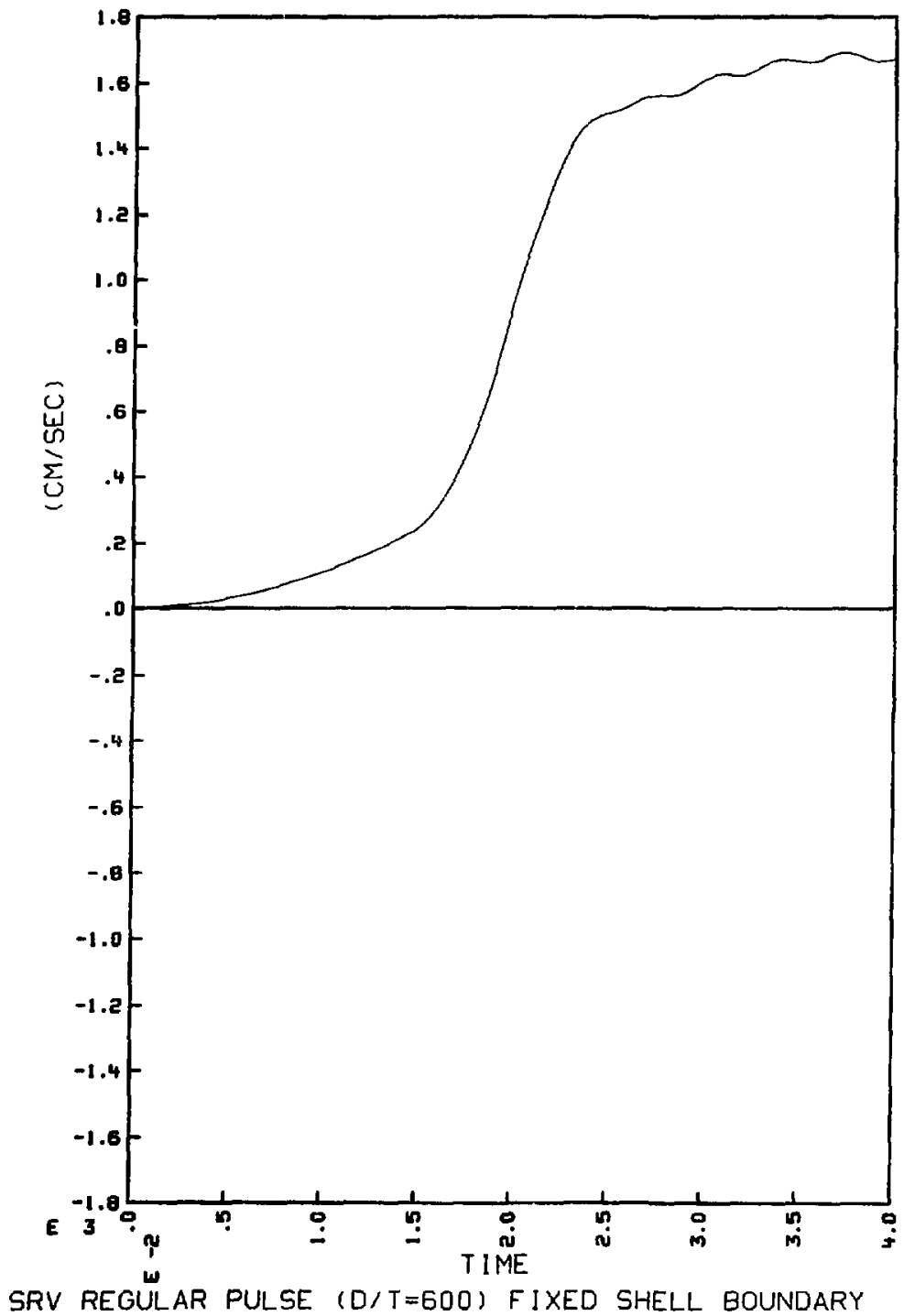

B-35. Bubble velocity at C (see Fig. B-1) (Dot $=600)$.

68 
APPENDIX c.

LOCA CHOG: DETAILED RESULIS

69 


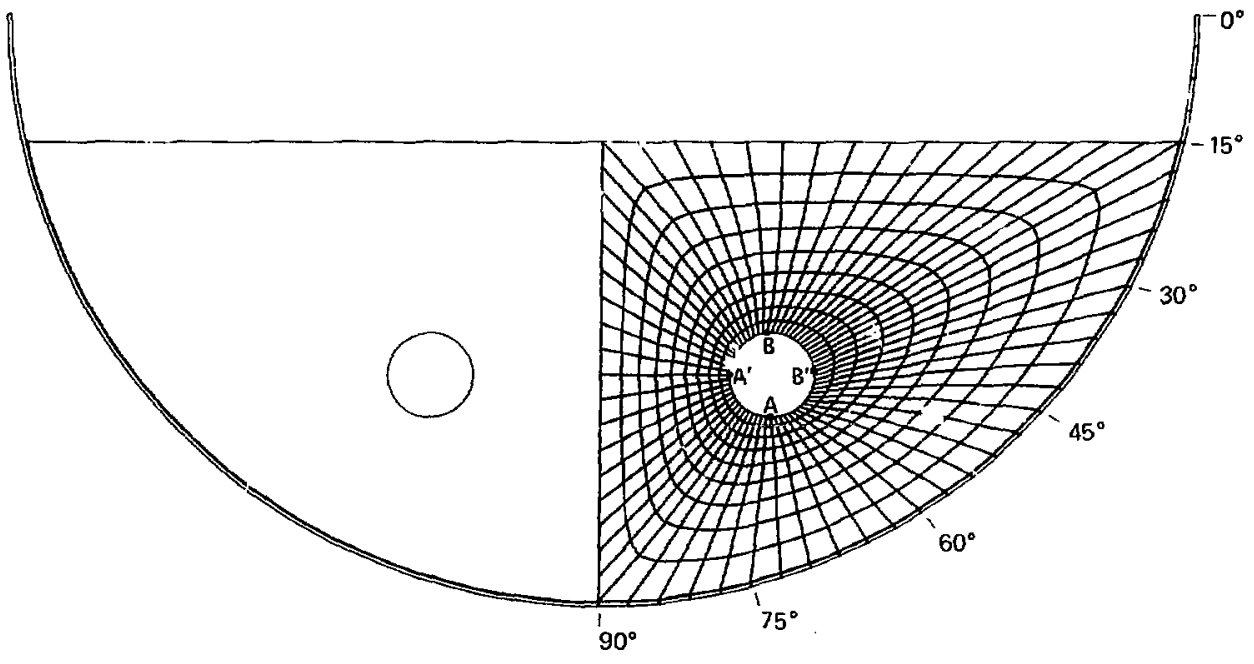

C-1. rypical finite element mesh for the LOCA chug problem $(D / t=300)$. 


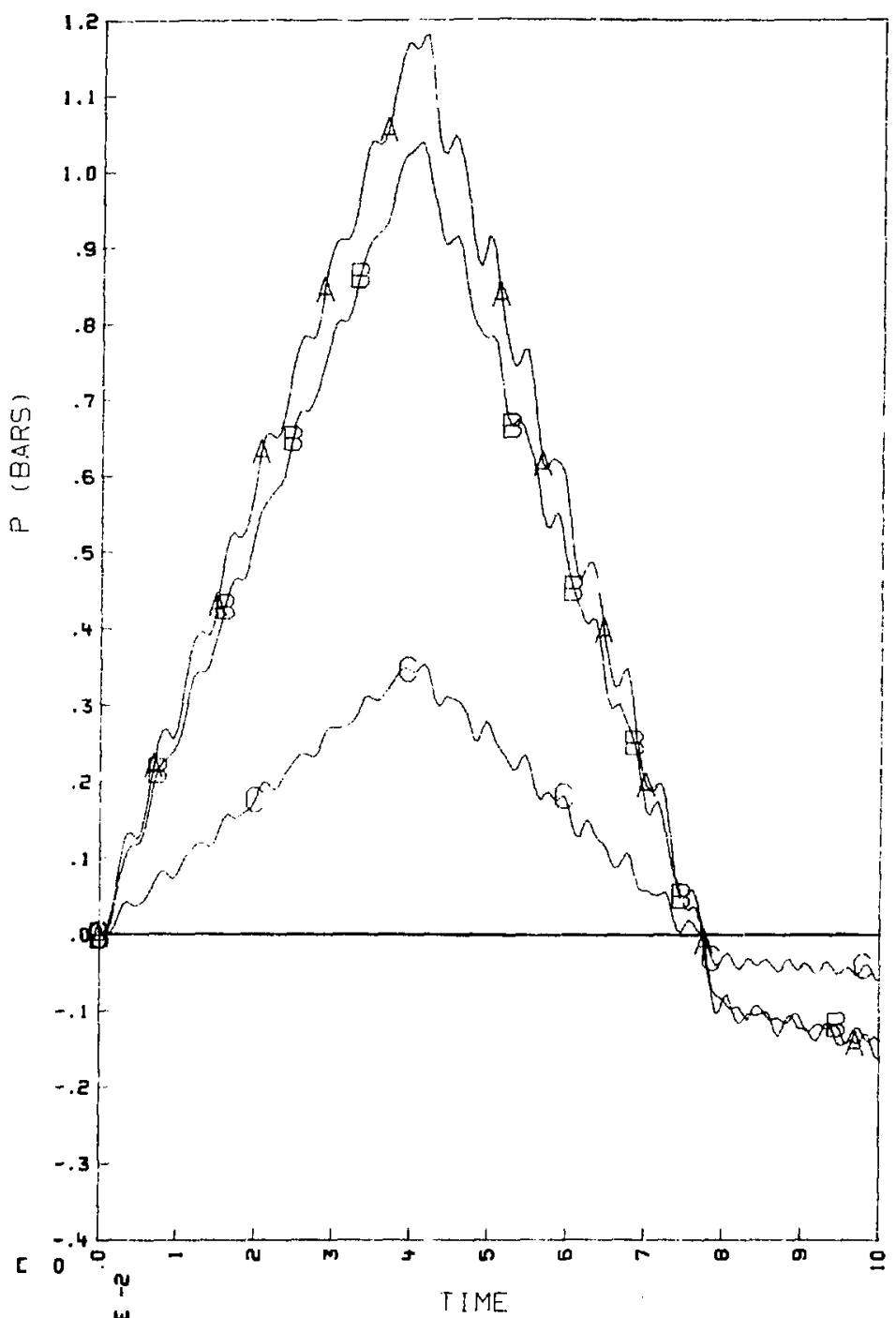

CHUG 2OP'SI PULSE ( RIGID) FIXED SHELL BOUNDARY

C-2. Pressure on shell wall $\left(A-90^{\circ} ; B-60^{\circ} ; C-30^{\circ}\right.$ ) (see Fig. 6) $(D / t=0)$. 


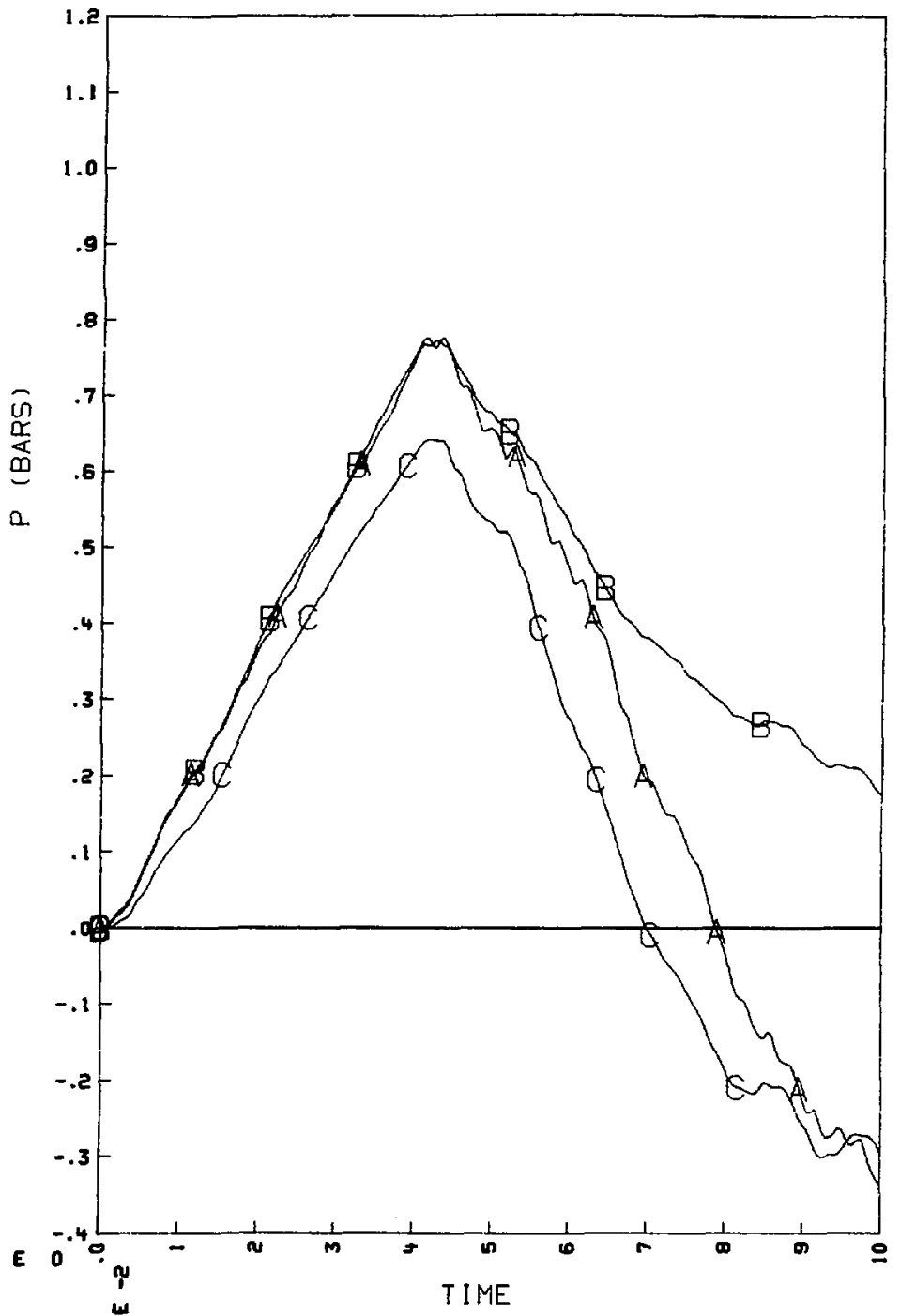

CHUG 2OPSI PULSE (D/T=300) FIXED SHELL BOUNDARY

C-3. Pressure on shell wall $\left(A-90^{\circ} ; \mathrm{B}-60^{\circ} ; \mathrm{C}-30^{\circ}\right)$ (see Fig. 6) $(D / t=300)$. 


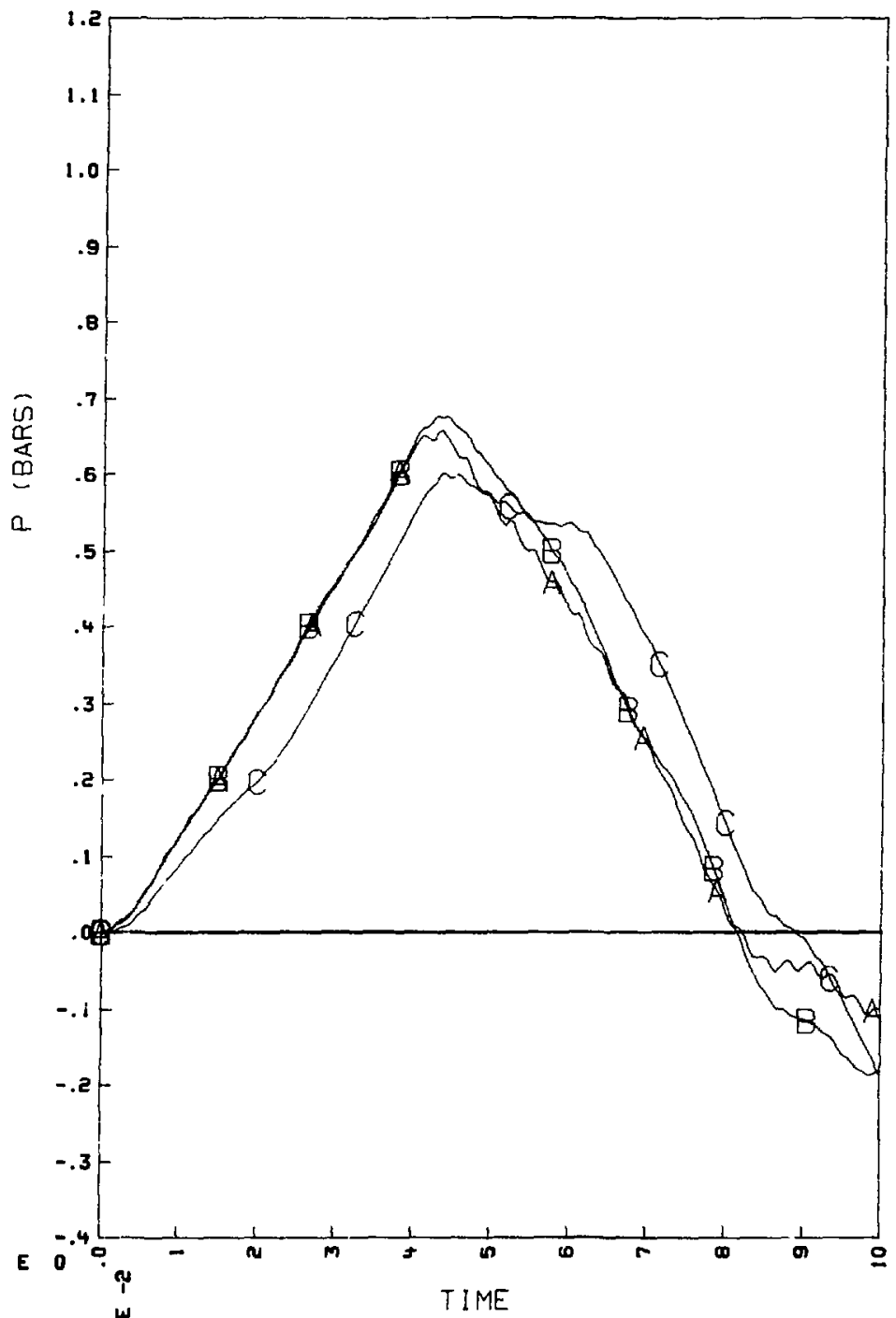

CHUG 2OPS! PULSE ( $/ T=600)$ FIXED SHELL BOUNDARY C-4. Pressure on shell wall $\left(\mathrm{A}-90^{\circ}, \mathrm{B}-60^{\circ}, \mathrm{C}-30^{\circ}\right.$ ) (see Fig. 6) $(D / t=600)$. 


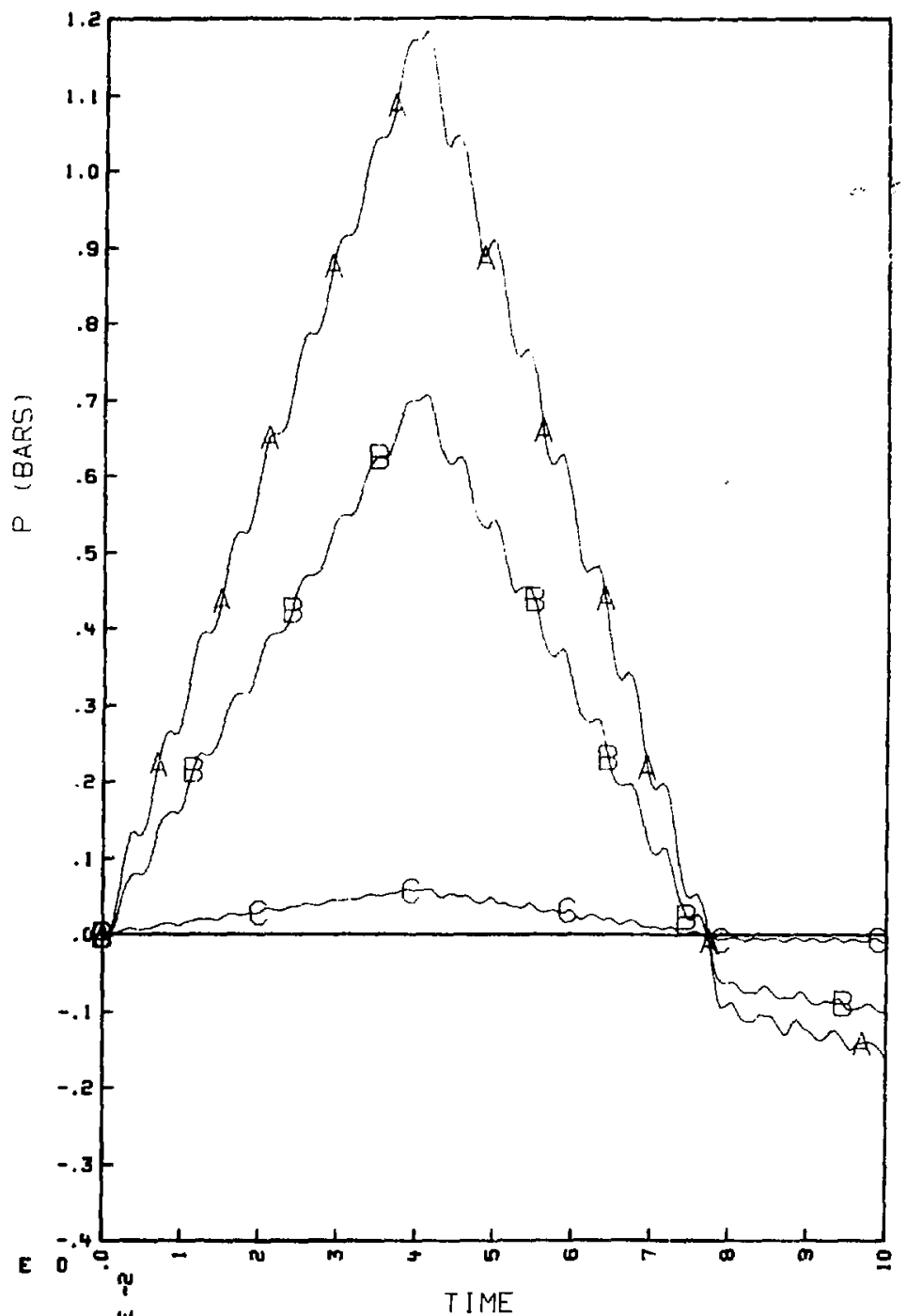

CHUG 2OPSI PULSE ( RIGID) FIXED SHELL BOUNDARY

C.5. Pressuce on shell wall $\left(A-75^{\circ} ; \mathrm{B}-45^{\circ} ; \mathrm{C}-15^{\circ}\right)$ (see Fig. 6) $(D / t=0)$. 


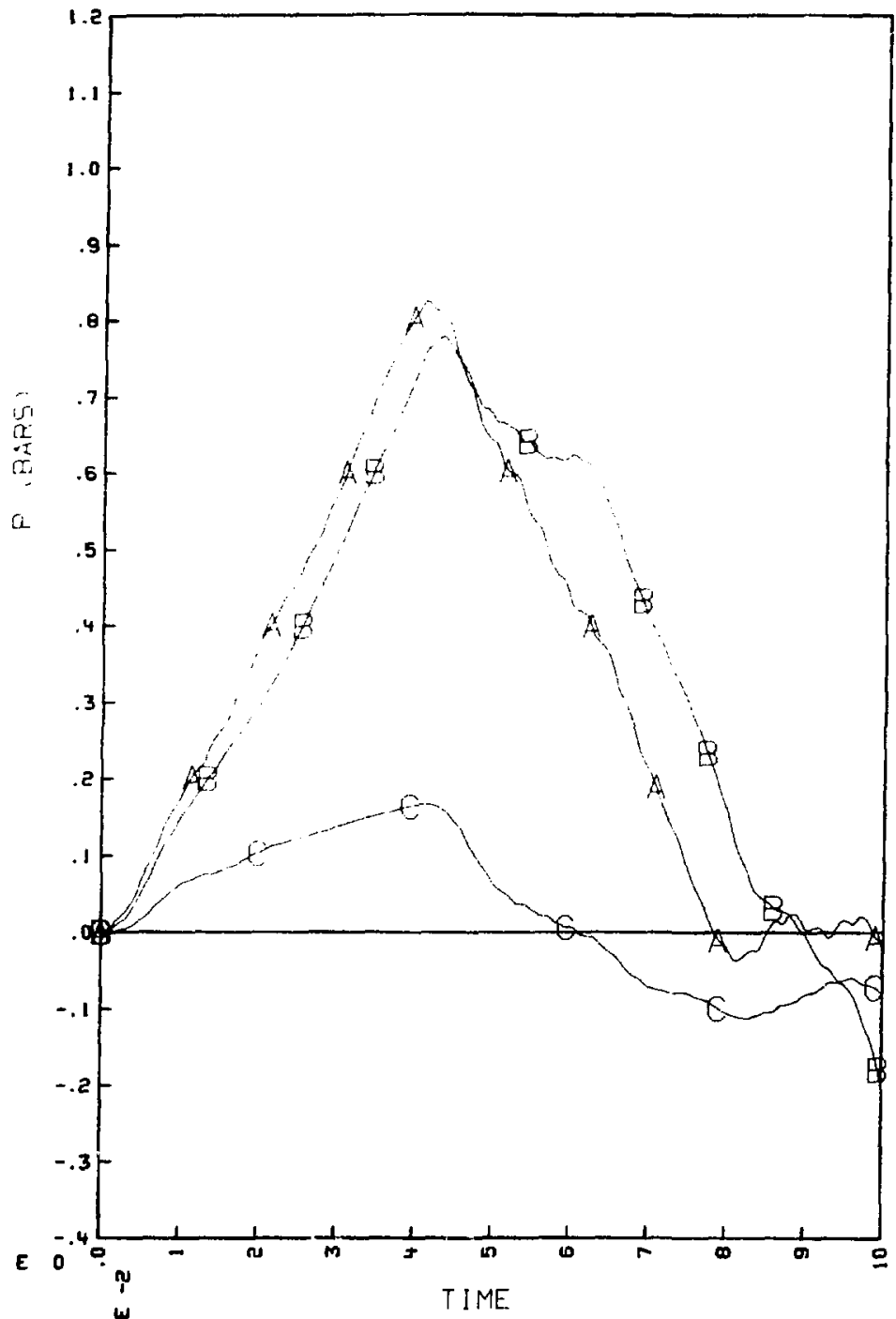

CHUG 2OPSI PULSE (D/T=300) FIXED SHELL BOUNDARY

$\mathrm{C}-6$. Pressure on shell wall $\left(\mathrm{A}-75^{\mathrm{D}}, \mathrm{B}-45^{\circ} ; \mathrm{C}-15^{\circ}\right.$ ) (see F1g. 6) $(D / t=300)$ 。 


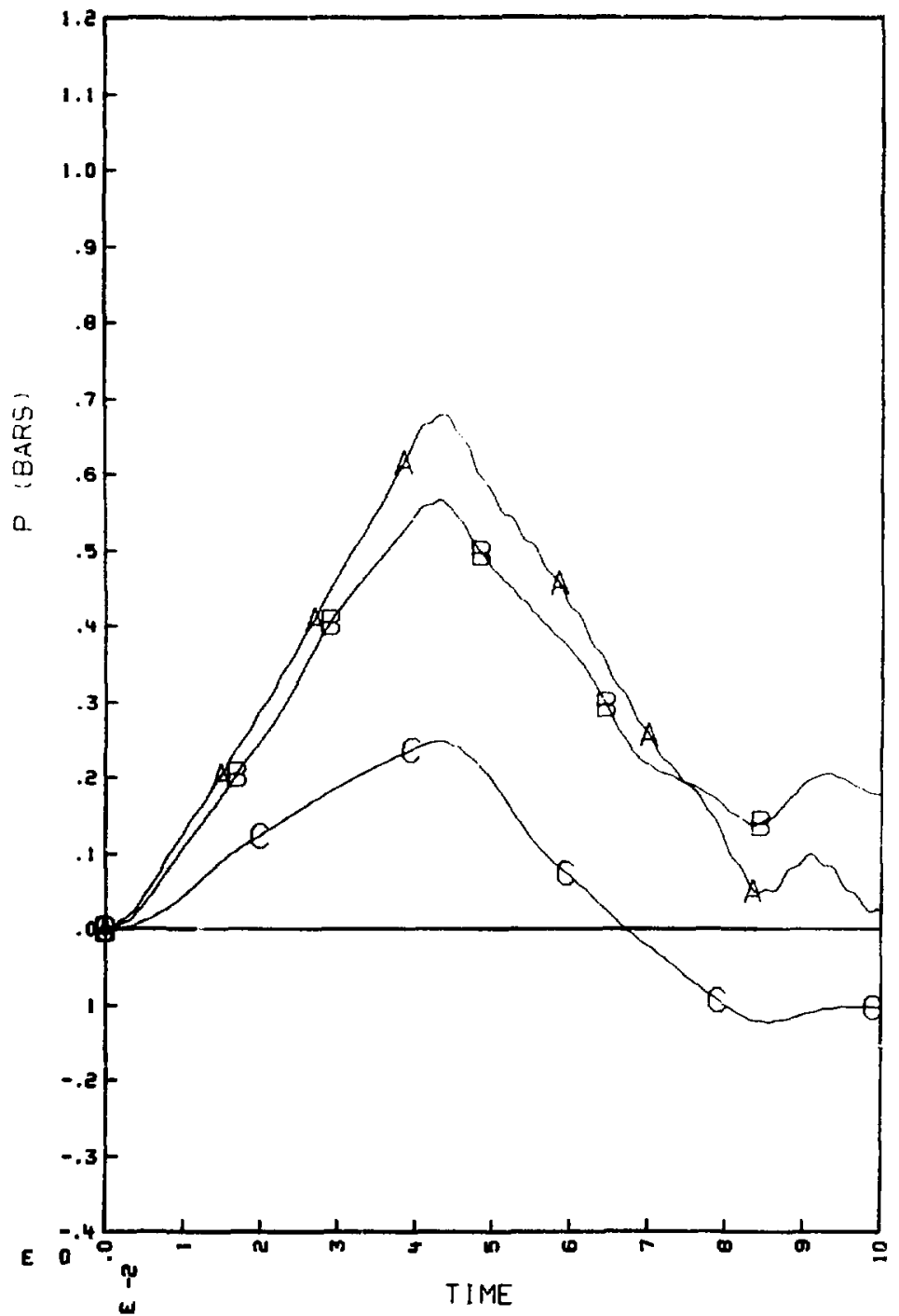

CHUG 2OPSI PULSE (D;T:600) FIXED SHELL BOUNDARY C-7. Pressure on shell wall $\left(A-75^{\circ} ; B-45^{\circ} ; C-15^{\circ}\right)$ (see Fis. 6) $(D / t=600)$. 


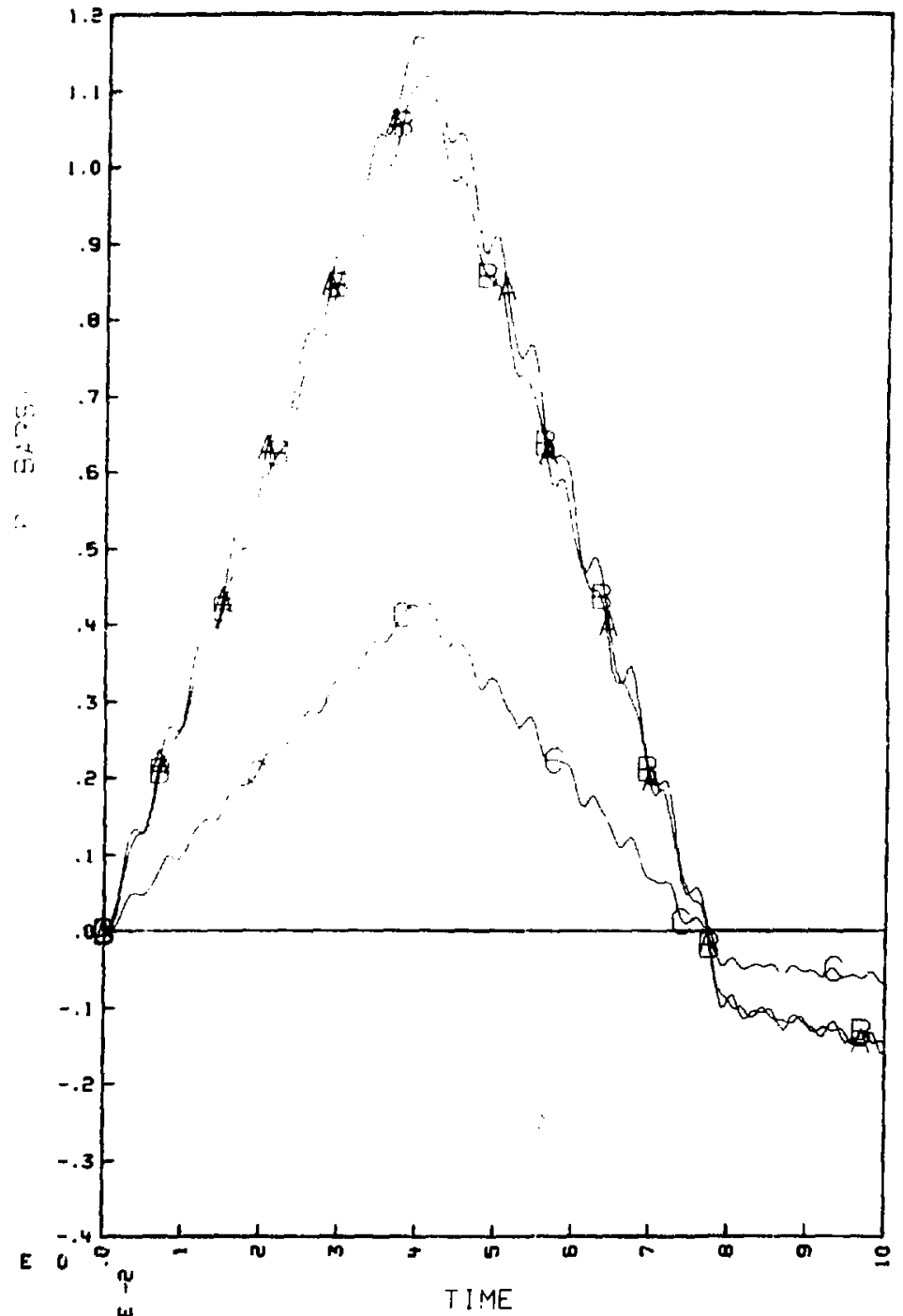

CHUG 2OPSI PULSE ( RIGID) FIXED SHELL BOUNDARY C-8, pressure in fluid at $\mathrm{F}=\mathrm{r}_{\mathrm{m}}$ (see $\mathrm{FIg}$. 6) $\left(\mathrm{A}-90^{\circ} ; \mathrm{B}-60^{\circ} ; \mathrm{C}-30^{\circ}\right.$ ) $(D / t=0)$. 


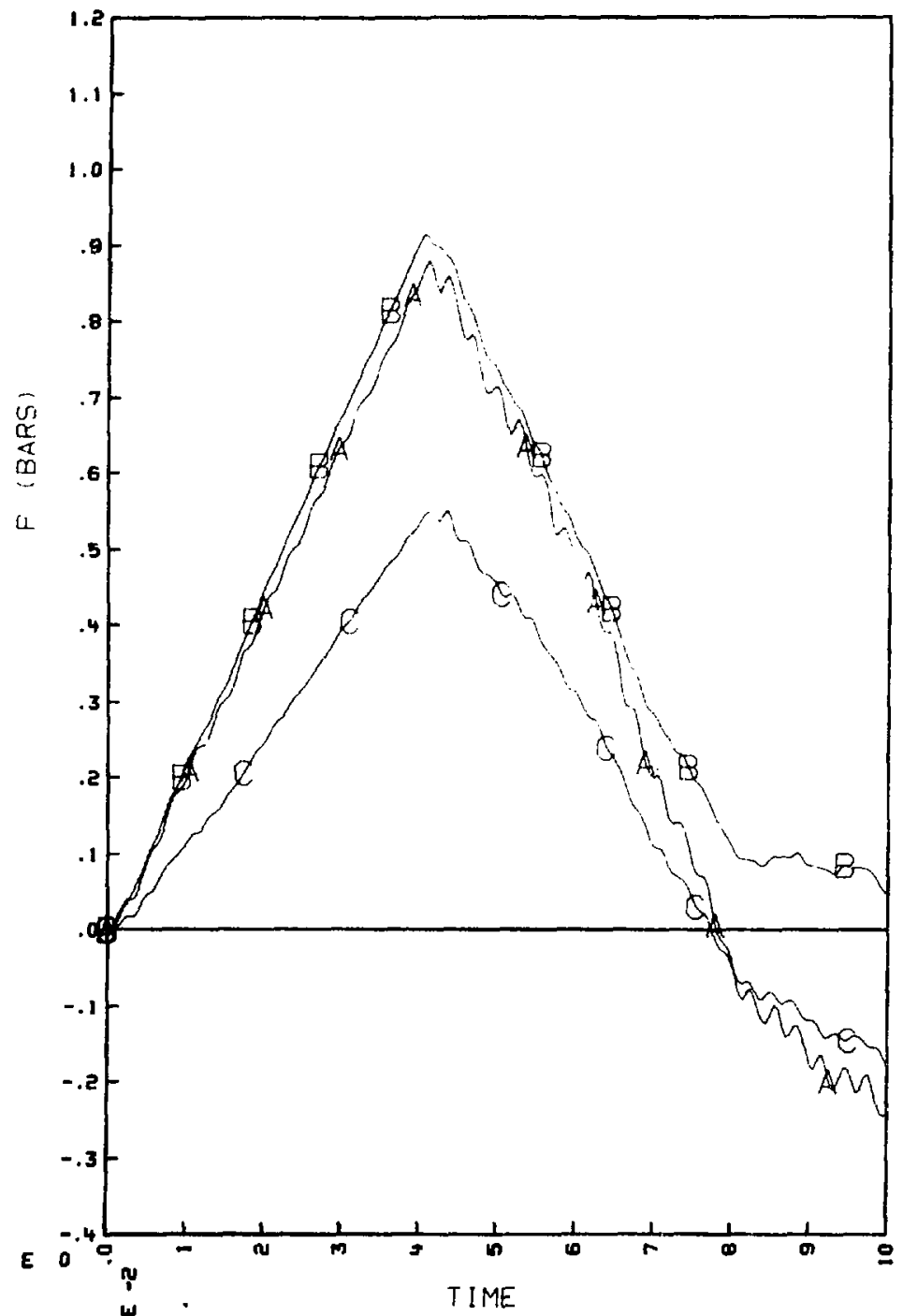

CHUG 2OPSI PULSE ( $/ T=300)$ F IXED SHELL BOUNDARY C-9. Pressure ir fluld at $r=r_{m}$ (see Fig. 6) $\left(A-90^{\circ} ; B-60^{\circ} ; C-30^{\circ}\right.$ ) $(D / t=300)$. 


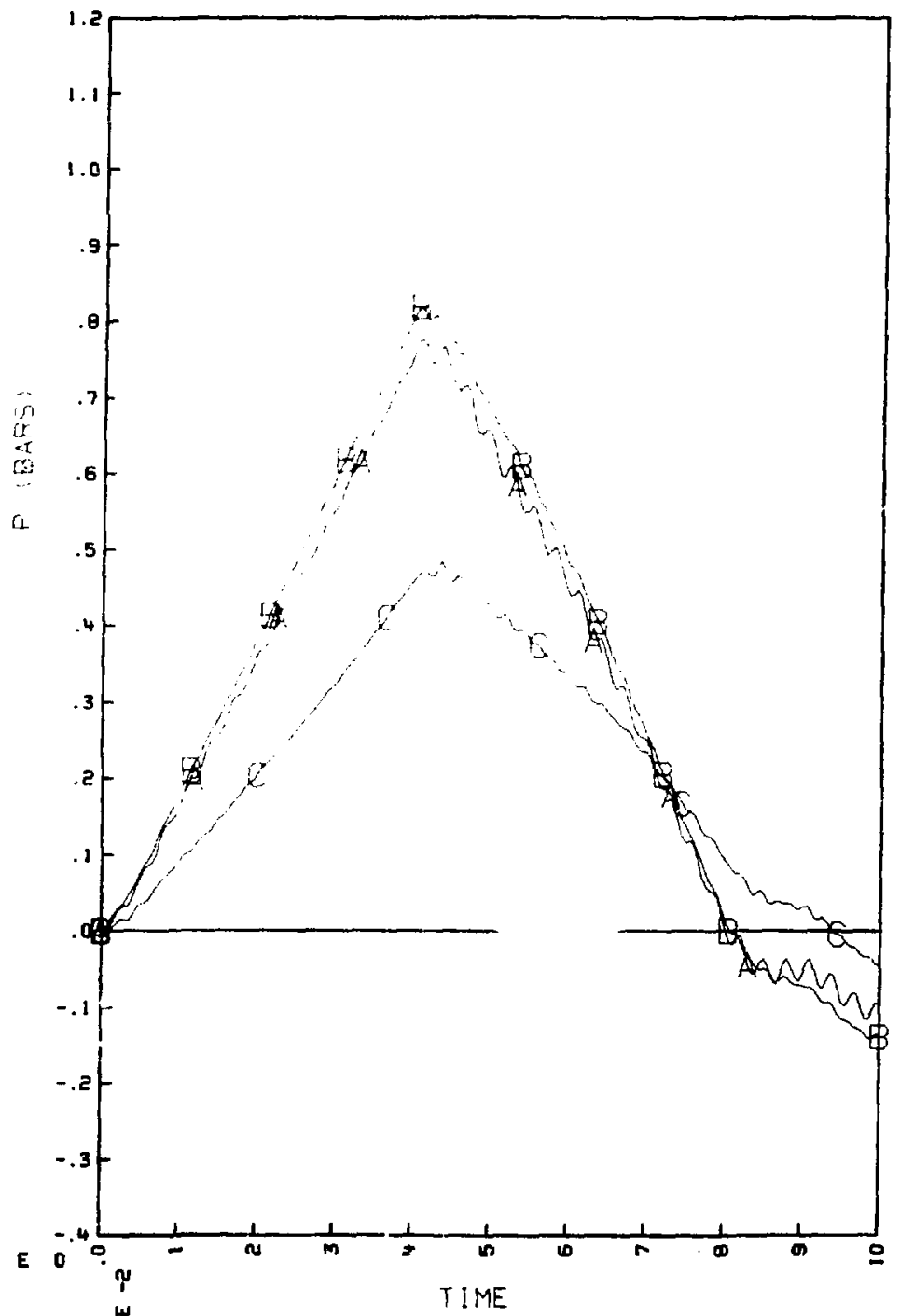

CHUG 2OPSI PULSE (D/T=600) FIXED SHELL BOUNDARY

C-10. Pressure in fluid at $x=x_{m}$ (see Fig. 6) $\left(A-90^{\circ} ; B-60^{\circ} ; C-30^{\circ}\right.$ ) $(D / t=600)$. 


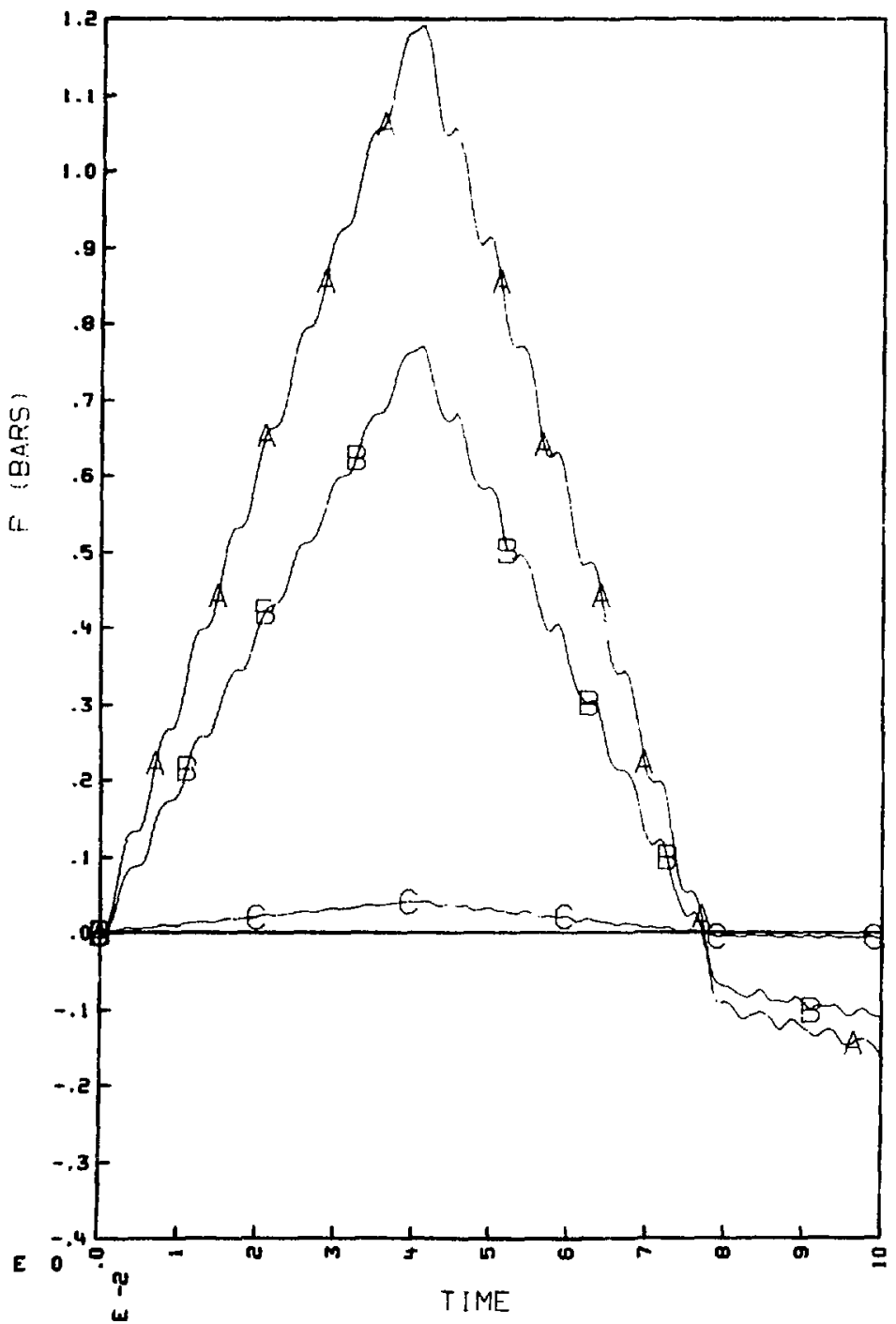

CHUG 2OPSI PULSE ( RIGID) FIXED SHELL BOUNDARY

C-11. Pressure in fluid at $r=r_{m}$ (see Fig. 6) $\left(A-75^{\circ}, 8-45^{\circ} ; C-15^{\circ}\right.$ ) $(D / t=0)$. 


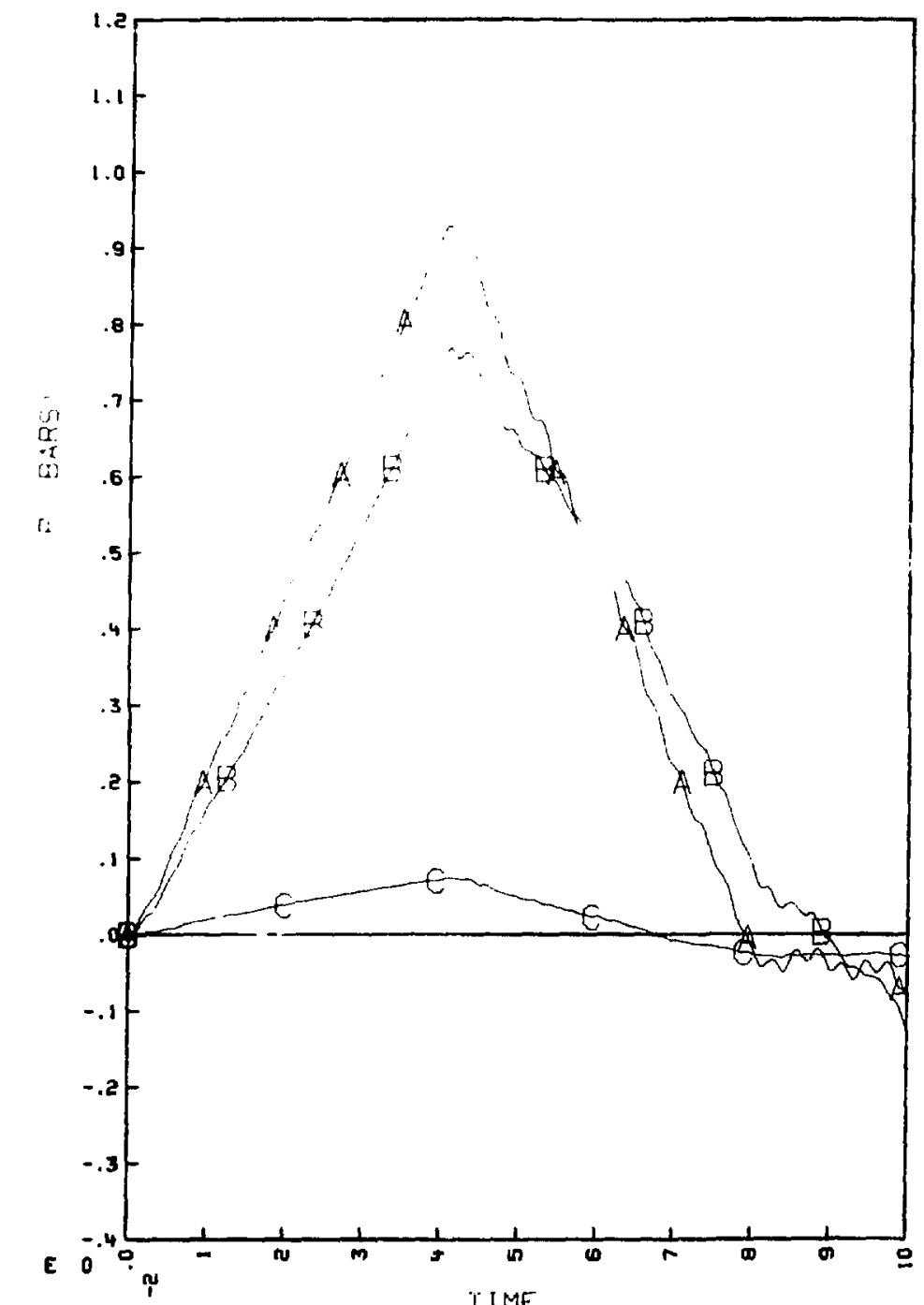

CHUG LOPS PULSE (DIT $=300)$ FIXED SHELL BOUNDARY

C-12. Pressure in fluid at $r=r_{m}$ (gee Fig. 6) $\left(A-75^{\circ} ; B-45^{\circ}, C-15^{\circ}\right.$ ) $(D / t=300)$.

81 


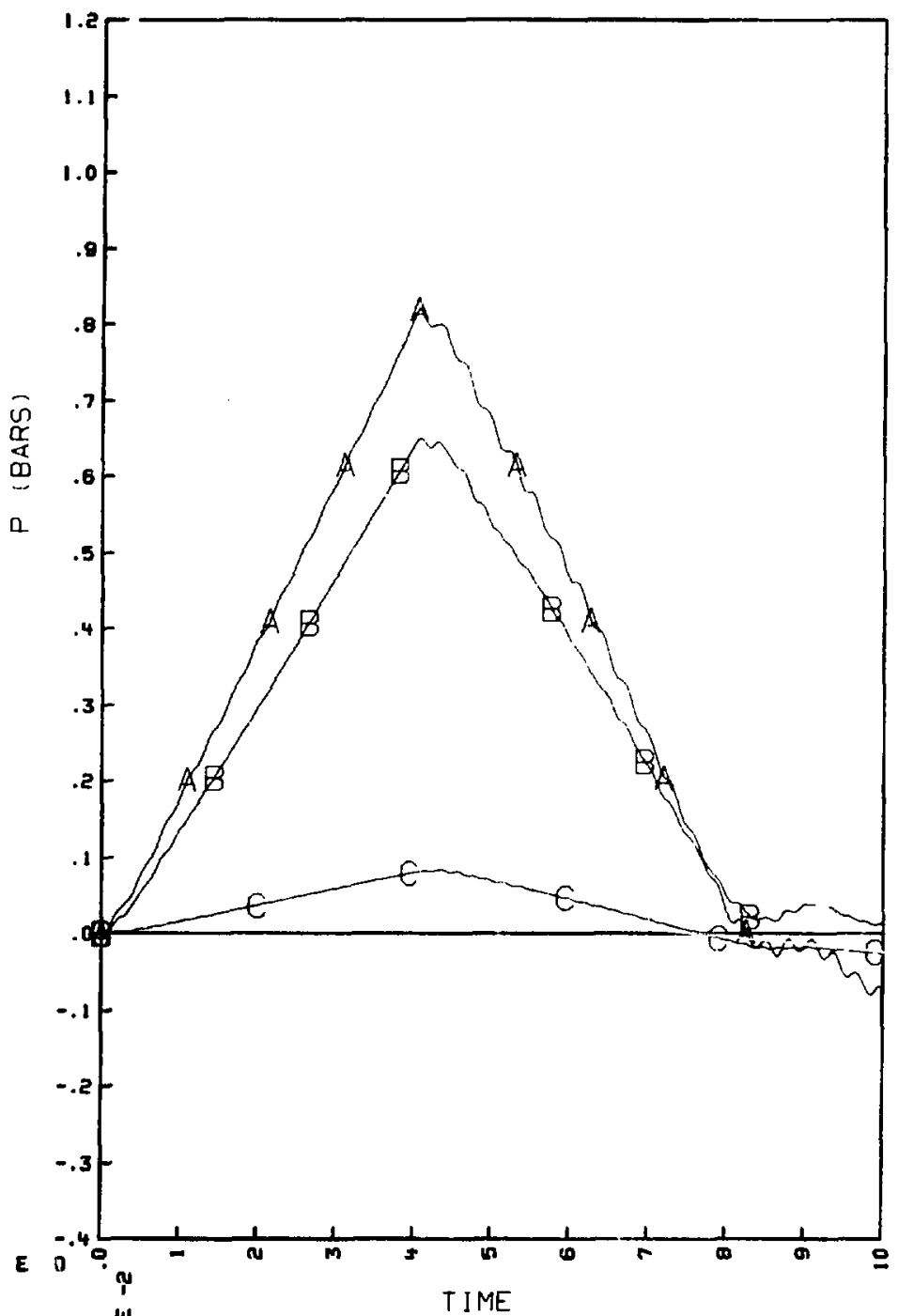

CHUG 2OFSI PULSE (D/T=600) FIXED SHELL BOUNDARY

$\mathrm{C}-13$. Pressure in tluid at $\mathrm{r}=\mathrm{x}_{\mathrm{m}}$ (Bee Fig. 6) $\left(\mathrm{A}-75^{\circ} ; \mathrm{B}-45^{\circ} ; \mathrm{C}-15^{\circ}\right.$ ) $(D / t=600)$. 


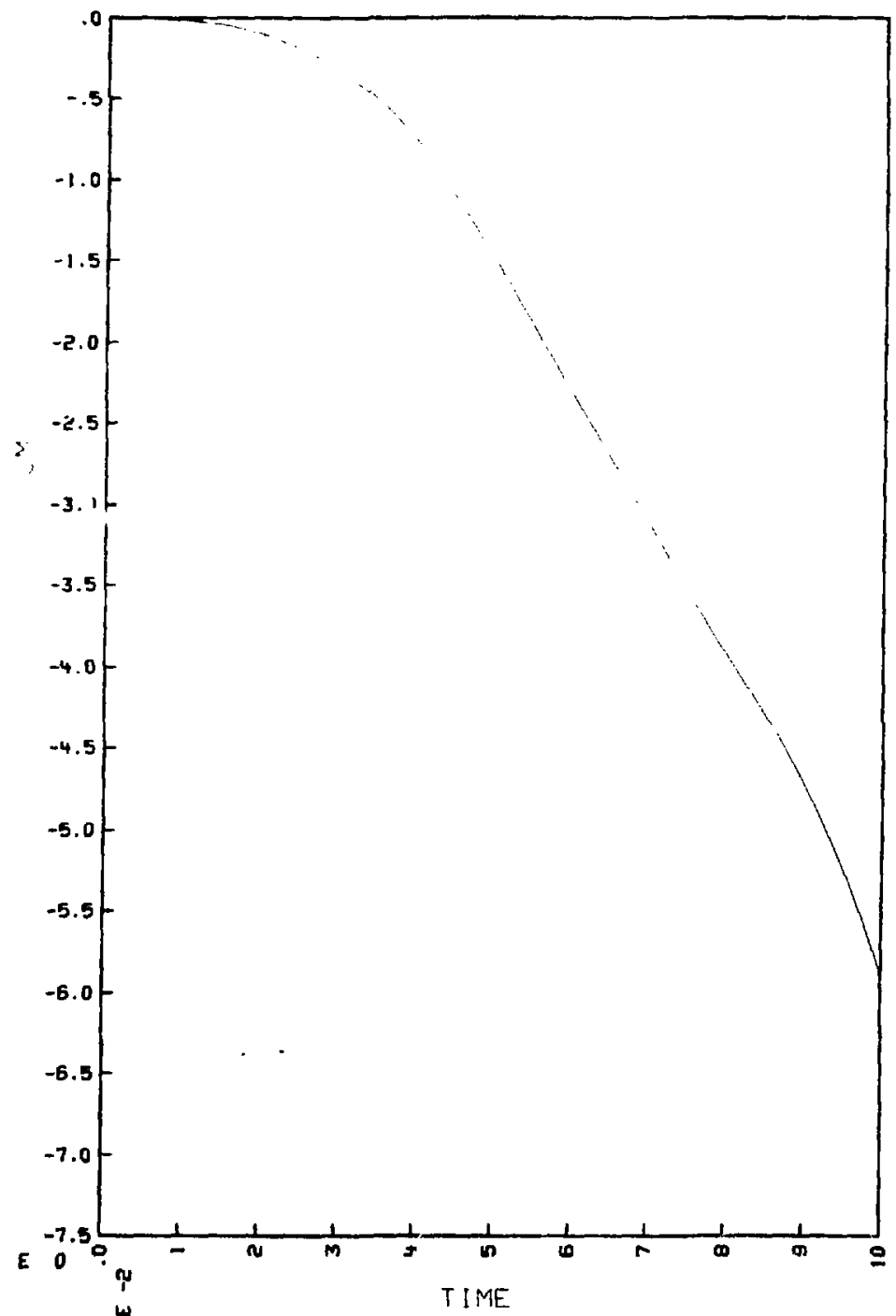

CHUG 2OPSI PULSE (D/T $=300)$ FIXED SHELL BOUNDARY

C-14. Shell displacement at $90^{\circ}(\mathrm{D} / \mathrm{t}=300)$. 


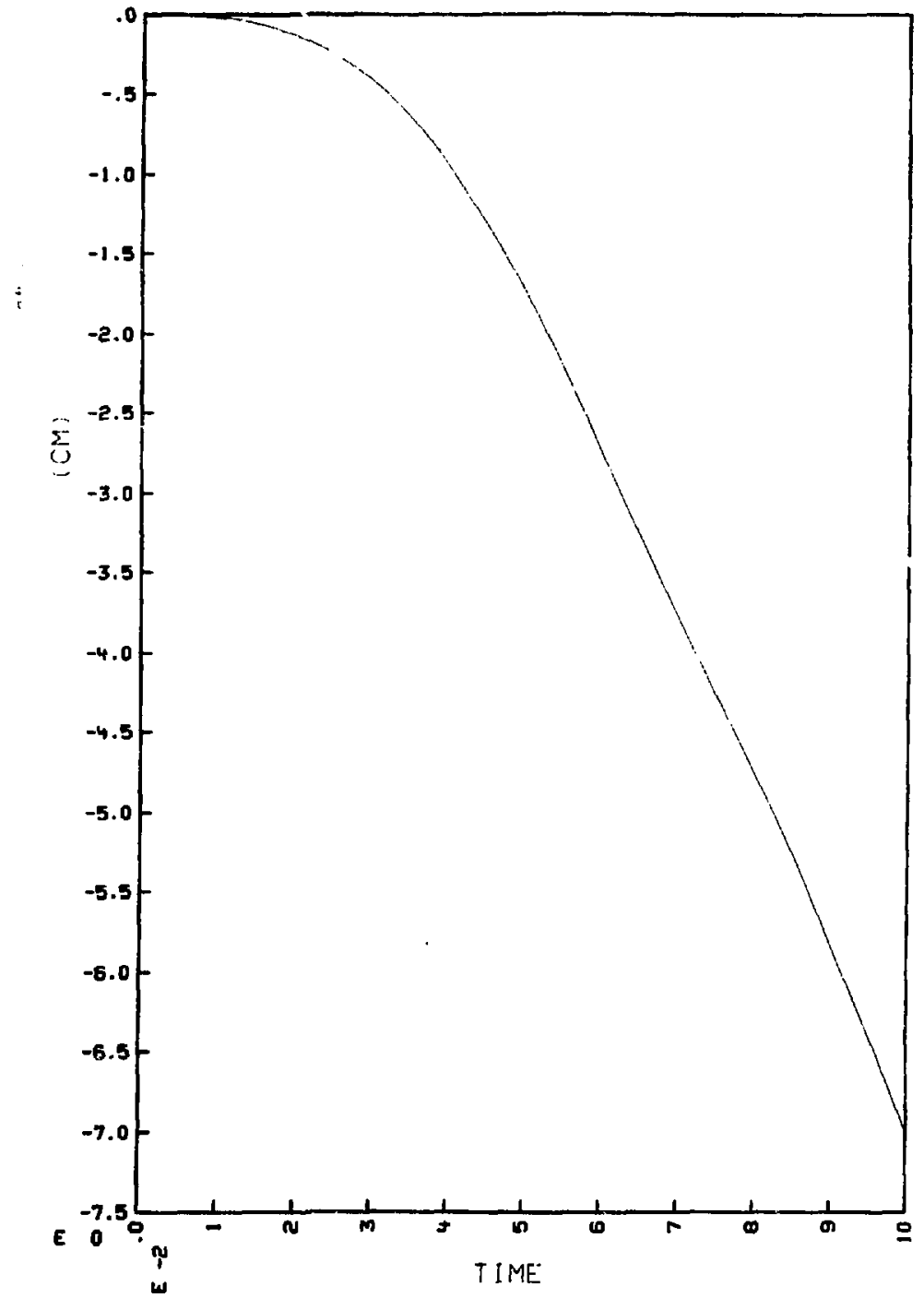

CHUG 2OPSI PULSE ( $/ T=600) F[X E D$ SHELL BDUNDARY

$$
\text { C-15. Shell displacement at } \left.90^{\circ}() / t=600\right) \text {. }
$$




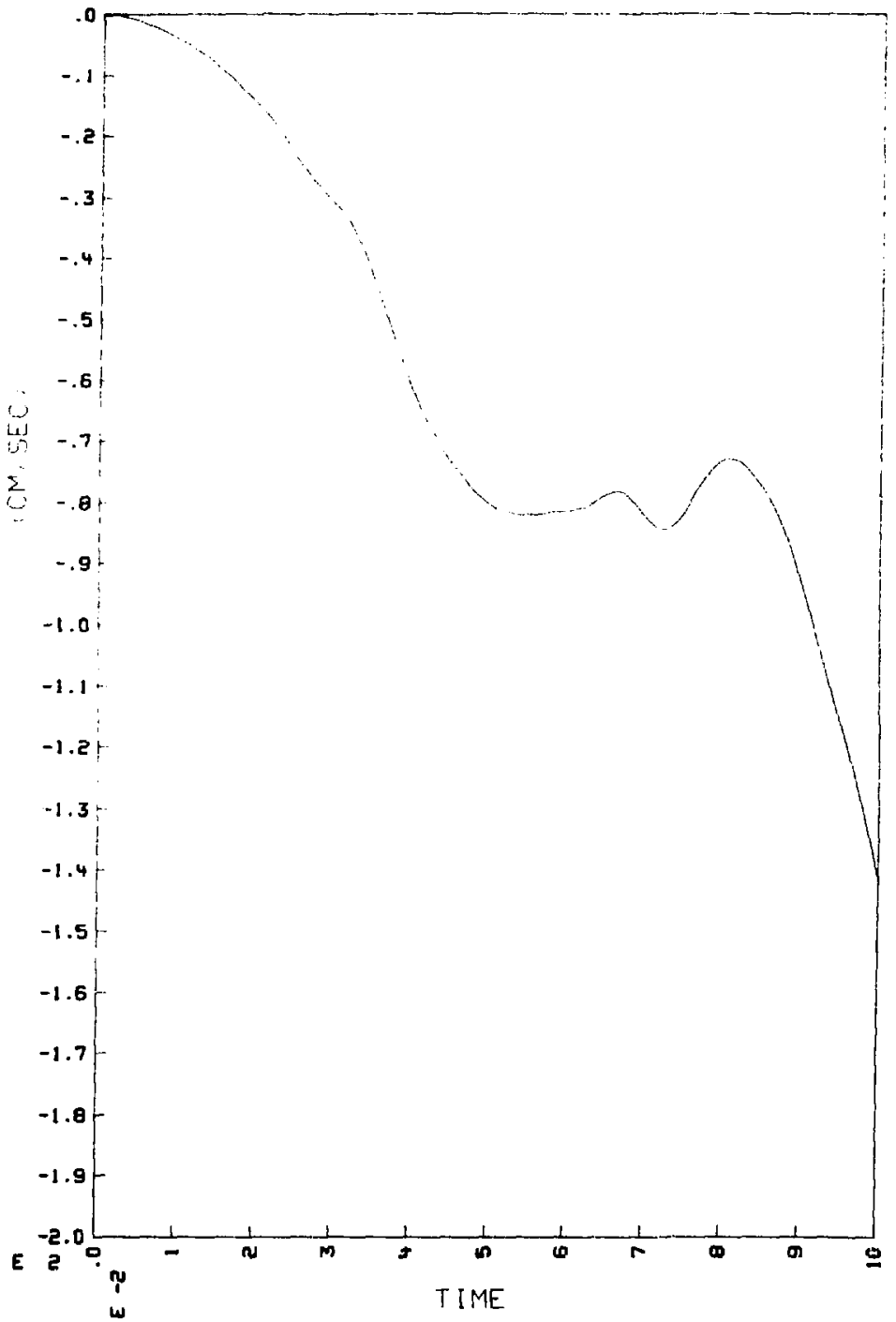

CHUG 2OPSI PULSE $(D / T=300)$ FIXED SHELL BOUNDARY

$$
\text { C-16. Shell velocity at } 90^{\circ}(\mathrm{D} / \mathrm{t}=300)
$$




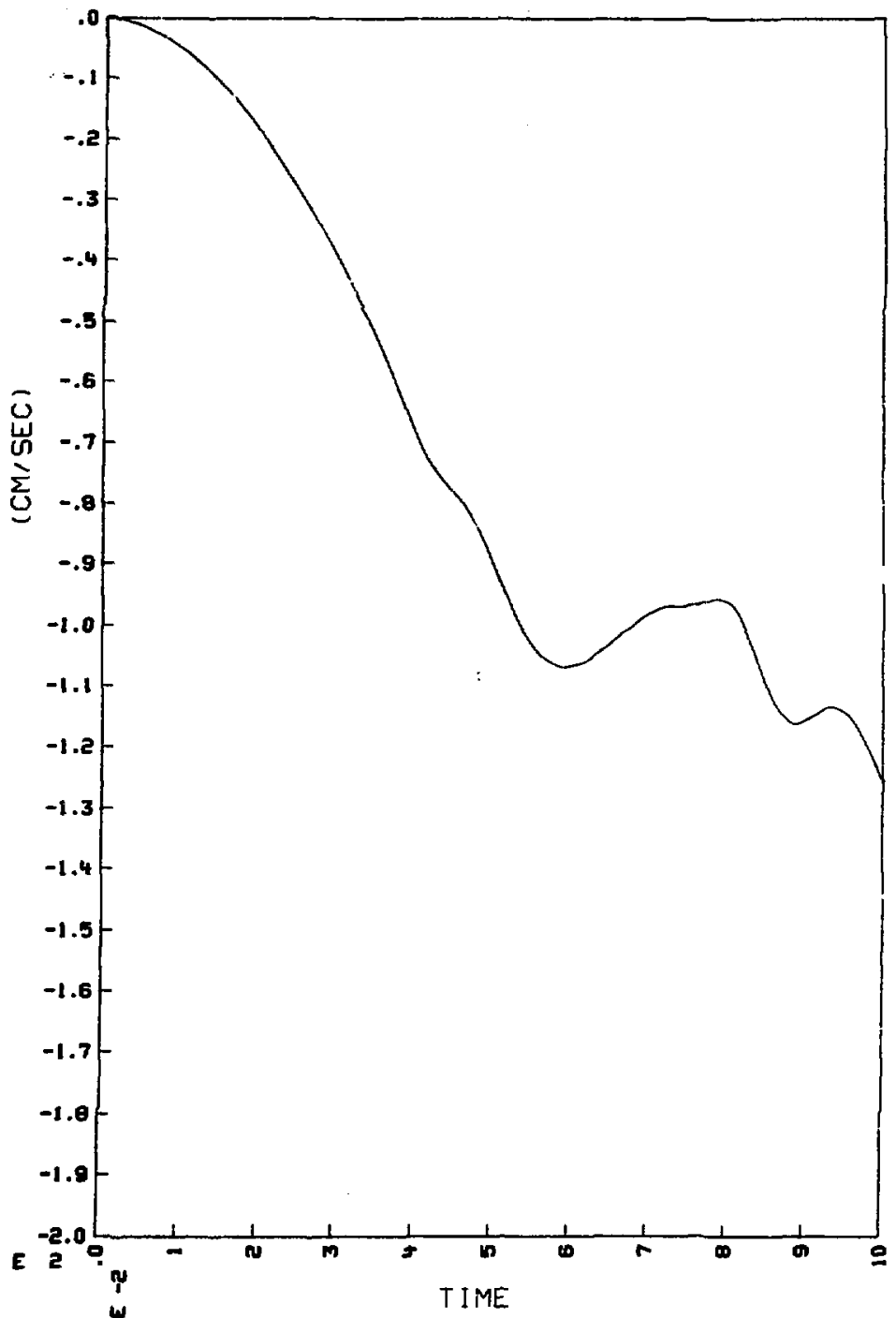

CHUG 2OPSI PULSE ( $/ T=600)$ FIXED SHELL BOUNDARY

C-17. Shell velocity at $90^{\circ}(\mathrm{D} / \mathrm{t}=600)$ 


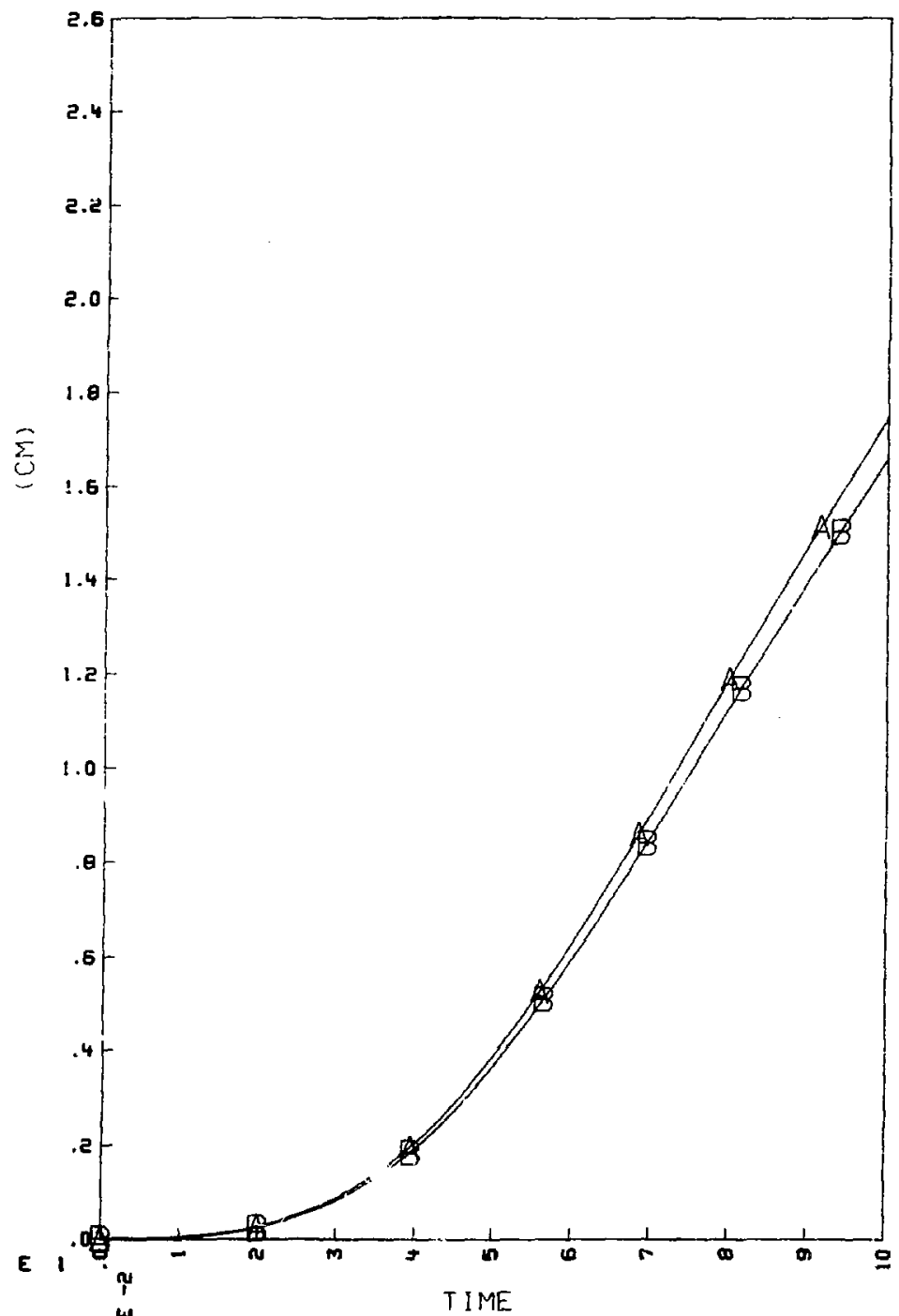

CHUG 2OPSI PULSE : RIGID I FIXED SHELL BOUNDARY

C-18. Free surface displacenent (A-bubble centerline; B-shell centerline) $(D / t=0)$. 


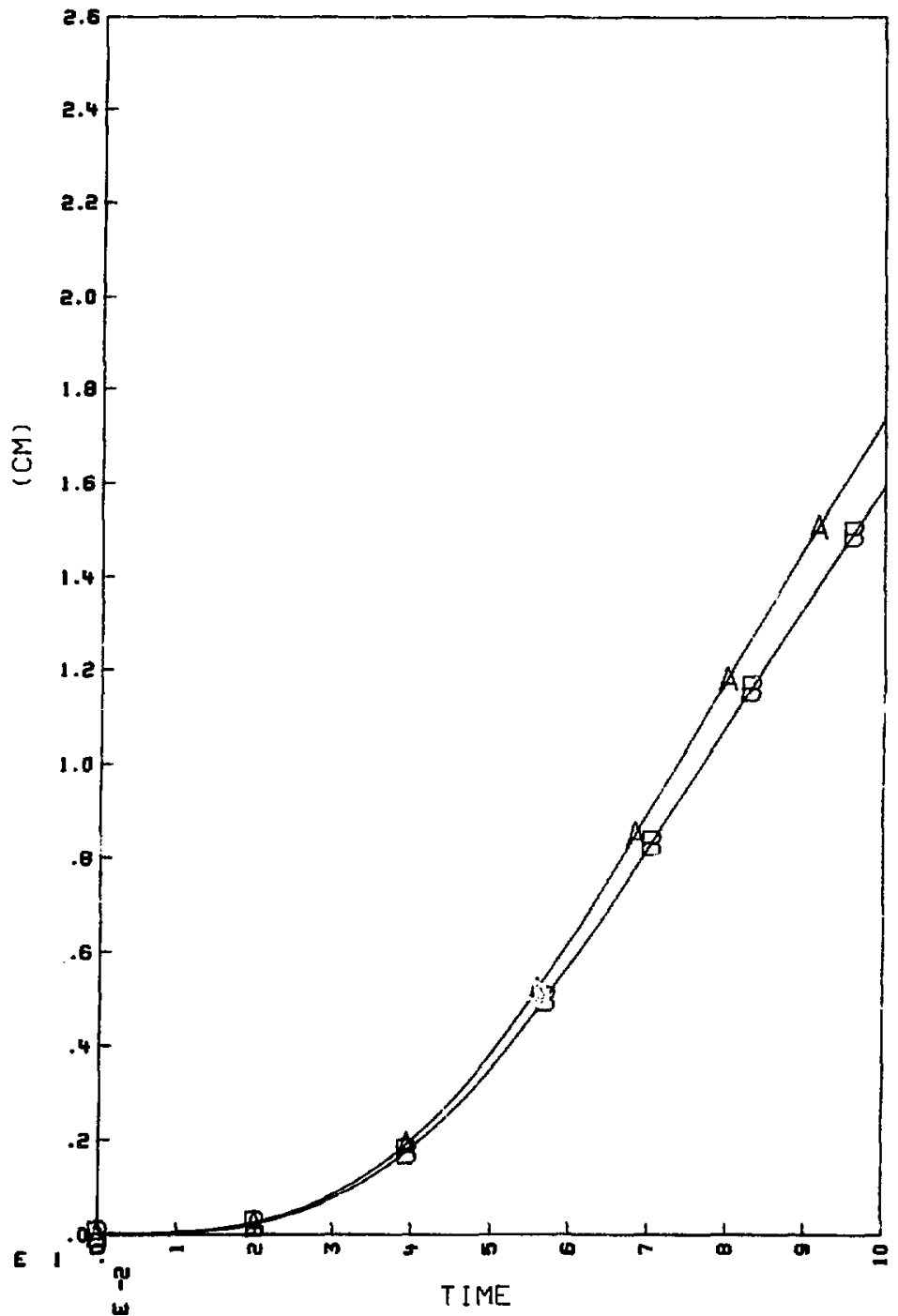

CHUG 2OPSI PULSE (D/T=300) FIXED SHELL BOUNDIARY

C-19. Free surface displacement (A-bubble centerline; B-shell centerline) $(D / t=300)$. 


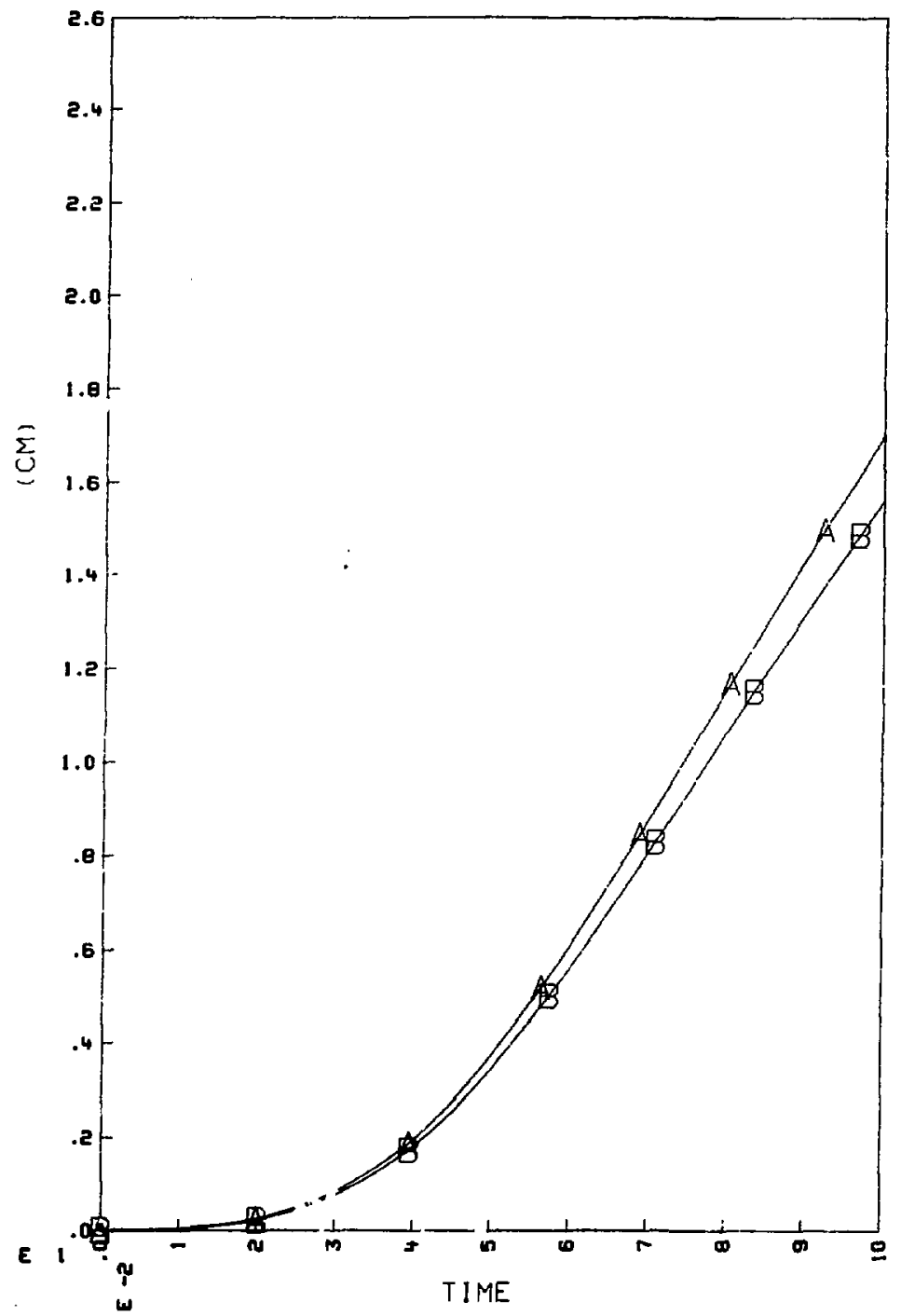

CHUG 2OPSI PULSE ( $/ T=600)$ FIXED SHELL BOUNDARY

C-20. Free ourface displacement (A-bubble centerline; B-shell centerline) $(D / t=600)$. 


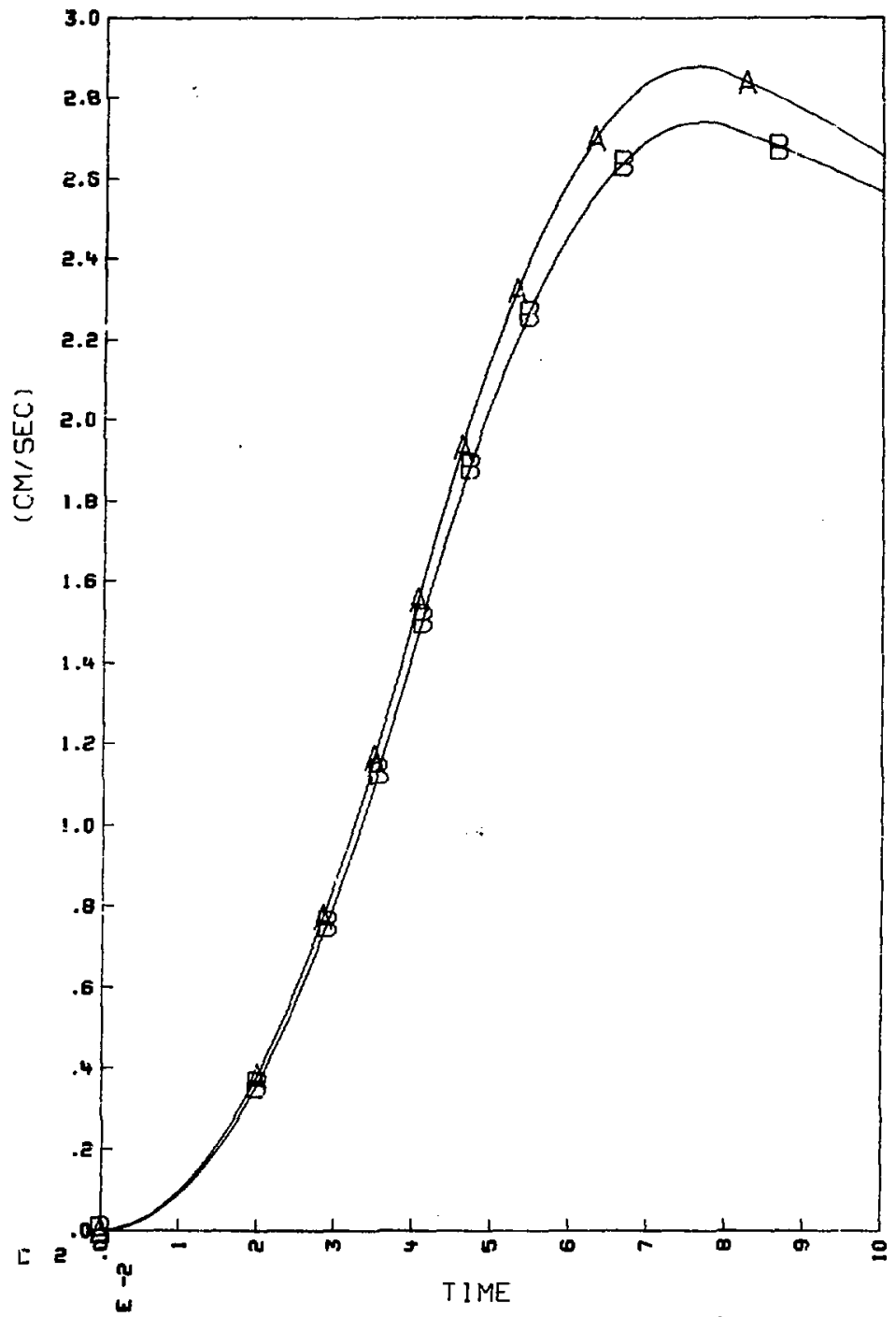

CHUG 2OPSI PULSE ( RIGID) FIXED SHELL BOUNDARY

C-21. Free surface velocity (A-bubble centerline; B-shell centerline) $(D / t=0)$. 


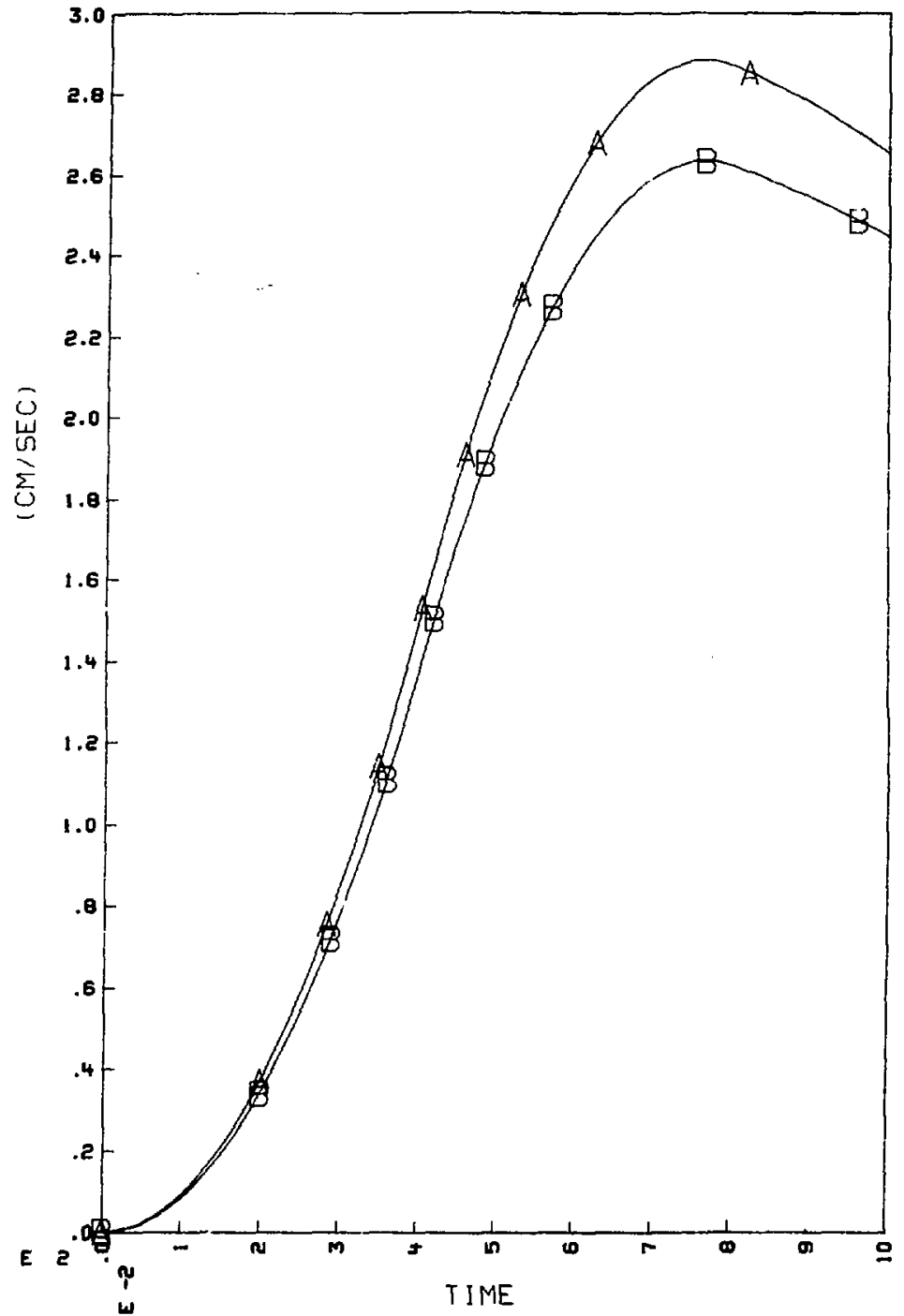

CHUG ZOPSI PULSE (D/T=300) FIXED SHELL BOUNDARY C-22. Free surface velocity (A-bubble centerline; B-shell centerline) $(D / t=300)$. 


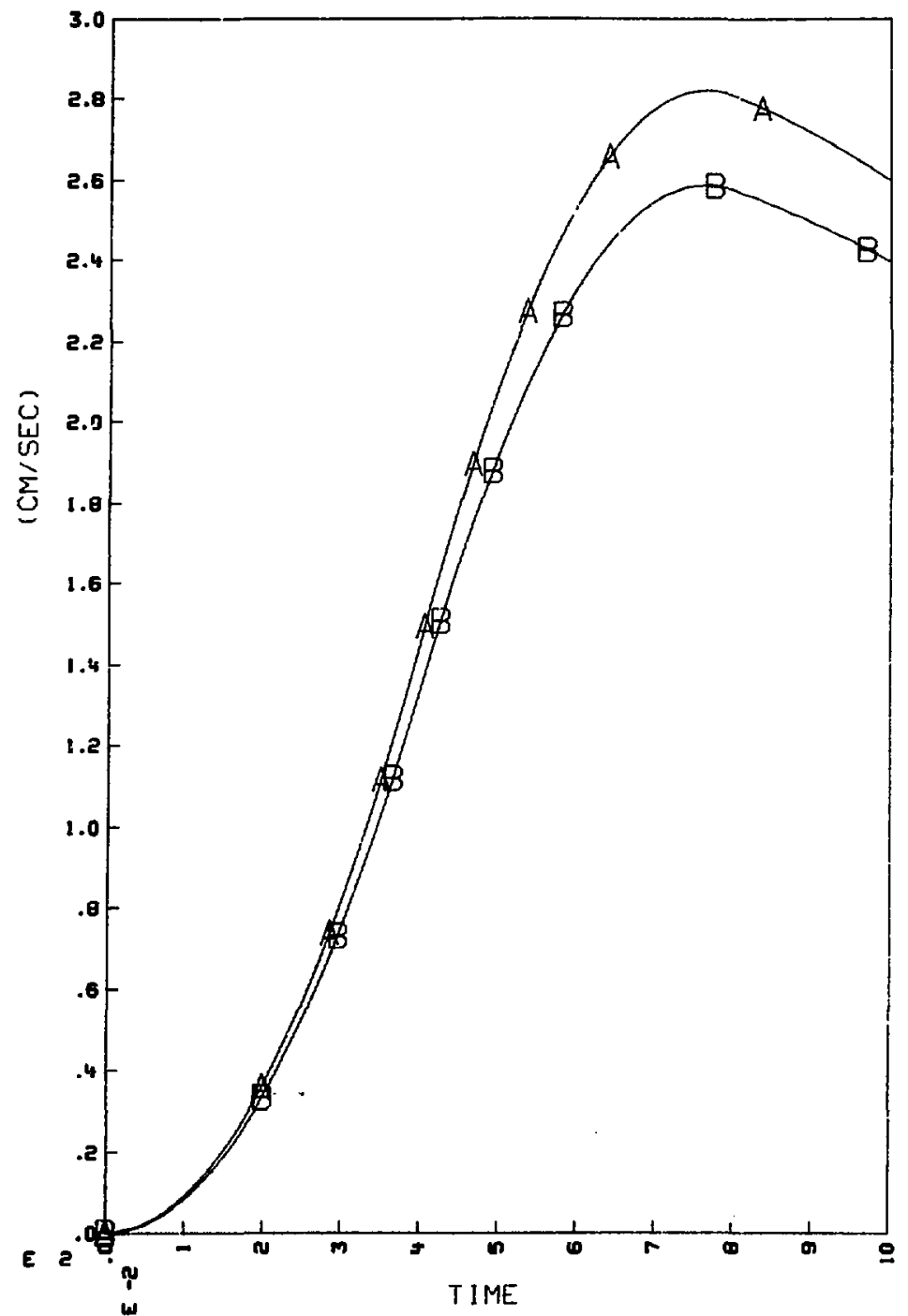

CHUG 2OPSI PULSE (D/T=600) FIXED SHELL BOUNDARY

C-23. Free surface veloeity (A-bubble centerline; B-shell centerline) $(D / t=600)$. 


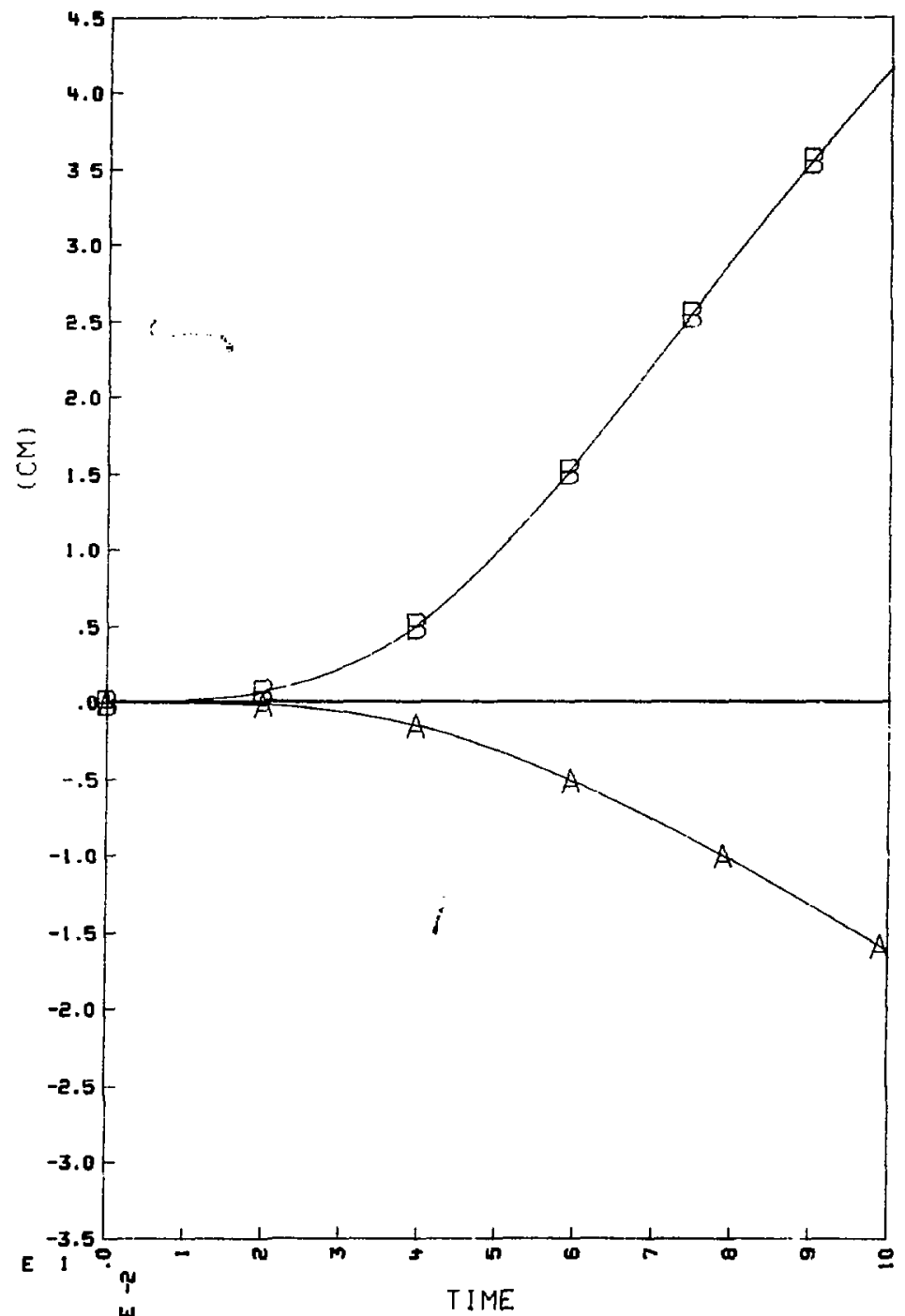

CHUG 2OPSI PULSE ( RIGID) FIXED SHELL BOUNDARY

C-24. Bubble displacenent at $A$ and $B$ (see Fig. C-1) $(D / t=0$ ). 


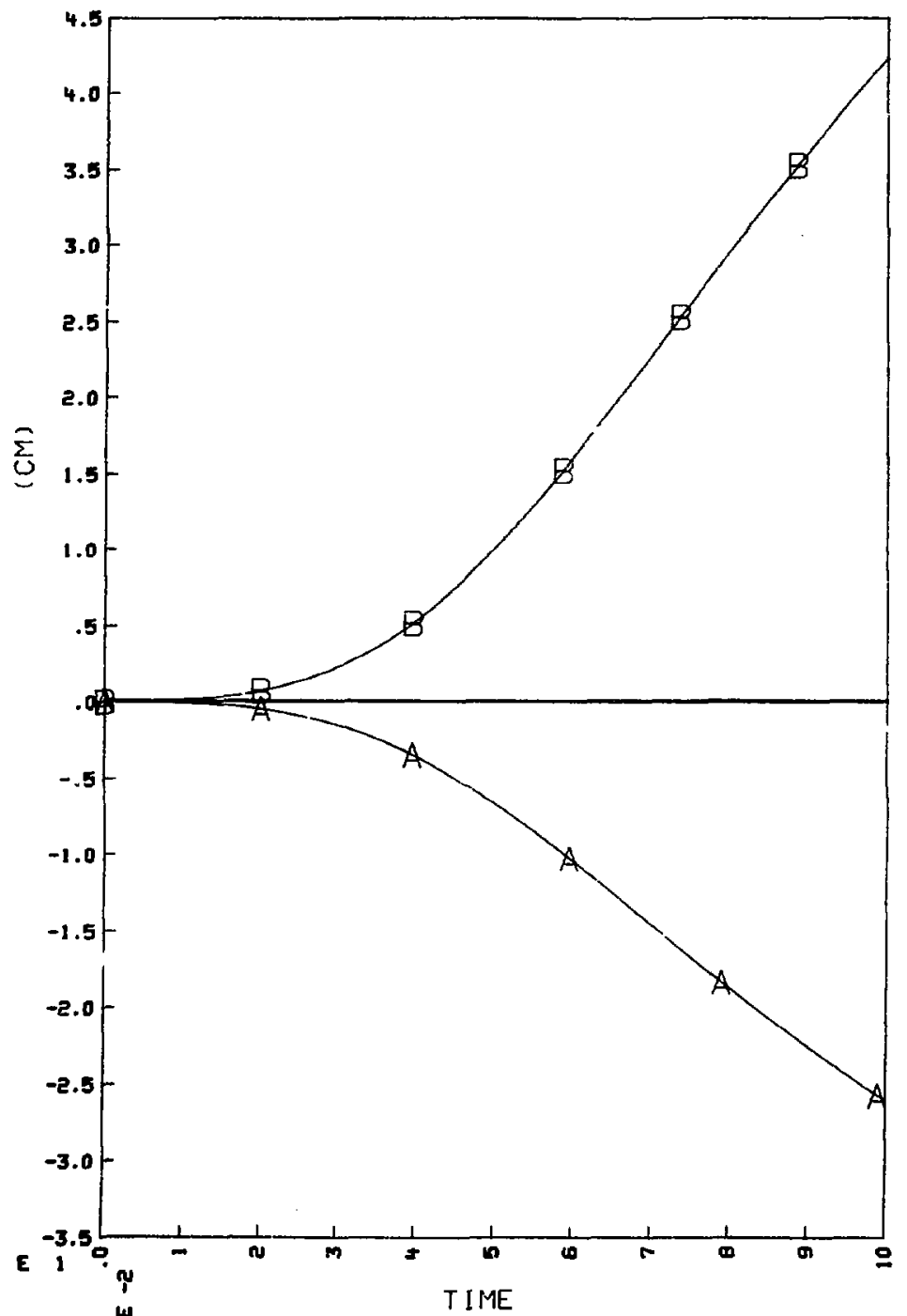

CHUG 2OPSI PULSE (D/T $=300)$ FIXED SHELL BOUNDARY

C-25. Bubble displacenent at $A$ and $B$ (aee Fig. C-1) $(D / t=300)$. 


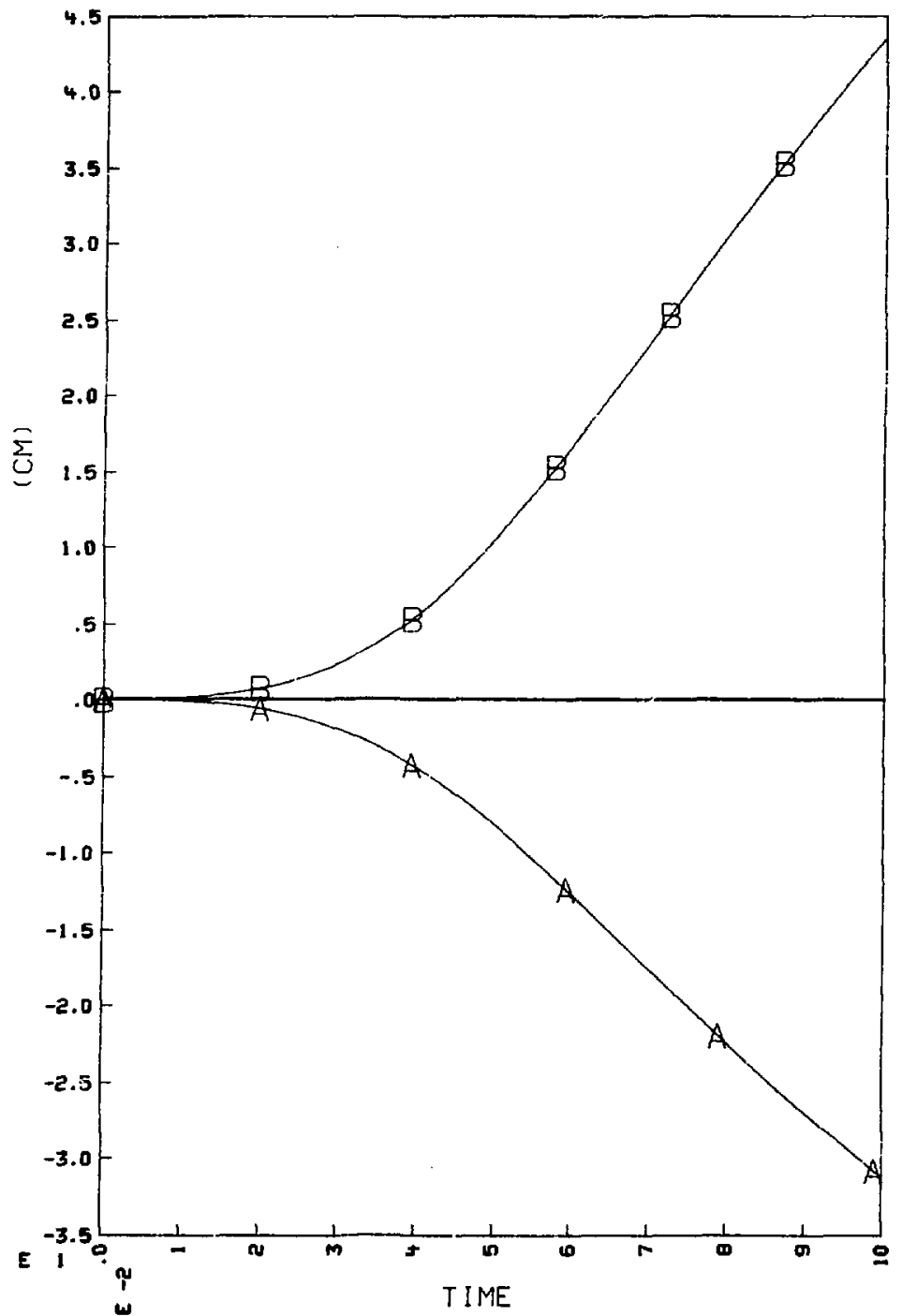

CHUG 2OPSI PULSE (D/T=600) FIXED SHELL BOUNDARY

C-26. Bubble diaplacenent at $A$ and $B$ (see Fig. C-1) (D/t $=600$ ). 


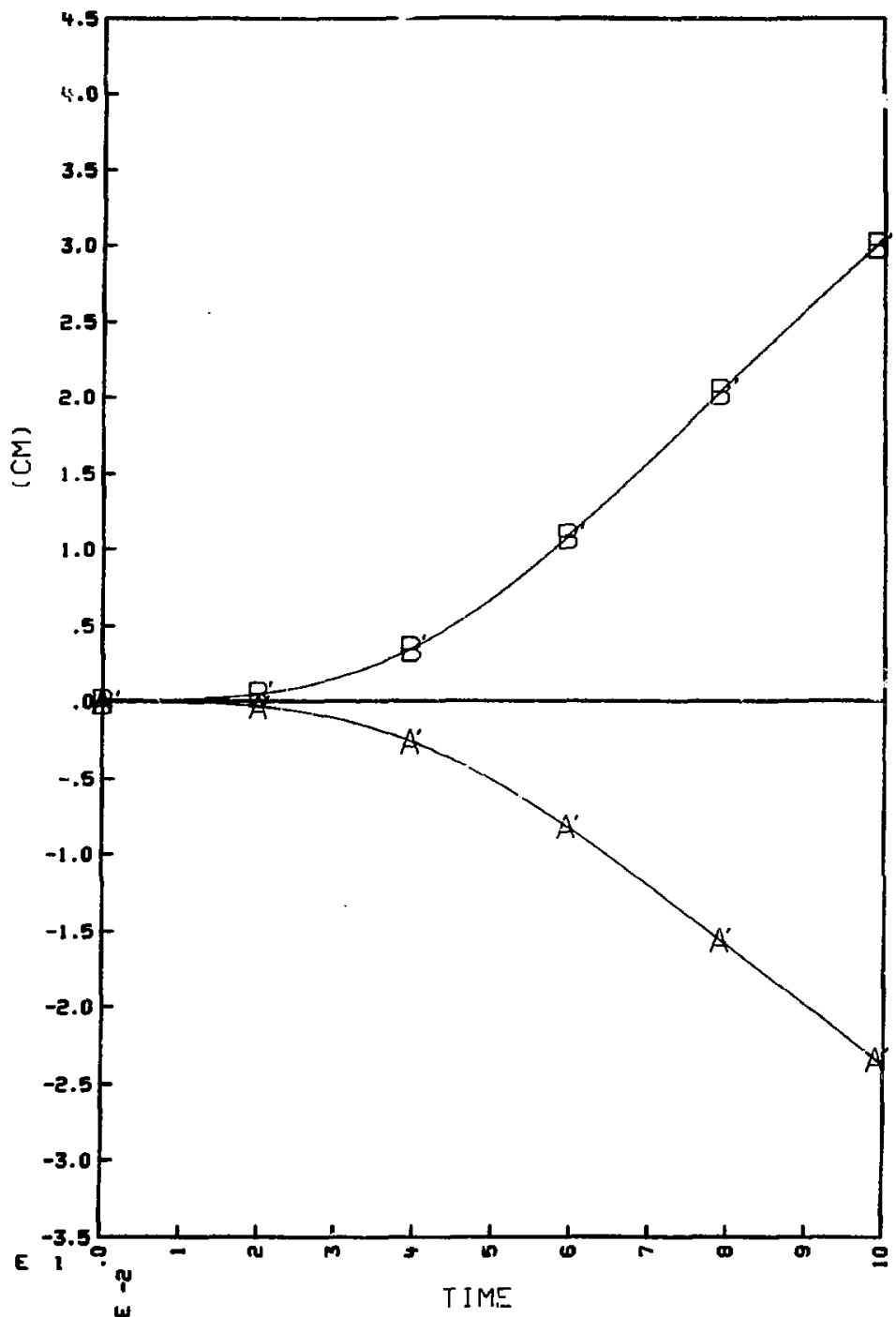

CHLO 2OPSI PULSE ( RIGID) FIXED SHELL BOUNDARY

C-27. Bubble displacement at $A^{\prime}$ and B' (see Fig. C-1) $(0, \tau=0)$. 


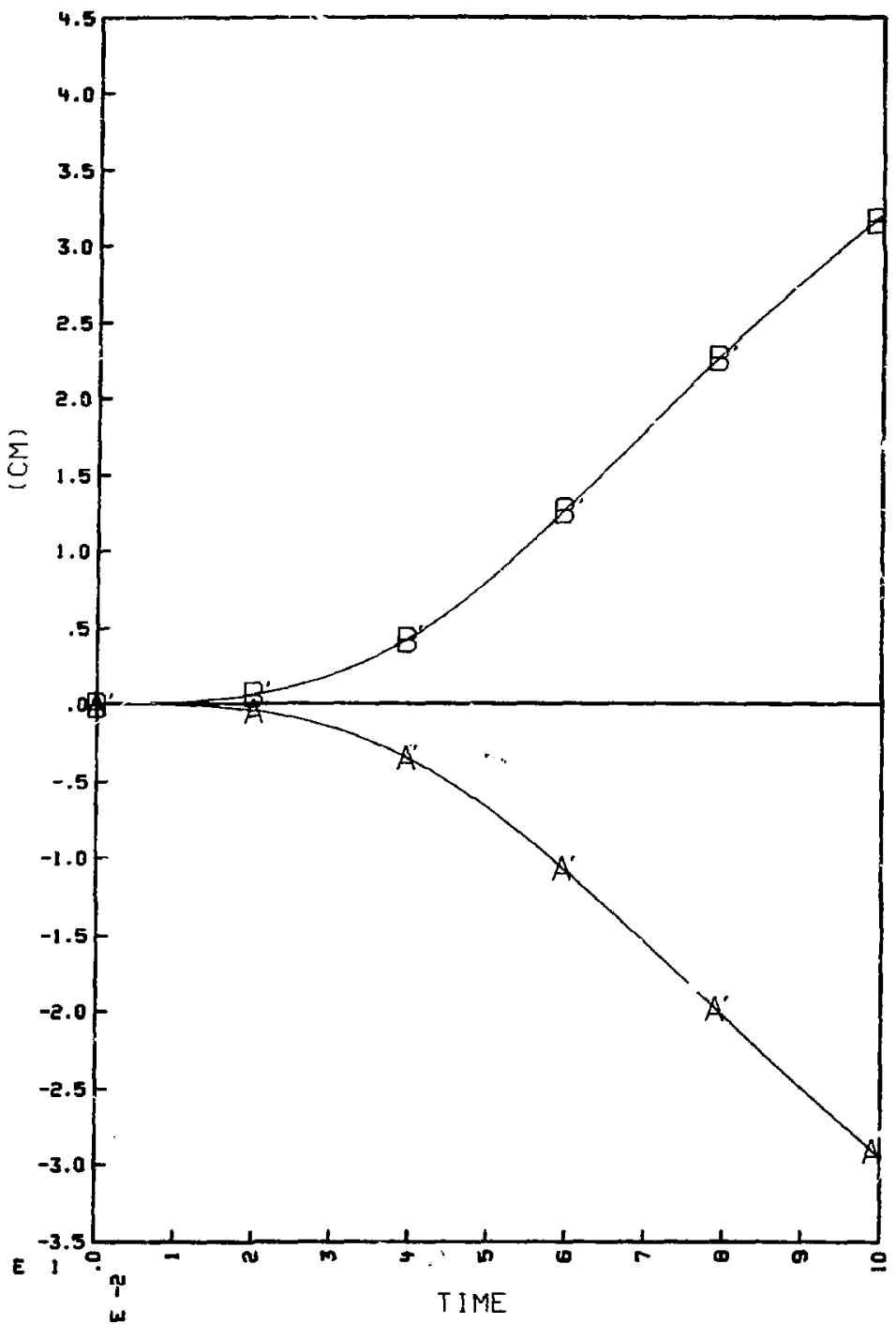

CHUC 2OPSI PULSE $(D / T=300)$ FIXED SHELL BOUNDARY

C-28. Bubble displacenent ac $A^{\prime}$ and $B^{\prime}$ (see Fig. $C-1$ ) $(D / t=300$ ) 


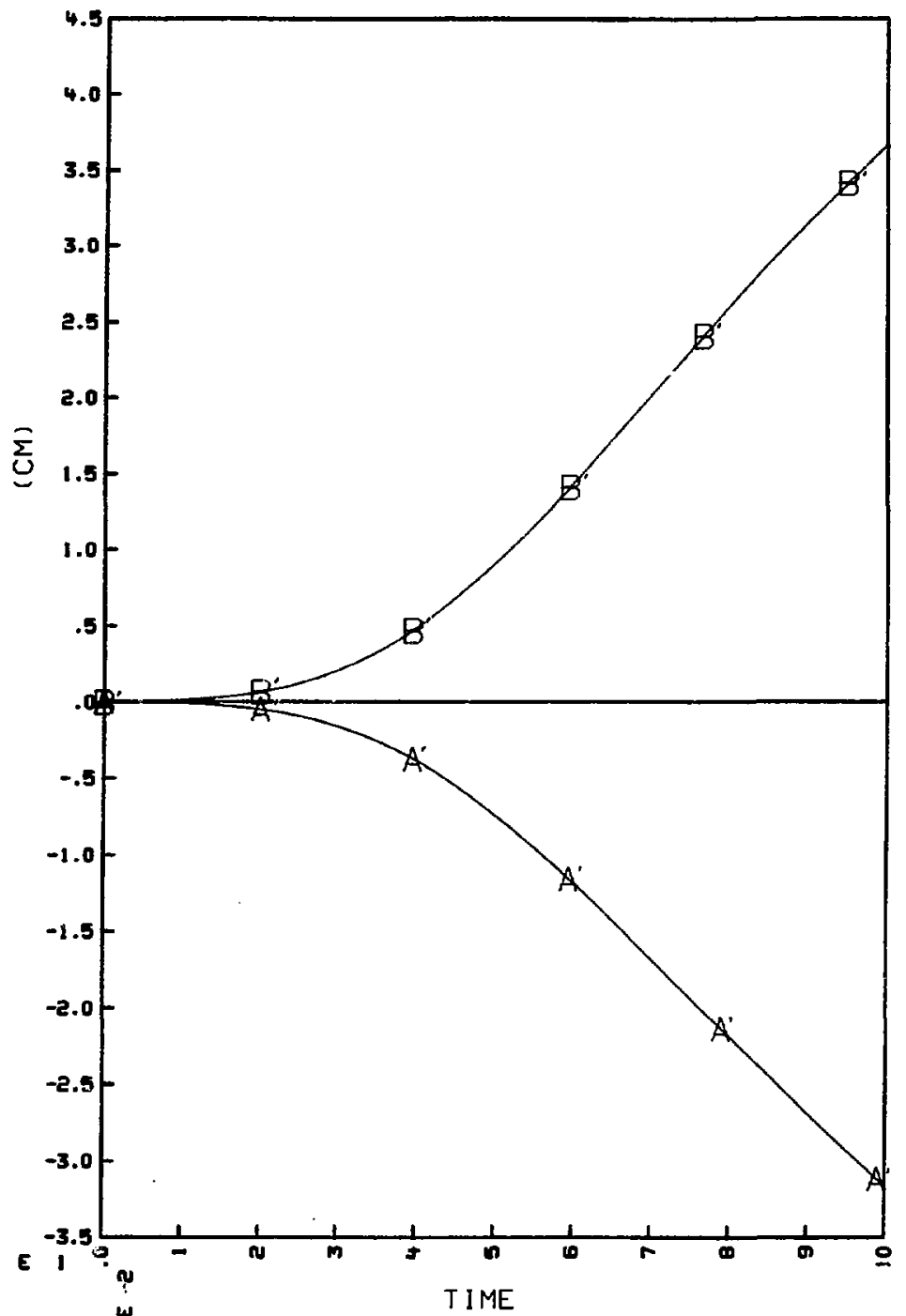

CHUG 2OPSI PULSE $(D / T=600)$ FIXED SHELL BOUNDARY

C-29. Bubble displacenent at $A^{\prime}$ and $B^{\prime}$ (sce Fig. C-1) (D/t $\left.=600\right)$. 


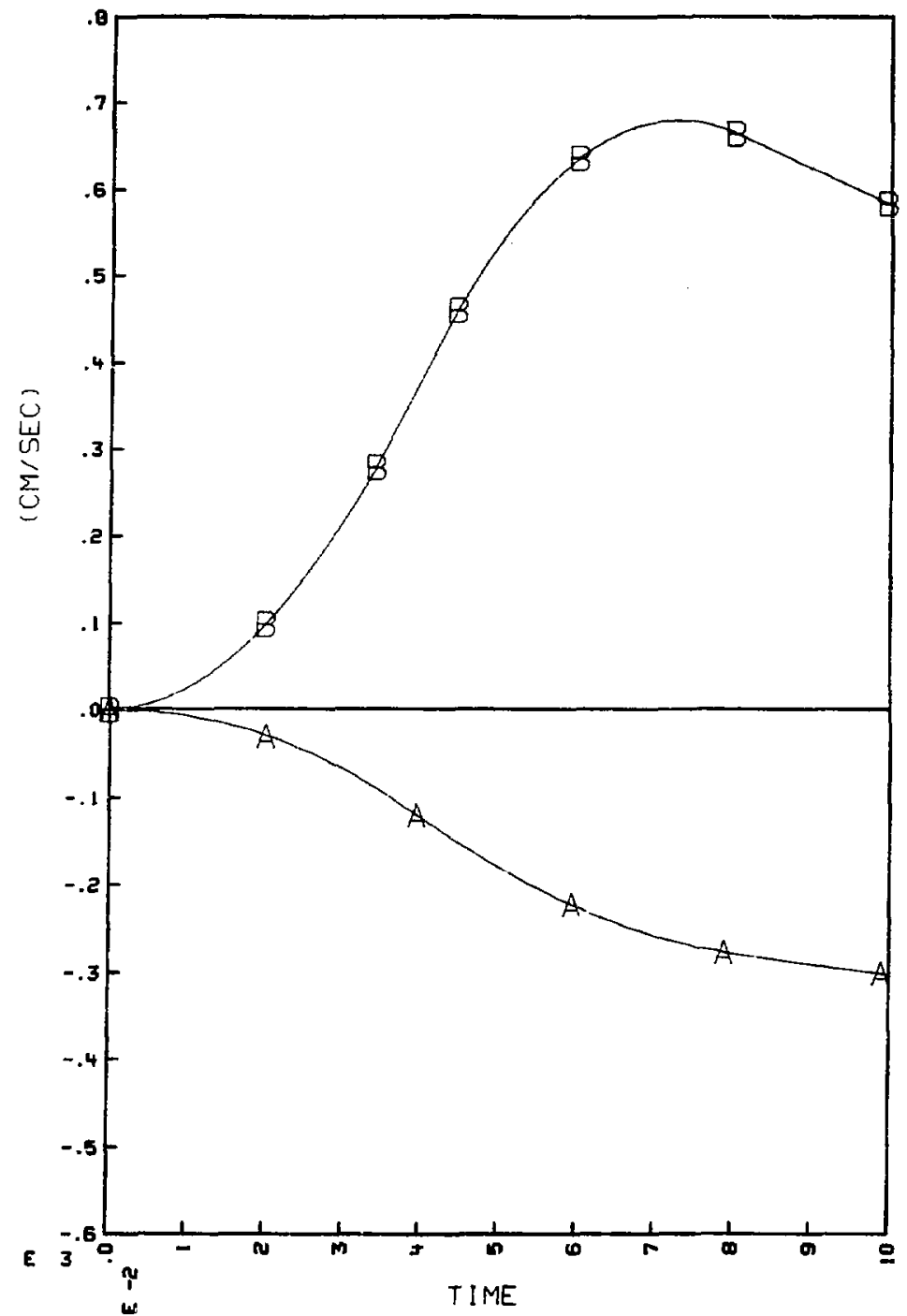

CHUG 2OPSI PULSE ( RIGID) FIXED SHELL BOUNDARY

C-30. Bubble velocity at $A$ and $B$ (see Fig. C-1) (D/t $=0$ ). 


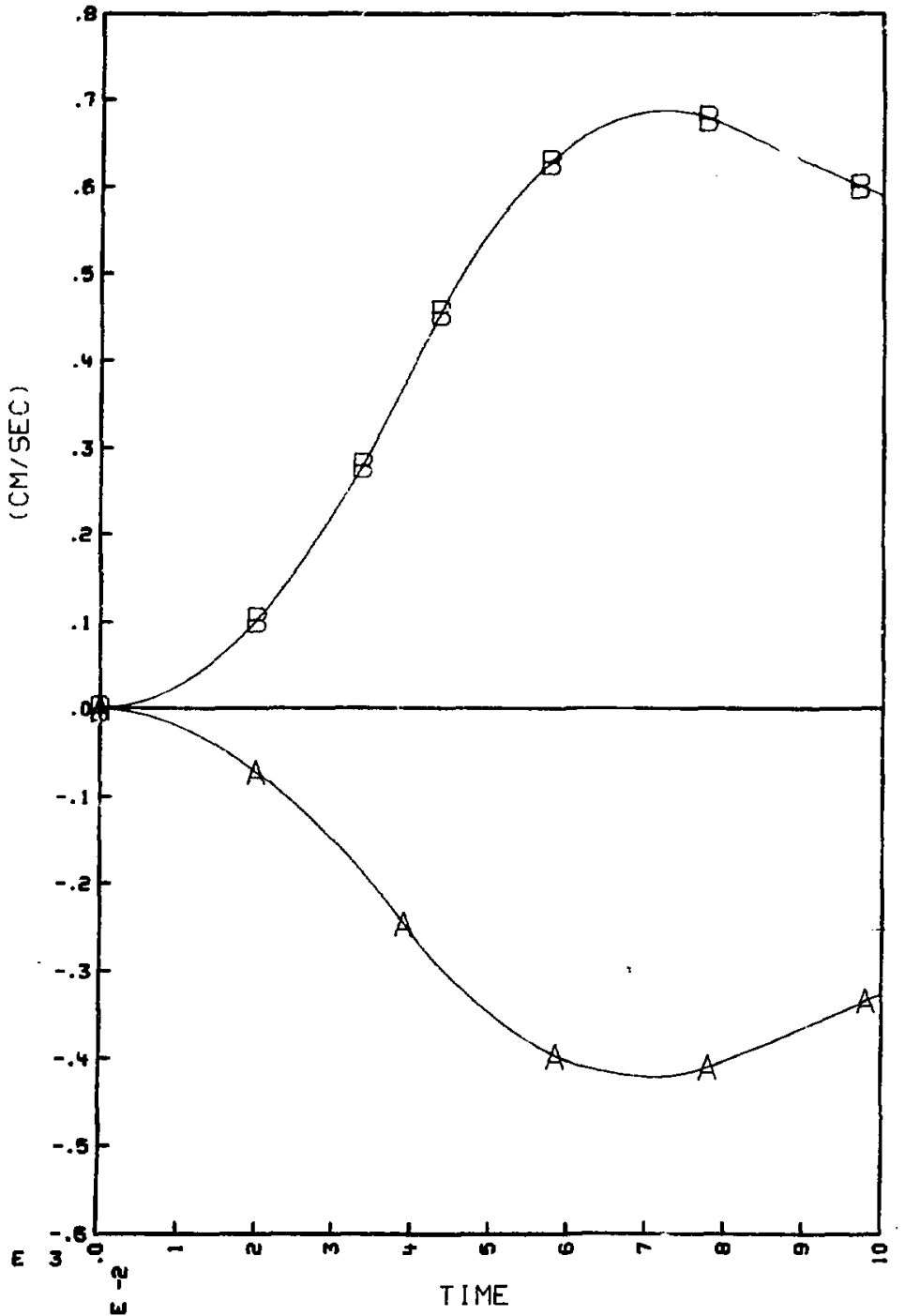

CHUG 2OPSI PULSE $(0 / T=300)$ FIXED SHELL BOUNDARY

C-31. Bubble velocity at $A$ and $B$ (tee Big. C-1) (D/t $=300$ ). 


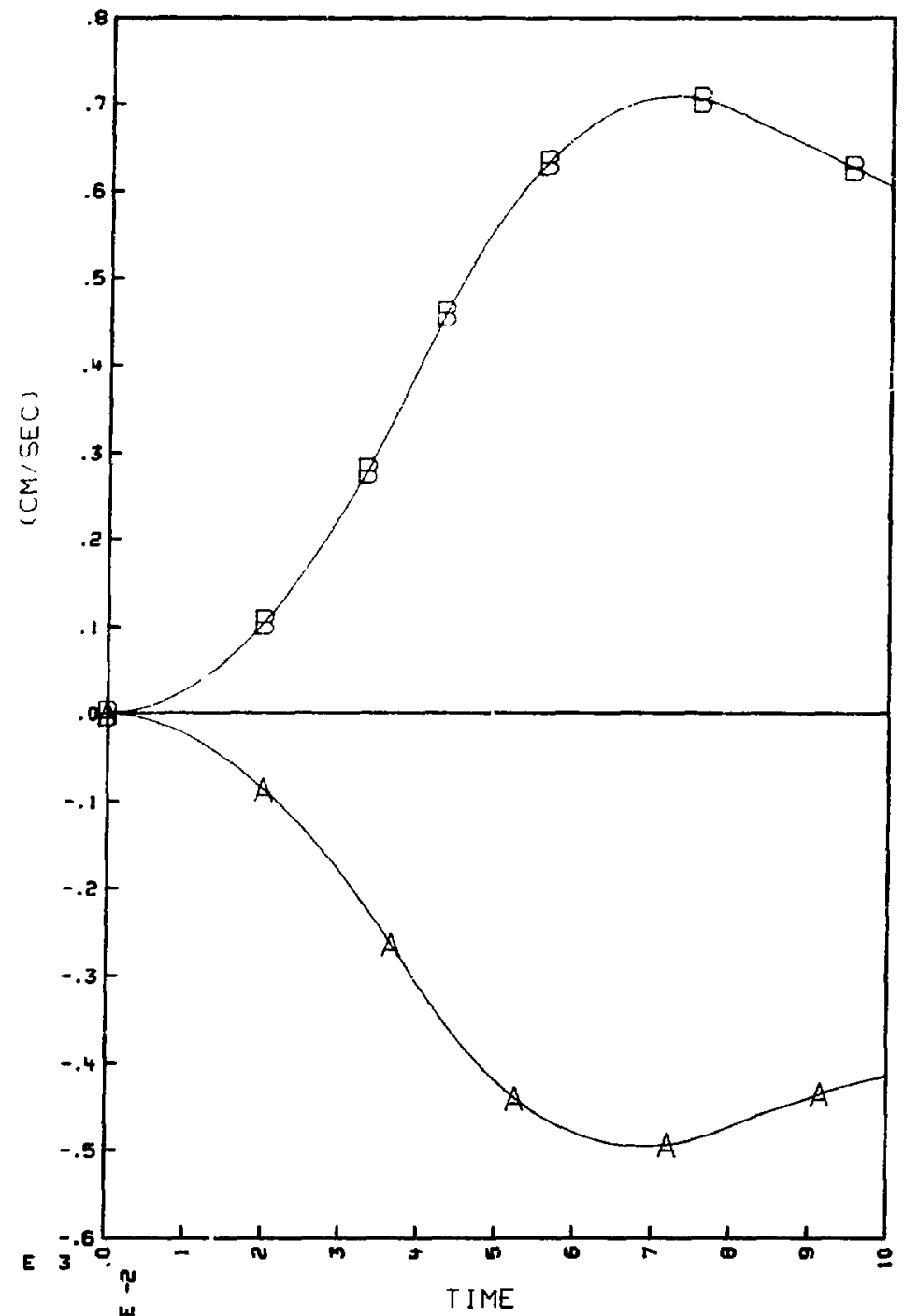

CHUG 20PSI PULSE (D/T=600) FIXED SHELL BOUNDARY

C-32. Bubble velootty at A and $B$ (aee Fig. C-1) (D/t $=600$ ). 


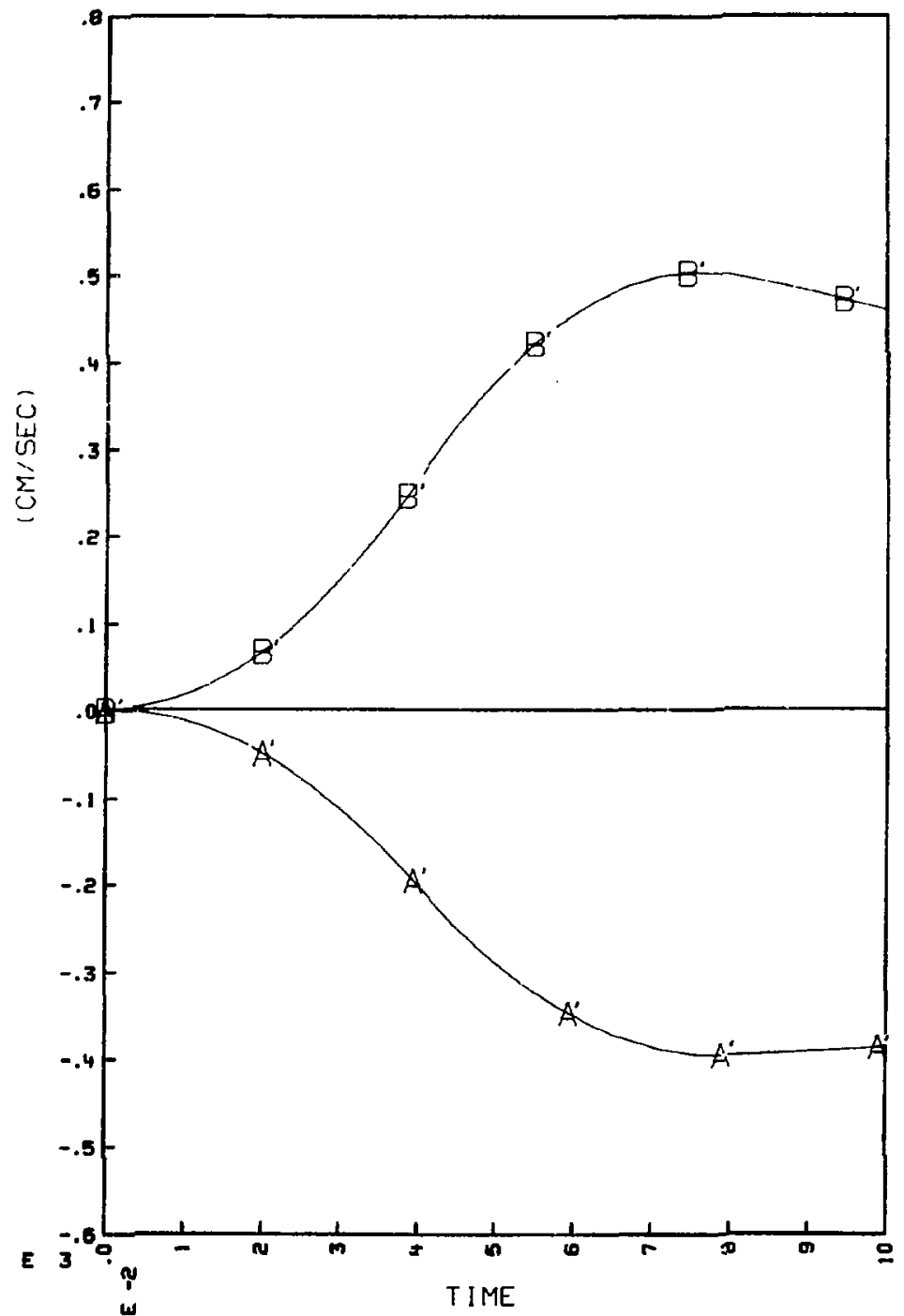

CHUG 2OPSI PULSE ( RIGID) FIXED SHELL BOUNDARY

C-33, Bubble velocity at $A^{\prime}$ and $B^{\prime}$ (see Fig, $\left.C-1\right)(D / t=0)$. 


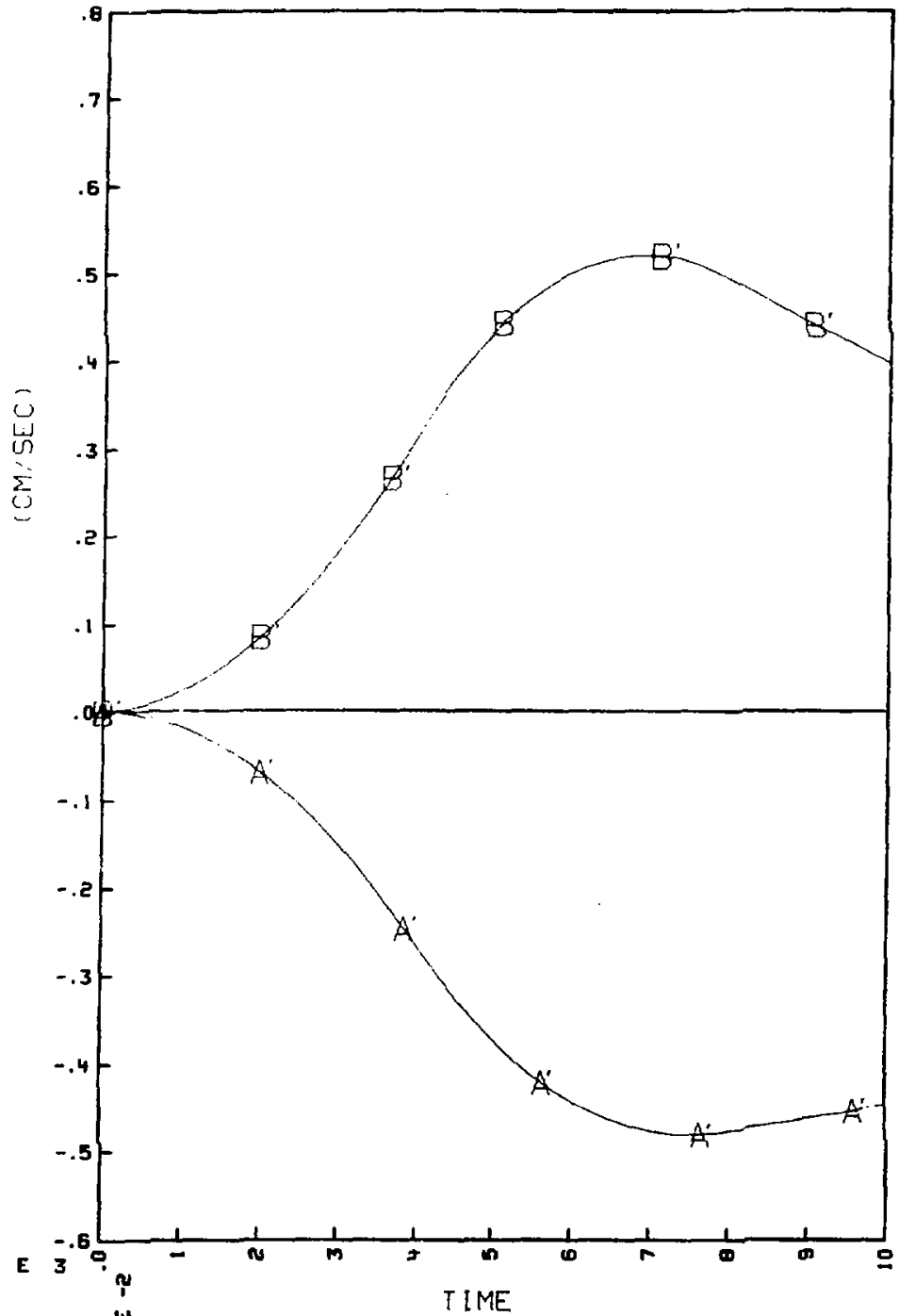

CHUG 2OPّSI PULSE (D/T=300) FIXED SHELL BOUNDARY

C-34. Bubble velocity at $A^{\prime}$ and $B^{\prime}$ (see Fig. $\left.C-1\right)(D / t=300)$. 


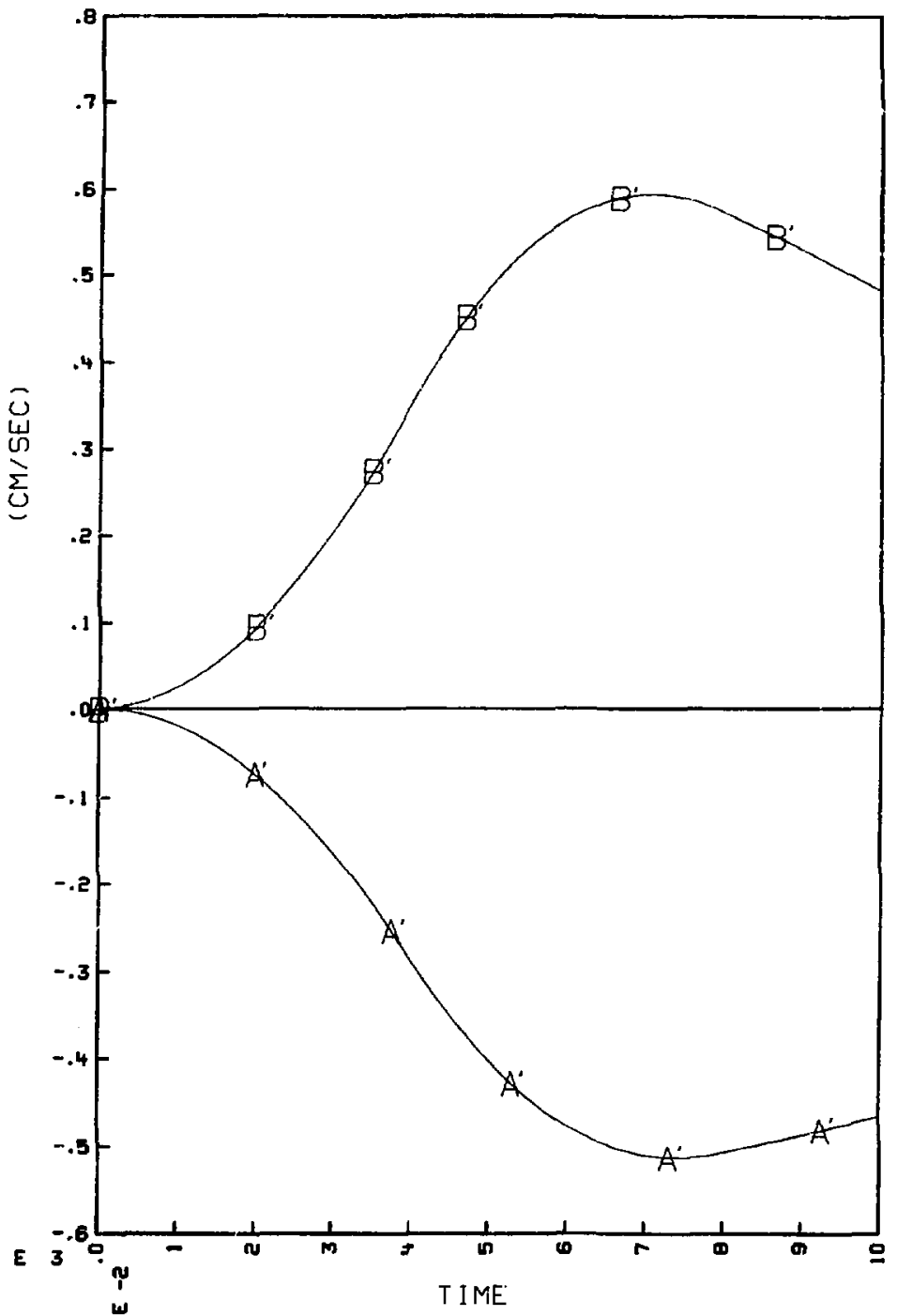

CH:JG EOPSI PULSE (D/T=600) FIXED SHELL BOUNDARY

C-35. Bubble velocity at $A^{\prime}$ and $B^{\prime}$ (see PIg. C-1) (D/t $=600$ ). 